\title{
Time-series plasma cell-free DNA analysis reveals disease severity of COVID- 19 patients
}

Authors: Xinping Chen ${ }^{1} \uparrow, \mathrm{Yu} \operatorname{Lin}^{2} \uparrow$, Tao $\mathrm{Wu}^{1} \uparrow$, Jinjin $\mathrm{Xu}^{2} \uparrow$, Zhichao Ma ${ }^{1} \uparrow$, Kun Sun ${ }^{2,5} \uparrow$, Hui $\mathrm{Li}^{1} \uparrow$, Yuxue Luo ${ }^{2,3} \dagger$, Chen Zhang ${ }^{1}$, Fang Chen ${ }^{2}$, Jiao Wang ${ }^{1}$, Tingyu Kuo ${ }^{2,4}$, Xiaojuan Li ${ }^{1}$, Chunyu Geng ${ }^{2}$, Feng Lin ${ }^{1}$, Chaojie Huang ${ }^{2}$, Junjie $\mathrm{Hu}^{1}$, Jianhua Yin ${ }^{2}$, Ming Liu ${ }^{1}$, Ye Tao ${ }^{2}$, Jiye Zhang $^{1}$, Rijing Ou ${ }^{2}$, Furong Xiao ${ }^{1}$, Huanming Yang ${ }^{2,6}$, Jian Wang ${ }^{2,6}$, Xun $\mathrm{Xu}^{2,7}$, Shengmiao $\mathrm{Fu}^{1 *}$, Xin $\mathrm{Jin}^{2,3 *}$, Hongyan Jiang ${ }^{1 *}$, Ruoyan $\mathrm{Chen}^{2 *}$

\author{
Affiliations: \\ ${ }^{1}$ Hainan General Hospital, Hainan Affiliated Hospital of Hainan Medical University, Hainan \\ Provincial Key Laboratory of Cell and Molecular Genetic Translational Medicine, Haikou \\ 570311, Hainan, China. \\ ${ }^{2}$ BGI-Shenzhen, Shenzhen, 518083, Guangdong, China \\ ${ }^{3}$ School of Medicine, South China University of Technology, Guangzhou 510006, Guangdong, \\ China \\ ${ }^{4}$ BGI Education Center, University of Chinese Academy of Sciences, Shenzhen 518083, \\ Guangdong, China \\ ${ }^{5}$ Shenzhen Bay Laboratory, Shenzhen 518132, Guangdong, China \\ ${ }^{6}$ James D. Watson Institute of Genome Sciences, Hangzhou 310058, China \\ ${ }^{7}$ Guangdong Provincial Key Laboratory of Genome Read and Write, BGI-Shenzhen, Shenzhen, \\ 518120, China
}

*Correspondence to: jinxin@genomics.cn; chenruoyan@genomics.cn; hyjiangus@ 163.com; smfu2000@126.com.

$\dagger$ These authors contributed equally to this work.

Abstract: Clinical symptoms of coronavirus disease 2019 (COVID-19) range from asymptomatic to severe pneumonia and death. Detection of individuals at high risk for critical condition is crucial for control of the disease. Herein, for the first time, we profiled and analyzed plasma cell-free DNA (cfDNA) of mild and severe COVID-19 patients. We found that in comparison between mild and severe COVID-19 patients, Interleukin-37 signaling was one of the most relevant pathways; top significantly altered genes included POTEH, FAM27C, SPATA48, which were mostly expressed in prostate and testis; adrenal glands, small intestines and liver were tissues presenting most differentially expressed genes. Our data thus revealed potential tissue involvement, provided insights into mechanism on COVID-19 progression, and highlighted utility of cfDNA as a noninvasive biomarker for disease severity inspections. 
medRxiv preprint doi: https://doi.org/10.1101/2020.06.08.20124305; this version posted June 9, 2020. The copyright holder for this preprint

(which was not certified by peer review) is the author/funder, who has granted medRxiv a license to display the preprint in perpetuity.

It is made available under a CC-BY-NC-ND 4.0 International license .

One Sentence Summary: CfDNA analysis in COVID-19 patients reveals severity-related tissue damage.

\section{Main Text:}

A novel coronavirus, severe acute respiratory syndrome-coronavirus 2 (SARS-CoV-2) emerged at the end of $2019(1,2)$, resulting in outbreak of the coronavirus disease 2019 (COVID-19) across the world and more than 5 million cases were confirmed by May 25, 2020 (3). In a report based on $\sim 72,000$ COVID-19 patients from China, 14\% were classified as severe, $5 \%$ were critical, and the rest $81 \%$ were considered mild (4). Clinical progression of COVID-19 varies greatly among individuals (4-8), whereas the real course of the disease is not yet well understood. In fact, the incubation period for COVID-19 ranges from 1 to 14 days; the duration of viral shedding ranges from 8 to 37 days; and time from illness onset to death or discharge mainly range from 15 to 25 days $(8,9)$. In addition, the case-mortality rate was found to be correlated with age, preexisting comorbid conditions such as cardiovascular disease, diabetes, and hypertension; however, reported deaths still contain high numbers of teenagers and cases without comorbidities (4-8). Laboratory records such as low lymphocyte counts, high C-reactive protein or D-dimer levels, and secondary bacterial infections could not provide insights into the actual process of death $(10,11)$. Hence, systematical understanding of clinical course of COVID19 and classification/prediction of severe cases precisely at early stage are essential for management of the disease.

Cell-free DNA (cfDNA) in plasma comprises short, naturally fragmented molecules that preserve valuable information related to gene expression and nucleosome footprint related to its tissues-of-origin (12-16). Numerous studies reported that cfDNA concentration, size profiles, coverage patterns around promoters are associated with various diseases, making cfDNA an intensively investigated biomarker for clinical use in various fields including oncology, noninvasive prenatal diagnosis, organ transplantation, autoimmune diseases, trauma, myocardial infarction, and diabetes (13-16). Circulating cfDNA mostly originate from died cells through apoptosis, necrosis and netosis $(14,17,18)$. CfDNA is found to be potential drivers and therapeutic targets of COVID-19 suggested novel therapy strategies of the disease $(14,18)$. However, to date, only subtotal concentration of cfDNA in serum from COVID-19 was investigated. Hence, to further explore the clinical value of cfDNA in COVID-19, we conducted systematical analysis of whole genome sequencing (WGS) data on cfDNA from mild and severe cases in time series. We report significantly different signals between mild and severe cases, which indicates potential genes, tissues, and pathways that are involved in disease course and severity, demonstrating high value in patient monitoring. Our functional analysis of cfDNA further shed light on mechanisms of progression of severe COVID-19, and demonstrated cfDNA as a potential noninvasive biomarker for disease severity inspections of COVID-19.

\section{Gene set enrichment analysis suggest pathways associated with severity of COVID-19}

Four subjects, including two male COVID-19 patients (one mild in his 30's and one serve in his 60's) and 2 healthy controls (one male in his 30's and one female in her 20's), were recruited in this study (Table S1). For the COVID-19 patients, peripheral blood was collected at various time 
points within 29 days of hospitalization; plasma cfDNA was extracted and sequenced to $\sim 12 \mathrm{x}$ human haploid genome coverage for each time point (Fig. S1 and Table S2). We investigated gene expression pattern in cfDNA via analyzing the sequencing depth-normalized, relative coverage of the promoters. Gene set enrichment analysis was performed using the relative coverage around promoters of known genes on the two time-course data sets and controls (Fig. 1). Six gene clusters showing significantly different patterns between mild and severe cases were identified (Fig. 1A and Fig. 1C). Notably, the average coverage around gene promoters from cluster 2 and 6 decreased along hospitalization time line for the severe case (suggesting upregulation of these genes), while such pattern did not exist in mild case (Fig. 1A), indicating that the genes involved in disease course could be different in mild and severe cases.

Pathway analysis was carried out on genes of the above six clusters separately (Fig. 1B). For cluster 1 containing the maximum number of genes among the six clusters, the most enriched pathway is interleukin-37 (IL-37) signaling ( $p=0.005$, Table S3), which is involved in suppression of cytokine production and inflammation inhibition $(19,20)$.Interestingly, this pathway had been reported to have potential therapeutic effect on COVID-19 (21). Cluster 2 shows a clear trend of increased expression in the severe case, especially at the last three time points; significantly enriched pathways in this cluster include cytosolic sulfonation of small molecules $(p=0.009)$ and RUNX1 regulates genes involved in megakaryocyte differentiation and platelet function $(p=0.01)$, which is in accordance with the dropping platelet counts from clinical laboratory records of the severe case (Table 1). Cluster 6, which showed similar trend with cluster 2 , involves Ub-specific processing proteases $\left(p=2.8 \times 10^{-9}\right)$ and deubiquitination pathways $\left(p=3.3 \times 10^{-9}\right)$, which are commonly hijacked by viruses for replication and pathogenesis, and were reported containing druggable targets to treat COVID-19 (22). Other enriched pathways include olfactory signaling pathway $(p=0.003), \mathrm{G}$ alpha $(\mathrm{s})$ signaling events $(p=0.006)$, signal regulatory protein family interactions $\left(p=4.5 \times 10^{-7}\right)$, and cell-cell communication $\left(p=2.3 \times 10^{-4}\right)$, which are expected given inflammatory and immune responses in severe COVID-19.

\section{Significantly altered genes and tissue specificity on progression of COVID-19}

To detect differentiated genes and tissues between mild and severe cases, relative coverages around promoters from cfDNA 1) within control group, 2) among 4 time points from mild case, 3) among 4 time points from severe case, 4) between mild and severe cases, 5) between cases and controls, were compared using Mann-Whitney rank-sum tests (Fig. 2). We laid emphasis on differences between mild and severe cases, while not significant either between cases and controls, or within controls. Table 2 lists top 10 genes out of all significantly differentially expressed genes (Fig. 2A and Table S4), and the coverage pattern around the promoters of the top 10 genes were shown in Fig. S2. Strikingly, the top 3 genes, namely POTEH (Prostate, Ovary, Testis-Expressed Protein On Chromosome 22), MGC39584 (Family With Sequence Similarity 27 Member C), and C7orf72 (Spermatogenesis Associated 48) are all highly linked to male gender: POTEH and MGC39584 are specifically expressed in prostate and testis, and C7orf72 is associated to spermatogenesis (23). The significant difference of genes related to male reproductive system are corroborated by previous studies that claimed spermatogonia cells to be targets attacked by SARS-CoV-2 (24,25). Other genes worth noting include SQLE that catalyzes oxidation of squalene, a reported conjugate of therapeutic drugs for COVID-19 (26), 
medRxiv preprint doi: https://doi.org/10.1101/2020.06.08.20124305; this version posted June 9, 2020. The copyright holder for this preprint

(which was not certified by peer review) is the author/funder, who has granted medRxiv a license to display the preprint in perpetuity.

It is made available under a CC-BY-NC-ND 4.0 International license .

and LAMP3, which is specifically expressed in lung and associated to dendritic cell function and adaptive immunity (27). Additionally, the significantly differentiated expression of SPEG gene which were essential for cardiac function was consistent with clinical laboratory records (Table 1, Table S5, and Table S6) that reported the severe case with atrial fibrillation.

Significantly altered genes that are known to be tissue-specific (N=28) selected (Fig. 2B) and their expressing tissues were analyzed (Fig. 2C). Except for prostate and small intestines that were also significant between cases and controls, tissues that include most percent of significantly differentiated genes between mild and severe cases are adrenal, liver, and whole blood, which were acceptable in consideration of the inflammatory and immune reactions associated with COVID-19. Moreover, tissues significant specifically among data collected at the 4 time points of severe case include heart, muscle, and artery, which can be explained by the clinical records reporting arrhythmia, atrial fibrillation, and general fatigue for the severe case.

\section{Microbial and mitochondrial cfDNA}

Besides autosomal cfDNA from cases and controls, infection of microbiomes in plasma and mitochondrial cfDNA concentration were also investigated (Fig. 3). In consistent with the RNAvirus nature of SARS-COV-2, we did not find any viral DNA of SARS-CoV-2 in the cfDNA sequencing data. Total counts of bacteria detected in plasma from COVID-19 patients were lower than that from controls (Fig. 3A), which could be explained by medication of interferons and antibiotics for these patients. Notably a novel virus infected in plasma collected at third and fourth time points of the severe case was human betaherpesvirus 5 (Table S7), which might cause pneumonia, colitis, or encephalitis in immunocompromised people (28).

Overall, mitochondrial cfDNA concentrations of plasma from cases were lower than controls, while the severe case had higher concentration than mild case (Fig. 3B). Notably distribution of mitochondrial concentration for severe case showed clear " $\mathrm{S}$ " shape, which was matched with hematocrit and hemoglobin at last four collection time (Table 1), suggesting hypoxia of the patient.

\section{Discussion}

Acute progression of COVID-19 makes it vital to discriminate patients at high risk to go through rapid deterioration. Results of this study on cfDNA from patients with COVID-19 revealed signals associated with disease severity. We found that IL-37 signaling pathway and SQLE gene are both altered in COVID-19 patients, which results were consistent with previous reports. We also discovered signals that are in line with clinical records, including differentially expressed genes related to atrial fibrillation and male reproduction system. In addition, we observed changes of mitochondrial cfDNA concentration, which matches with hematocrit and hemoglobin of the patient. Moreover, alterations in Ub-specific processing proteases and deubiquitination pathways, SQLE, LAMP3, and SPEG genes provide clues on drug targets and biomarkers for COVID-19. Considering the relatively small sample size, follow-up analyses with large-scale sample size is required to make solid conclusions. Nevertheless, the preliminary results demonstrate that cfDNA could serve as a valuable analyte for surveillance, medication guidance, and prognosis of COVID-19 patients. 
medRxiv preprint doi: https://doi.org/10.1101/2020.06.08.20124305; this version posted June 9, 2020. The copyright holder for this preprint

(which was not certified by peer review) is the author/funder, who has granted medRxiv a license to display the preprint in perpetuity. It is made available under a CC-BY-NC-ND 4.0 International license .

\section{References and Notes:}

1. N. Zhu, D. Zhang, W. Wang, X. Li, B. Yang, J. Song, X. Zhao, B. Huang, W. Shi, R. Lu, P. Niu, F. Zhan, X. Ma, D. Wang, W. Xu, G. Wu, G. F. Gao, W. Tan, China Novel Coronavirus Investigating and Research Team, A Novel Coronavirus From Patients With Pneumonia in China, 2019. N. Engl. J. Med. 382(8), 727-733 (2020).

2. P. Zhou, X. Yang, X. Wang, B. Hu, L. Zhang, W. Zhang, H. Si, Y. Zhu, B. Li, C. Huang, H. Chen, J. Chen, Y. Luo, H. Guo, R. Jiang, M. Liu, Y. Chen, X. Shen, X. Wang, X. Zheng, K. Zhao, Q. Chen, F. Deng, L. Liu, B. Yan, F. Zhan, Y. Wang, G. Xiao, Z. Shi, A Pneumonia Outbreak Associated With a New Coronavirus of Probable Bat Origin. Nature. 579(7798), 270-273 (2020).

3. World Health Organization, Coronavirus disease (COVID-2019) situation reports. https://www.who.int/emergencies/diseases/novel-coronavirus-2019/situation-reports/ [accessed 25 May 2020].

4. Z. Wu, J. M. McGoogan, Characteristics of and Important Lessons From the Coronavirus Disease 2019 (COVID-19) Outbreak in China: Summary of a Report of 72314 Cases From the Chinese Center for Disease Control and Prevention. JAMA. 10.1001/jama.2020.2648 (2020).

5. S. Richardson, J. S. Hirsch, M. Narasimhan, J. M. Crawford, T. McGinn, K. W. Davidson, the Northwell COVID-19 Research Consortium, D. P. Barnaby, L. B. Becker, J. D. Chelico, S. L. Cohen, J. Cookingham, K. Coppa, M. A. Diefenbach, A. J. Dominello, J. Duer-Hefele, L. Falzon, J. Gitlin, N. Hajizadeh, T. G. Harvin, D. A. Hirschwerk, E. J. Kim, Z. M. Kozel, L. M. Marrast, J. N. Mogavero, G. A. Osorio, M. Qiu, T. P. Zanos, Presenting Characteristics, Comorbidities, and Outcomes Among 5700 Patients Hospitalized With COVID-19 in the New York City Area. JAMA. 10.1001/jama.2020.6775 (2020).

6. H. Tian, Y. Liu, Y. Li, C. Wu, B. Chen, M. U. G. Kraemer, B. Li, J. Cai, B. Xu, Q. Yang, B. Wang, P. Yang, Y. Cui, Y. Song, P. Zheng, Q. Wang, O. N. Bjornstad, R. Yang, B. T. Grenfell, O. G. Pybus, C. Dye, An investigation of transmission control measures during the first 50 days of the COVID-19 epidemic in China. Science. 10.1126/science.abb6105 (2020).

7. G. Grasselli, A. Zangrillo, A. Zanella, M. Antonelli, L. Cabrini, A. Castelli, D. Cereda, A. Coluccello, G. Foti, R. Fumagalli, G. Iotti, N. Latronico, L. Lorini, S. Merler, G. Natalini, A. Piatti, M. V. Ranieri, A. M. Scandroglio, E. Storti, M. Cecconi, A. Pesenti, COVID-19 Lombardy ICU Network, A. Nailescu, A. Corona, A. Zangrillo, A. Protti, A. Albertin, A. F. Molinari, A. Lombardo, A. Pezzi, A. Benini, A. M. Scandroglio, A. Malara, A. Castelli, A. Coluccello, A. Micucci, A. Pesenti, A. Sala, A. Alborghetti, B. Antonini, C. Capra, C. Troiano, C. Roscitano, D. Radrizzani, D. Chiumello, D. Coppini, D. Guzzon, E. Costantini, E. Malpetti, E. Zoia, E. Catena, E. Agosteo, E. Barbara, E. Beretta, E. Boselli, E. Storti, F. Harizay, F. D. Mura, F. L. Lorini, F. D. Sigurtà, F. Marino, F. Mojoli, F. Rasulo, G. Grasselli, G. Casella, G. D. Filippi, G. Castelli, G. Aldegheri, G. Gallioli, G. Lotti, G. Albano, G. Landoni, G. Marino, G. Vitale, G. B. Perego, G. Evasi, G. Citerio, G. Foti, G. Natalini, G. Merli, I. Sforzini, L. Bianciardi, L. Carnevale, L. Grazioli, L. Cabrini, L. Guatteri, L. Salvi, M. D. Poli, M. Galletti, M. Gemma, M. Ranucci, M. Riccio, M. Borelli, M. Zambon, M. Subert, M. Cecconi, M. G. Mazzoni, M. Raimondi, M. Panigada, M. Belliato, N. Bronzini, N. Latronico, N. Petrucci, N. Belgiorno, P. Tagliabue, P. Cortellazzi, 
medRxiv preprint doi: https://doi.org/10.1101/2020.06.08.20124305; this version posted June 9, 2020. The copyright holder for this preprint

(which was not certified by peer review) is the author/funder, who has granted medRxiv a license to display the preprint in perpetuity. It is made available under a CC-BY-NC-ND 4.0 International license .

P. Gnesin, P. Grosso, P. Gritti, P. Perazzo, P. Severgnini, P. Ruggeri, P. Sebastiano, R. D. Covello, R. Fernandez-Olmos, R. Fumagalli, R. Keim, R. Rona, R. Valsecchi, S. Cattaneo, S. Colombo, S. Cirri, S. Bonazzi, S. Greco, S. Muttini, T. Langer, V. Alaimo, U. Viola, Baseline Characteristics and Outcomes of 1591 Patients Infected With SARS-CoV-2 Admitted to ICUs of the Lombardy Region, Italy. JAMA. 323(16), 1574-1581 (2020).

8. B. E. Young, S. W. X. Ong, S. Kalimuddin, J. G. Low, S. Y. Tan, J. Loh, O. Ng, K. Marimuthu, L. W. Ang, T. M. Mak, S. K. Lau, D. E. Anderson, K. S. Chan, T. Y. Tan, T. Y. Ng, L. Cui, Z. Said, L. Kurupatham, M. I. Chen, M. Chan, S. Vasoo, L. Wang, B. H. Tan, R. T. P. Lin, V. J. M. Lee, Y. Leo, D. C. Lye, Singapore 2019 Novel Coronavirus Outbreak Research Team, Epidemiologic Features and Clinical Course of Patients Infected With SARS-CoV-2 in Singapore. JAMA. 323(15),1488-1494 (2020).

9. F. Zhou, T. Yu, R. Du, G. Fan, Y. Liu, Z. Liu, J. Xiang, Y. Wang, B. Song, X. Gu, L. Guan, Y. Wei, H. Li, X. Wu, J. Xu, S. Tu, Y. Zhang, H. Chen, B. Cao, Clinical Course and Risk Factors for Mortality of Adult Inpatients With COVID-19 in Wuhan, China: A Retrospective Cohort Study. Lancet. 395(10229), 1054-1062 (2020).

10. J. Vincent, F. S. Taccone, Understanding pathways to death in patients with COVID-19. Lancet. Respir. Med. 10.1016/S2213-2600(20)30165-X (2020).

11. J. Phua, L. Weng, L. Ling, M. Egi, C. Lim, J. V. Divatia, B. R. Shrestha, Y. M. Arabi, J. Ng, C. D. Gomersall, M. Nishimura, Y. Koh, B. Du, Asian Critical Care Clinical Trials Group, Intensive care management of coronavirus disease 2019 (COVID-19): challenges and recommendation. Lancet. Respir. Med. 10.1016/S2213-2600(20)30161-2 (2020).

12. P. Ulz, G. G. Thallinger, M. Auer, R. Graf, K. Kashofer, S. W. Jahn, L. Abete, G. Pristauz, E. Petru, J. B. Geigl, E. Heitzer, M. R. Speicher, Inferring expressed genes by whole-genome sequencing of plasma DNA. Nat. Genet. 48(10),1273-8 (2016).

13. M. W. Snyder, M. Kircher, A. J. Hill, R. M. Daza, J. Shendure, Cell-free DNA comprises an in vivo nucleosome footprint that informs its tissues-of-origin. Cell. 164, 57-68 (2016).

14. A. Thierry et al., https://www.preprints.org/manuscript/202004.0238/v1 (2020).

15. K. Sun, P. Jiang, K. C. A. Chan, J. Wong, Y. K. Y. Cheng, R. H. S. Liang, W. Chan, E. S. K. Ma, S. L. Chan, S. H. Cheng, R. W. Y. Chan, Y. K. Tong, S. S. M. Ng, R. S. M. Wong, D. S. C. Hui, T. N. Leung, T. Y. Leung, P. B. S. Lai, R. W. K. Chiu, Y. M. D. Lo, Plasma DNA Tissue Mapping by Genome-Wide Methylation Sequencing for Noninvasive Prenatal, Cancer, and Transplantation Assessments. Proc. Natl. Acad. Sci. U. S. A. 112(40), E5503-12 (2015).

16. K. Sun, P. Jiang, S. H. Cheng, T. H. T. Cheng, J. Wong, V. W. S. Wong, S. S. M. Ng, B. B. Y. Ma, T. Y. Leung, S. L. Chan, T. S. K. Mok, P. B. S. Lai, H. L. Y. Chan, H. Sun, K. C. A. Chan, R. W. K. Chiu, Y. M. D. Lo, Orientation-aware Plasma Cell-Free DNA Fragmentation Analysis in Open Chromatin Regions Informs Tissue of Origin. Genome. Res. 29(3), 418-427 (2019).

17. B. J. Barnes, J. M. Adrover, A. Baxter-Stoltzfus, A. Borczuk, J. Cools-Lartigue, J. M. Crawford, J. Daßler-Plenker, P. Guerci, C. Huynh, J. S. Knight, M. Loda, M. R. Looney, F. McAllister, R. Rayes, S. Renaud, S. Rousseau, S. Salvatore, R. E. Schwartz, J. D. Spicer, C. 
medRxiv preprint doi: https://doi.org/10.1101/2020.06.08.20124305; this version posted June 9, 2020. The copyright holder for this preprint

(which was not certified by peer review) is the author/funder, who has granted medRxiv a license to display the preprint in perpetuity. It is made available under a CC-BY-NC-ND 4.0 International license .

C. Yost, A. Weber, Y. Zuo, M. Egeblad, Targeting potential drivers of COVID-19:

Neutrophil extracellular traps. J. Exp. Med. 217(6), e20200652 (2020).

18. Y. Zuo, S. Yalavarthi, H. Shi, K. Gockman, M. Zuo, J. A. Madison, C. N. Blair, A. Weber, B. J. Barnes, M. Egeblad, R. J. Woods, Y. Kanthi, J. S. Knight, Neutrophil extracellular traps in COVID-19. JCI. Insight. 10.1172/jci.insight.138999 (2020).

19. D. Boraschi, D. Lucchesi, S. Hainzl, M. Leitner, E. Maier, D. Mangelberger, G. J. Oostingh, T. Pfaller, C. Pixner, G. Posselt, P. Italiani, M. F. Nold, C. A. Nold-Petry, P. Bufler, C. A. Dinarello, IL-37: a new anti-inflammatory cytokine of the IL-1 family. Eur. Cytokine Netw. 22, 127-47 (2011).

20. X. Yan, B. Xie, G. Wu, J. Hu, D. Wang, X. Cai, J. Li, Interleukin-37: The Effect of AntiInflammatory Response in Human Coronary Artery Endothelial Cells. Mediators. Inflamm. 2019, 2650590 (2019).

21. P. Conti, G. Ronconi, A. Caraffa, C. Gallenga, R. Ross, I. Frydas, S. Kritas, Induction of pro-inflammatory cytokines (IL-1 and IL-6) and lung inflammation by COVID-19 antiinflammatory strategies. J. Biol. Regul. Homeost. Agents. 34(2), 1 (2020).

22. D. E. Gordon, G. M. Jang, M. Bouhaddou, J. Xu, K. Obernier, K. M. White, M. J. O'Meara, V. V. Rezelj, J. Z. Guo, D. L. Swaney, T. A. Tummino, R. Huettenhain, R. M. Kaake, A. L. Richards, B. Tutuncuoglu, H. Foussard, J. Batra, K. Haas, M. Modak, M. Kim, P. Haas, B. J. Polacco, H. Braberg, J. M. Fabius, M. Eckhardt, M. Soucheray, M. J. Bennett, M. Cakir, M. J. McGregor, Q. Li, B. Meyer, F. Roesch, T. Vallet, A. M. Kain, L. Miorin, E. Moreno, Z. Z. C. Naing, Y. Zhou, S. Peng, Y. Shi, Z. Zhang, W. Shen, I. T. Kirby, J. E. Melnyk, J. S. Chorba, K. Lou, S. A. Dai, I. Barrio-Hernandez, D. Memon, C. Hernandez-Armenta, J. Lyu, C. J. P. Mathy, T. Perica, K. B. Pilla, S. J. Ganesan, D. J. Saltzberg, R. Rakesh, X. Liu, S. B. Rosenthal, L. Calviello, S. Venkataramanan, J. Liboy-Lugo, Y. Lin, X. Huang, Y. Liu, S. A. Wankowicz, M. Bohn, M. Safari, F. S. Ugur, C. Koh, N. S. Savar, Q. D. Tran, D. Shengjuler, S. J. Fletcher, M. C. O'Neal, Y. Cai, J. C. J. Chang, D. J. Broadhurst, S. Klippsten, P. P. Sharp, N. A. Wenzell, D. Kuzuoglu, H. Wang, R. Trenker, J. M. Young, D. A. Cavero, J. Hiatt, T. L. Roth, U. Rathore, A. Subramanian, J. Noack, M. Hubert, R. M. Stroud, A. D. Frankel, O. S. Rosenberg, Kliment. A. Verba, D. A. Agard, M. Ott, M. Emerman, N. Jura, M. Zastrow, E. Verdin, A. Ashworth, O. Schwartz, C. d'Enfert, S. Mukherjee, M. Jacobson, H. S. Malik, D. G. Fujimori, T. Ideker, C. S. Craik, S. N. Floor, J. S. Fraser, J. D. Gross, A. Sali, B. L. Roth, D. Ruggero, J. Taunton, T. Kortemme, P. Beltrao, M. Vignuzzi, A. García-Sastre, K. M. Shokat, B. K. Shoichet, N. J. Krogan, A SARS-CoV-2 Protein Interaction Map Reveals Targets for Drug Repurposing. Nature. 10.1038/s41586-020-2286-9 (2020).

23. J. Zhang, R. Yan, C. Wu, H. Wang, G. Yang, Y. Zhong, Y. Liu, L. Wan, A. Tang, Spermatogenesis-associated 48 Is Essential for Spermatogenesis in Mice. Andrologia. 50(6), e13027 (2018).

24. Z. Wang, X. Xu, scRNA-seq Profiling of Human Testes Reveals the Presence of the ACE2 Receptor, A Target for SARS-CoV-2 Infection in Spermatogonia, Leydig and Sertoli Cells. Cells. 2020, 9(4), 920 (2020).

25. C. Fan et al. https://www.medrxiv.org/content/10.1101/2020.02.12.20022418v1 (2020). 
medRxiv preprint doi: https://doi.org/10.1101/2020.06.08.20124305; this version posted June 9, 2020. The copyright holder for this preprint

(which was not certified by peer review) is the author/funder, who has granted medRxiv a license to display the preprint in perpetuity.

It is made available under a CC-BY-NC-ND 4.0 International license .

26. F. Dormont, R. Brusini, C. Cailleau, F. Reynaud, A. Peramo, A. Gendron, J. Mougin, F. Gaudin, M. Varna, P. Couvreur, Squalene-based multidrug nanoparticles for improved mitigation of uncontrolled inflammation. Sci. Adv. eaaz5466 (2020).

27. M. Xiong, D. P. Heruth, L. Zhang, S. Ye, Identification of lung-specific genes by metaanalysis of multiple tissue RNA-seq data. FEBS. Open. Bio. 6(7), 774-781 (2016).

28. G. H. Taylor, Cytomegalovirus, Am. Fam. Physician. 67(3),519-24 (2003).

Acknowledgments: This work was supported by China National GeneBank. We sincerely thank the support provided by China National GeneBank. Funding: 1.the Hainan Medical University novel coronavirus pneumonia project (XGZX2020002) 2. National natural science foundation of china (81960389) 3. Natural Science Foundation of Guangdong Province, China (2017A030306026) 4 Guangdong Provincial Key Laboratory of Genome Read and Write (2017B030301011) 5 Talent Support Project of Guangdong, China (2017TQ04R858) 6. Distinguished Young Scholar of South China University of China (2017JQ017). Author contributions: Ruoyan Chen, Xin Jin, Hongyan Jiang, and Shengmiao Fu had full access to all of the data in the study and take responsibility for the integrity of the data and the accuracy of the data analysis; concept and design: Xin Jin, Xinping Chen, Ruoyan Chen; acquisition, analysis, or interpretation of data: Ruoyan Chen, Yu Lin, Jinjin Xu, Yuxue Luo, Tingyu Kuo, Ye Tao; drafting of the manuscript: Ruoyan Chen, Kun Sun; critical revision of the manuscript for important intellectual content: Xin Jin, Xun Xu, Kun Sun; statistical analysis: Ruoyan Chen, Yu Lin, Jinjin Xu; obtained funding: Xun Xu, Xin Jin, Xinping Chen, Huanming Yang, Jian Wang; administrative, technical, or material support: Tao Wu, Zhichao Ma, Hui Li, Chen Zhang, Jiao Wang, Xiaojuan Li, Feng Lin, Junjie Hu, Ming Liu, Jiye Zhang, Fang Chen, Chunyu Geng, Chaojie Huang, Jianhua Yin, Rijing Ou, Xiaorong Fu; supervision: Xin Jin, Xinping Chen, Hongyan Jiang, Shengmiao Fu. Competing interests: Authors declare no competing interests. Data and materials availability: The data that support the findings of this study have been deposited into CNSA (CNGB Nucleotide Sequence Archive) of CNGBdb with accession number CNP0001081 (https://db.cngb.org/cnsa/). 
medRxiv preprint doi: https://doi.org/10.1101/2020.06.08.20124305; this version posted June 9, 2020. The copyright holder for this preprint (which was not certified by peer review) is the author/funder, who has granted medRxiv a license to display the preprint in perpetuity.

It is made available under a CC-BY-NC-ND 4.0 International license .

A

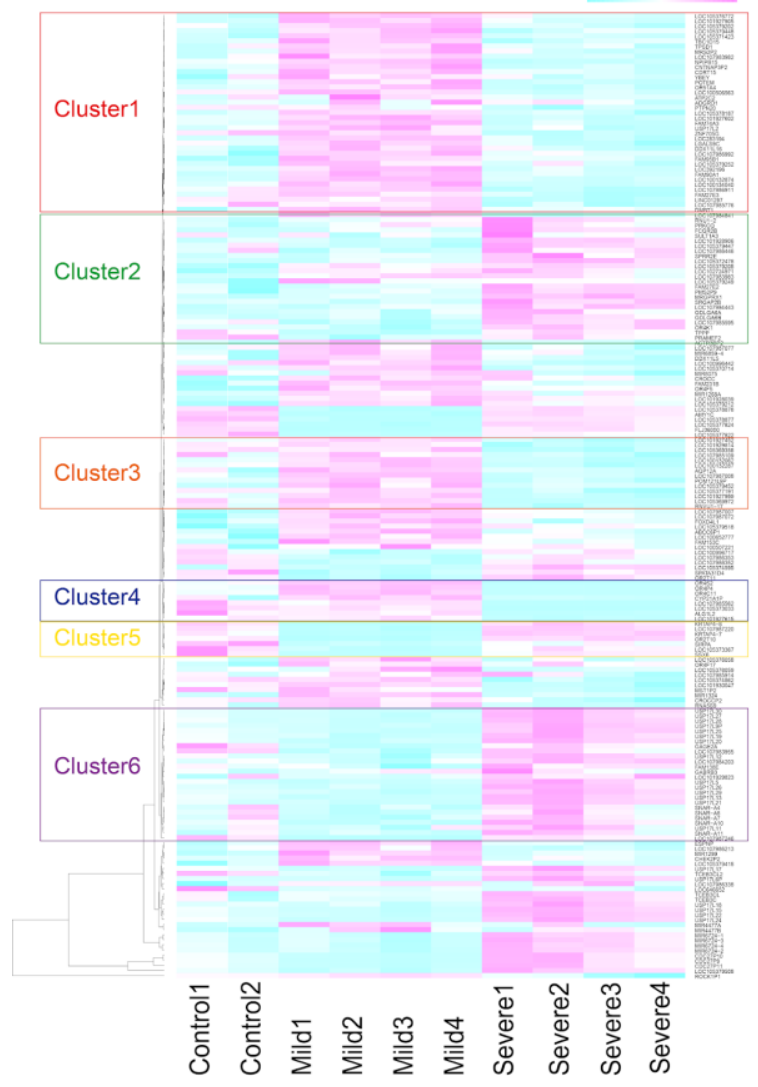

B

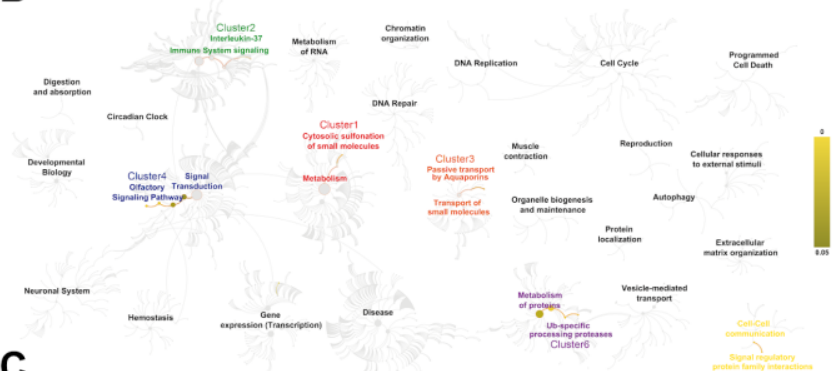

C

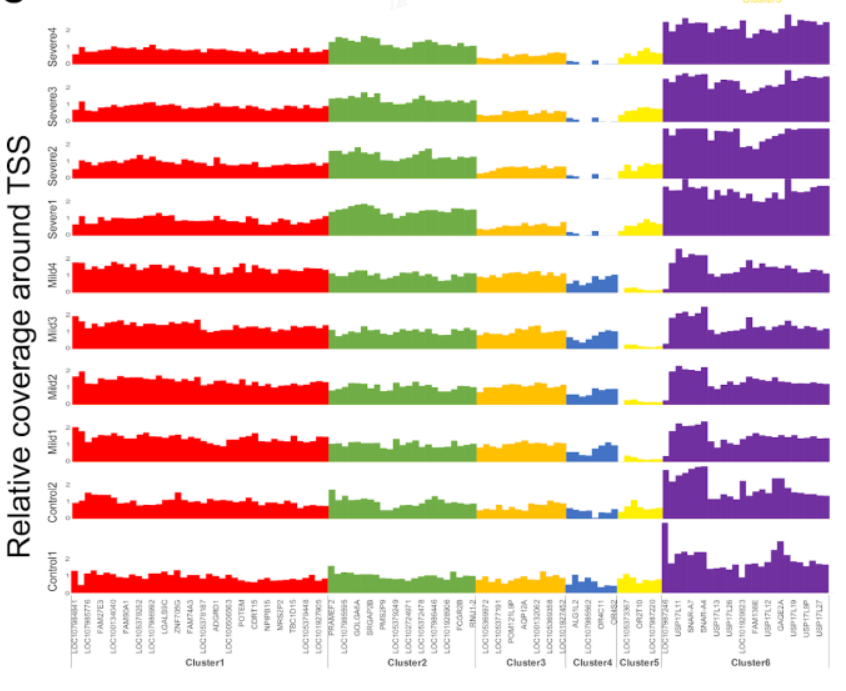

Fig. 1. Gene set enrichment and pathway analysis on mild and severe COVID-19 cases and controls. (A) Heatmap on data collected at hospitalization day 11 (Mild1), 17 (Mild2), 19 (Mild3), 22 (Mild4) for mild case and day 16 (Severe1), 19 (Severe2), 25 (Severe3), 29 (Severe4) for severe case, and data from two control individuals. Color scale represents average coverage around TSSs of each gene weighted by average whole-genome sequencing depth from cfDNA. 6 clusters with differentiated pattern between mild and severe cases were marked and corresponding gene lists and relative coverage for each data set were shown (C). Top significant 
medRxiv preprint doi: https://doi.org/10.1101/2020.06.08.20124305; this version posted June 9, 2020. The copyright holder for this preprint (which was not certified by peer review) is the author/funder, who has granted medRxiv a license to display the preprint in perpetuity. It is made available under a CC-BY-NC-ND 4.0 International license .

pathways based on genes of the 6 clusters were illustrated and mapped to six different functional modules (B).

A

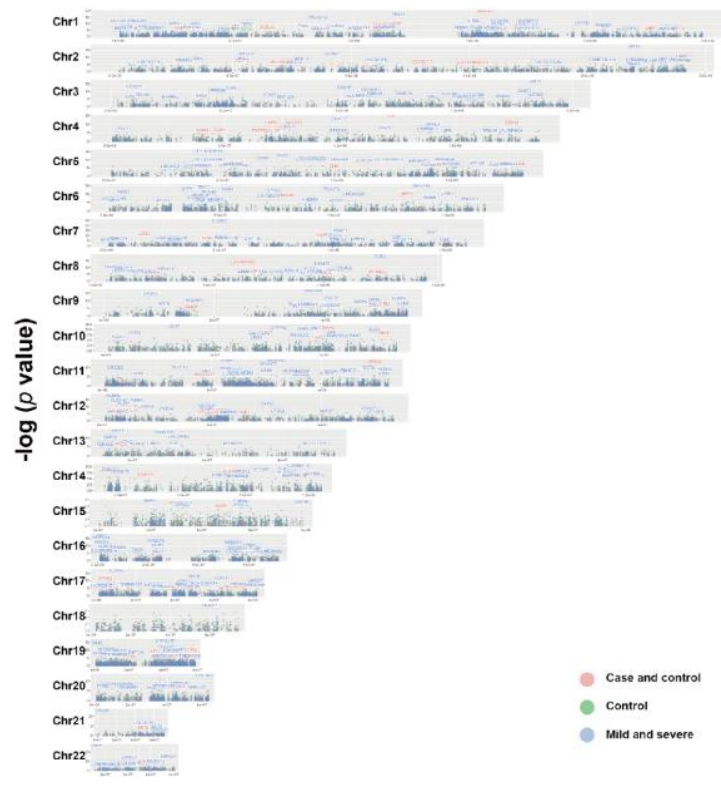

B

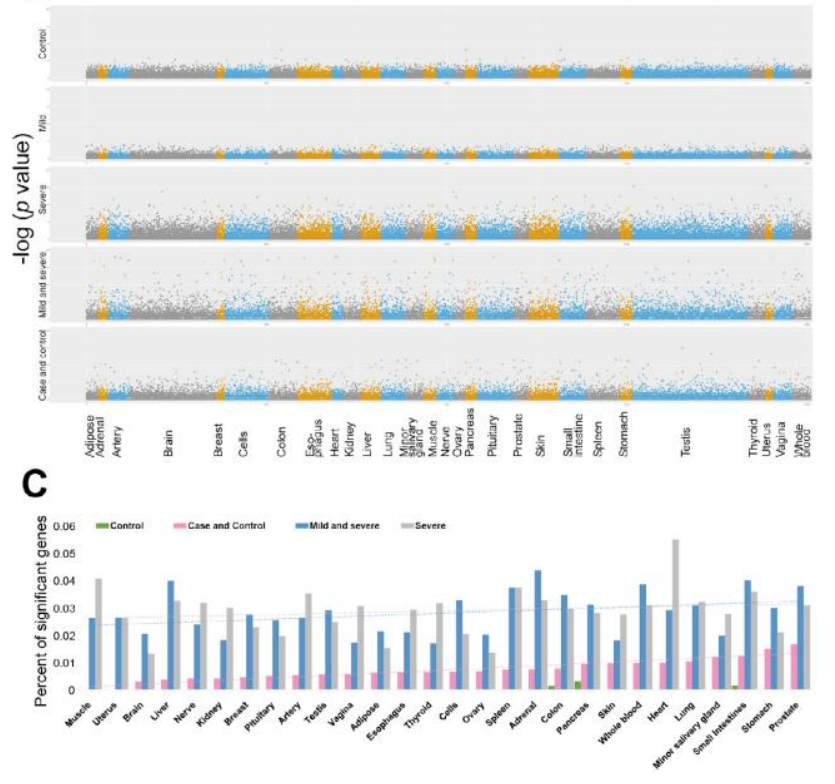

Fig. 2. Significant tests on genes and tissues of two controls and two mild and severe cases. (A) Meta $p$ values of rank-sum tests on coverage distribution in 200bp TSSs of genes on whole genome for case and control (pink), mild and severe (green), and control (blue). Name of genes with $-\log _{10}(p$ value $)$ greater than 6 within each group were marked. (B) Meta $p$ values of genes that were expressed specifically in 28 tissues from 1) controls, 2) mild time series, 3) severe time series, 4) mild and severe cases, 5) cases and controls, from top to bottom. (C) Percent of significant genes marked in (A) within each tissue from $(\mathbf{B})$ were summarized for control (green), case and control (pink), mild and severe (blue), severe (grey). Tissues were sorted based on percent of significant genes between case and control.

A

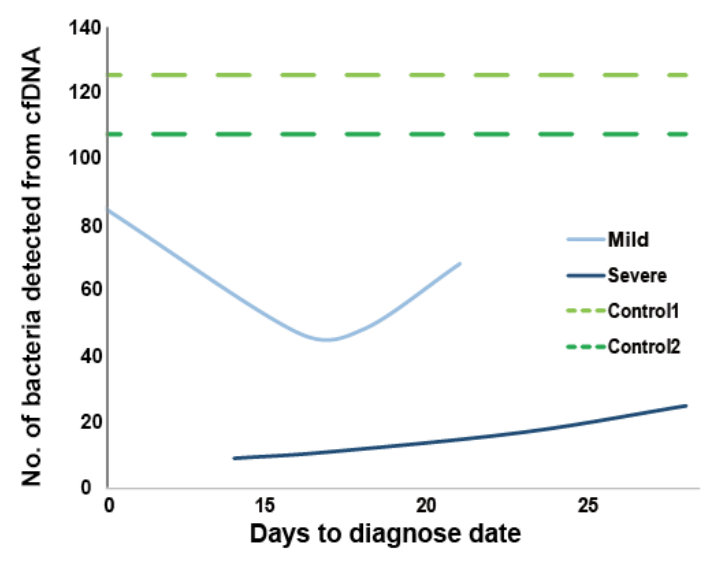

B

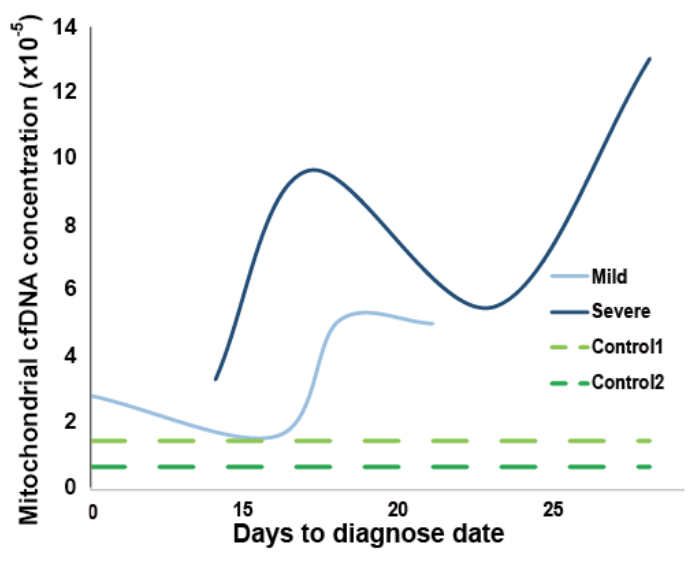

Fig. 3. Microbial and mitochondrial cfDNA from two controls and two mild and severe cases. No. of bacteria detected (A) and mitochondrial cfDNA concentration (B) from cfDNA of 
medRxiv preprint doi: https://doi.org/10.1101/2020.06.08.20124305; this version posted June 9, 2020. The copyright holder for this preprint (which was not certified by peer review) is the author/funder, who has granted medRxiv a license to display the preprint in perpetuity.

It is made available under a CC-BY-NC-ND 4.0 International license .

plasma collected at 4 time points for mild (light blue) and severe (dark blue) cases, and at once for the two cases (green, time for dotted lines are invented only for comparison).

Table 1. Clinical laboratory records of the mild and severe cases

\begin{tabular}{|c|c|c|c|c|c|c|c|c|c|c|}
\hline \multirow[b]{2}{*}{ Variable } & \multirow[b]{2}{*}{ Unit } & \multicolumn{6}{|c|}{ Severe } & \multicolumn{3}{|c|}{ Mild } \\
\hline & & $\begin{array}{c}\text { Hospit } \\
\text { al Day } \\
1\end{array}$ & $\begin{array}{c}\text { Hospit } \\
\text { al Day } \\
2\end{array}$ & $\begin{array}{c}\text { Hospit } \\
\text { al Day } \\
16\end{array}$ & $\begin{array}{c}\text { Hospit } \\
\text { al Day } \\
19\end{array}$ & $\begin{array}{c}\text { Hospit } \\
\text { al Day } \\
25\end{array}$ & $\begin{array}{c}\text { Hospit } \\
\text { al Day } \\
29\end{array}$ & $\begin{array}{c}\text { Hospit } \\
\text { al Day } \\
1\end{array}$ & $\begin{array}{c}\text { Hospit } \\
\text { al Day } \\
11\end{array}$ & $\begin{array}{c}\text { Hospit } \\
\text { al Day } \\
20\end{array}$ \\
\hline Gender & & \multicolumn{6}{|c|}{ Male } & \multicolumn{3}{|c|}{ Male } \\
\hline Temperature & ${ }^{\circ} \mathrm{C}$ & 36 & 37.5 & 38 & 39 & 38 & 37.6 & 36.5 & & \\
\hline Breathing rate & bpm & 30 & 22 & 24 & 19 & 20 & 26 & 20 & & \\
\hline Blood pressure & $\underset{\mathrm{g}}{\mathrm{mmH}}$ & $179 / 99$ & $125 / 84$ & $104 / 67$ & $98 / 54$ & $\begin{array}{r}78- \\
163 / 52- \\
86\end{array}$ & $116 / 68$ & $126 / 88$ & & \\
\hline $\begin{array}{l}\text { Blood oxygen } \\
\text { saturation }\end{array}$ & $\%$ & 46.00 & 98.00 & 99.00 & 98.00 & 96.00 & 97.00 & 99.00 & & \\
\hline White blood cell count & $10^{9} / \mathrm{L}$ & 10.89 & 10.23 & 19.29 & 10.47 & 10.16 & 6.48 & & & 8.07 \\
\hline Red blood cell count & $10^{12} / \mathrm{L}$ & 3.56 & & & 5.49 & 2.92 & 3.98 & & & \\
\hline Hematocrit & & & 0.34 & 0.221 & 0.333 & 0.267 & 0.375 & & & \\
\hline $\mathrm{PH}$ & & 7.4 & 7.251 & 7.386 & 7.425 & 7.371 & 7.384 & & & 7.342 \\
\hline $\begin{array}{l}\text { partial pressure of } \\
\text { oxygen }\end{array}$ & $\underset{\mathrm{g}}{\mathrm{mmH}}$ & 80 & 169 & 98 & 94 & 82 & 66 & & & 118 \\
\hline $\begin{array}{l}\text { partial pressure of } \\
\text { carbon dioxygen }\end{array}$ & $\underset{\mathrm{g}}{\mathrm{mmH}}$ & 33 & 58.1 & 43.6 & 37.8 & 52.4 & 49.8 & & & 35.4 \\
\hline C-reactive protein & $\mathrm{mg} / \mathrm{L}$ & 92.95 & & 180.6 & 107.4 & 159.4 & 166.5 & & & 4.57 \\
\hline $\begin{array}{l}\text { N-terminal pro b-type } \\
\text { Natriuretic Peptide }\end{array}$ & $\mathrm{ng} / \mathrm{L}$ & & 922 & 354 & & 98 & 607 & & & \\
\hline Magnesium & $\underset{\mathrm{L}}{\mathrm{mmol} /}$ & & & 1.16 & & & 0.72 & & & \\
\hline D-dimer & $\mathrm{ng} / \mathrm{ml}$ & & & & & 8.5 & 16.1 & & & \\
\hline Sodium & $\underset{\mathrm{L}}{\mathrm{mmol} /}$ & 129.3 & 134.7 & 145.9 & 148 & 143 & 142 & & & 138.3 \\
\hline Potassium & $\underset{\mathrm{L}}{\mathrm{mmol} /}$ & 3.53 & & 4.02 & 4.08 & 3.7 & 3.65 & & & 3.93 \\
\hline Chloride & $\underset{\mathrm{L}}{\mathrm{mmol} /}$ & & & 112.3 & & & & & & \\
\hline Creatinine & $\underset{\mathrm{Lmol} /}{\mathrm{mm}}$ & 54 & & 139.7 & & & & & & \\
\hline Glucose & $\underset{\mathrm{Lmol} /}{\mathrm{m}}$ & & & 9.05 & & 8.54 & 7.6 & & & \\
\hline Urea & $\underset{\mathrm{L}}{\mathrm{mmol} /}$ & & & 29.36 & & & 1.63 & & & \\
\hline Calcium & $\underset{\mathrm{L}}{\mathrm{mmol} /}$ & 1.86 & & 2.11 & & 1.11 & 1.88 & & & \\
\hline $\begin{array}{l}\text { Aspartate } \\
\text { aminotransferase }\end{array}$ & $\mathrm{U} / \mathrm{L}$ & & & 22.2 & & & 58.7 & & & \\
\hline $\begin{array}{l}\text { Alanine } \\
\text { aminotransferase }\end{array}$ & $\mathrm{U} / \mathrm{L}$ & & & 9.9 & & & 54.8 & & & \\
\hline Albumin & $\mathrm{g} / \mathrm{L}$ & 28.6 & & 32.8 & 35.1 & & 35.7 & & & 41.3 \\
\hline Alkaline phosphatase & $\mathrm{U} / \mathrm{L}$ & & & & & & 42 & & & \\
\hline $\begin{array}{l}\text { Lactate } \\
\text { dehydrogenase }\end{array}$ & $\mathrm{U} / \mathrm{L}$ & & & & & & 413 & & & \\
\hline Lactic acid & $\underset{\mathrm{L}}{\mathrm{mmol} /}$ & & & 2.32 & & 1.61 & 1.72 & & 2.59 & \\
\hline Hemoglobin & $\mathrm{g} / \mathrm{L}$ & 113 & 114 & 96 & 108 & 89 & 121 & & & 141 \\
\hline Platelet count & $10 \% / \mathrm{L}$ & 164 & & 264 & 281 & 164 & 106 & & & \\
\hline $\begin{array}{l}\text { Absolute neutrophil } \\
\text { count }\end{array}$ & $\%$ & 92.00 & & 92.90 & 89.60 & 82.10 & 88.70 & & & 61.60 \\
\hline $\begin{array}{l}\text { Absolute lymphocyte } \\
\text { count }\end{array}$ & $\%$ & 3.50 & & & 5.80 & & 5.90 & & & \\
\hline $\begin{array}{l}\text { The high-sensitivity } \\
\text { cardiac troponin }\end{array}$ & $\mu g / L$ & & & 0.027 & & & 0.028 & & & \\
\hline$(1 \rightarrow 3)-\beta$-D-Glucan & $\mathrm{pg} / \mathrm{ml}$ & & & & 128.2 & 197.1 & 218.3 & & & \\
\hline $\begin{array}{l}\text { Aspergillus } \\
\text { galactomannan }\end{array}$ & $\mu g / L$ & & & & & 0.12 & 0.13 & & & \\
\hline
\end{tabular}


medRxiv preprint doi: https://doi.org/10.1101/2020.06.08.20124305; this version posted June 9, 2020. The copyright holder for this preprint (which was not certified by peer review) is the author/funder, who has granted medRxiv a license to display the preprint in perpetuity.

It is made available under a CC-BY-NC-ND 4.0 International license .

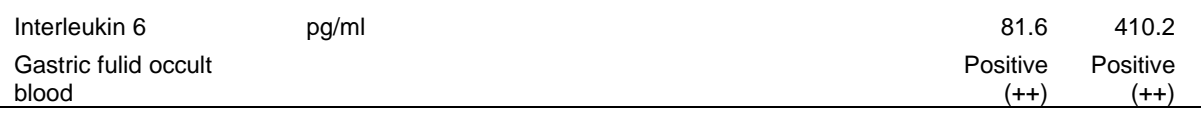

Table 2. Top 10 significantly differentiated expressed genes between mild and severe cases

\begin{tabular}{crccccc} 
& & & & \multicolumn{2}{c}{$\boldsymbol{p}$ values } \\
\cline { 3 - 7 } CHR & Position & Gene & Aliases of gene & $\begin{array}{c}\text { Control } \\
\text { and } \\
\text { control }\end{array}$ & $\begin{array}{c}\text { Mild and } \\
\text { severe }\end{array}$ \\
\hline 22 & 15690025 & POTEH & Prostate, Ovary, Testis-Expressed Protein On Chromosome 22 & 0.17 & 0.24 & $2.58 \times 10^{-28}$ \\
21 & 9821060 & MGC39584 & Family With Sequence Similarity 27 Member C & 0.08 & 1.00 & $7.44 \times 10^{-27}$ \\
7 & 50096085 & C7orf72 & Spermatogenesis Associated 48 & 0.11 & $2.74 \times 10^{-3}$ & $2.81 \times 10^{-25}$ \\
8 & 124999756 & SQLE & Squalene Epoxidase & 1.00 & $1.15 \times 10^{-6}$ & $1.23 \times 10^{-19}$ \\
12 & 5043918 & KCNA5 & Potassium Voltage-Gated Channel Subfamily A Member 5 & 0.17 & 1.00 & $8.64 \times 10^{-19}$ \\
2 & 219473003 & SPEG & Striated Muscle Enriched Protein Kinase & 0.02 & 0.04 & $1.87 \times 10^{-18}$ \\
16 & 1773227 & EME2 & Essential Meiotic Structure-Specific Endonuclease Subunit 2 & $4.63 \times 10^{-3}$ & 0.32 & $7.22 \times 10^{-18}$ \\
1 & 118989555 & TBX15 & T-Box Transcription Factor 15 & 0.19 & $7.96 \times 10^{-3}$ & $7.65 \times 10^{-18}$ \\
3 & 183162878 & LAMP3 & Lysosomal Associated Membrane Protein 3 & 0.70 & $1.96 \times 10^{-3}$ & $1.23 \times 10^{-17}$ \\
17 & 9905366 & RCVRN & Recoverin & 0.06 & $1.63 \times 10^{-6}$ & $1.83 \times 10^{-17}$ \\
\hline
\end{tabular}




\title{
Supplementary Materials for
}

\section{Time-series plasma cell-free DNA analysis reveals disease severity of COVID-19 patients}

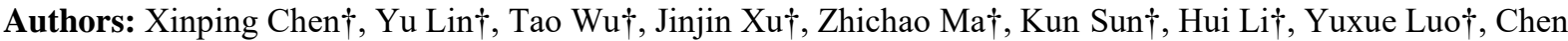
Zhang, Fang Chen, Jiao Wang, Tingyu Kuo, Xiaojuan Li, Chunyu Geng, Feng Lin, Chaojie Huang, Junjie Hu, Jianhua Yin, Ming Liu, Ye Tao, Jiye Zhang, Rijing Ou, Furong Xiao, Huanming Yang, Jian Wang, Xun Xu, Shengmiao Fu*, Xin Jin*, Hongyan Jiang*, Ruoyan Chen*
\end{abstract}

*Correspondence to: chenruoyan@genomics.cn; hyjiangus@163.com;jinxin@genomics.cn; smfu2000@126.com. $\dagger$ These authors contributed equally to this work.

\section{This supplementary file includes:}

Materials and Methods

Fig. S1 to S3

Tables $\mathrm{S} 1$ to $\mathrm{S} 8$

References 


\section{Materials and Methods \\ Data collection}

A total of 10 samples were collected from 2 patients with COVID-19 at 4 time points and 2 health controls. Leftover surplus blood was collected from participants who had signed consent forms after clinical diagnosis. Peripheral blood was stored using EDTA anticoagulant-coated tubes. The blood samples pretreatment and DNA extraction were proceeded at a Biosafety Level 2 (BSL-2) laboratory to ensure the appropriate biosafety practices (1). All samples were centrifuged at low speed $(3000 \mathrm{rpm})$ for $10 \mathrm{~min}$ at $4^{\circ} \mathrm{C}$ within six hours after collection. The supernatant was centrifuged at high speed $(1,4000 \mathrm{rpm})$ for $10 \mathrm{~min}$ at $4^{\circ} \mathrm{C}$. Then the plasma was set at $56^{\circ} \mathrm{C}$ water bath for 30 minutes. Circulating cfDNA was extracted from 200uL plasma using MagPure Circulating DNA Mini KF Kit (MD5432-02) following the manufacturer's guide. The cfDNA was eluted by 200uL TE buffer for QC and $40 \mathrm{uL}$ for the rest. For cfDNA library construction, the extracted cfDNAs were processed to library using MGIEasy Cell-free DNA Library Prep kit (MGI, cat. No.: AA00226).

For upstream data processing, firstly, soapnuke (version 1.5.0) (2) was used for trimming the sequencing adapters from raw reads, and filtering low quality and high ratio $\mathrm{N}$. N rate threshold was set to 0.1 , low quality rate was set to 0.5 , and low quality threshold, namely the max mismatch number when match the adapter to 2 and the clean data quality system to sanger, was set to 12 . Secondly, BWA (version 0.7.17-r1188) (3) was used to map reads against the human reference genome (build hg38). After sorting and removing duplication of the aligned reads, variants were detected by Haplotype caller from GATK (4). The above steps were performed by sention (5), a platform for processing of genomic data that combined alignment, variants calling, and quality recalibration together efficiently.

\section{Gene set enrichment and pathway analysis}

Firstly, for each gene, average sequencing depth within $2 \mathrm{~kb}$ region around transcription start sites (2kb-TSSs) and 200bp region around TSSs (200bp-TSSs) were calculated respectively by DepthOfCoverage package from GATK (4). The relative coverage around TSS was the above depth normalized by average depth of WGS data from each sample. Secondly, for each gene, $S_{i}=D_{\operatorname{maxi}}-D_{\operatorname{mini}}$ was calculated, where $D_{\operatorname{maxi}}$ represented the highest depth among group $i$ within $2 \mathrm{~kb}-\mathrm{TSS} / 200 \mathrm{bp}$-TSSs and $\mathrm{D}_{\text {mini }}$ represented the lowest depth among group $i$ within $2 \mathrm{~kb}$ TSSs/200bp-TSSs. Genes with $S_{\text {controls }}>S_{\text {cases }}$ were filtered, and remained genes were ranked by $S_{\text {cases. }}$ Gene set enrichment analysis was performed on the top $1 \%$ ranked genes by the heatmap package from $\mathrm{R}$ version 3.5.1, and clusters of genes were selected from dendrogram output by heatmap package. Pathway analysis was carried out by Reactom (6) on the 6 clusters of genes separately (Table S2). Results based on 2kb-TSS regions were presented in Fig. 1, and results based on 200bp-TSS regions were summarized in Fig. S3.

\section{Analysis on differentiated genes and tissue specificity}

To test difference among different groups, including 1) $\mathrm{G}_{\text {control }} 2$ samples from 2 control individuals, 2) $\mathrm{G}_{\text {mild: }}$ : 4 samples from 1 mild case at 4 time points, 3) $\mathrm{G}_{\text {severe }}: 4$ samples from 1 severe case at 4 time points, 4$) \mathrm{G}_{\text {mild,severe }} 4$ mild and 4 severe samples, 5) $\mathrm{G}_{\text {case,control }} 2$ controls and 8 cases, reads start counts, namely counts of starts of sequencing reads pairs, were calculated within $200 \mathrm{bp}$ region around transcription start site (TSS) of each gene. For the 2 samples from 2 control individuals and the 8 samples from 4 cases collected at 4 time points, pairwise Wilcox's Rank-sum tests were carried out by wilcox package from $\mathrm{R}$ version 3.5.1, and corresponding $p$ values, including $\mathrm{G}_{\text {control }} \in\left\{p_{\text {control1,control2 }}\right\}, \mathrm{G}_{\text {mild }} \in\left\{p_{\text {mild1,mild2, }}, p_{\text {mild1_mild3 }}, p_{\text {mild1_mild4, }} p_{\text {mild2_mild3 }}, p_{\text {mild2,mild4, }} p_{\text {mild3_mild4 }}\right\}, \mathrm{G}_{\text {severe }}$ $\in\left\{p_{\text {severe1,severe2 }}, p_{\text {severe1,severe3 }}, p_{\text {severe1,severe4 }}, p_{\text {severe2,severe3, }}, p_{\text {severe2,severe4, }}, p_{\text {severe3,severe4 }}\right\}, \mathrm{G}_{\text {mild,severe }} \in\left\{p_{\text {mild1,severel, }}, p_{\text {mild1,severe2, }}\right.$ $p_{\text {mild1,severe3 }}, p_{\text {mild1,severe4, }} p_{\text {mild2,severe1 }}, p_{\text {mild2,severe2 }}, p_{\text {mild2,severe3, }} p_{\text {mild2,severe4, }} p_{\text {mild3,severel, }} p_{\text {mild3,severe2, }}, p_{\text {mild3,severe3, }} p_{\text {mild3,severe4 }}$, $\left.p_{\text {mild4,severel },} p_{\text {mild4,severe2, }}, p_{\text {mild4,severe3 }}, p_{\text {mild4,severe }}\right\}, \mathrm{G}_{\text {case,control }} \in\left\{p_{\text {control1,mild1 }}, p_{\text {control1,mild2, }} p_{\text {control 1,mild3, }}, p_{\text {control1,mild4, }}\right.$ $p_{\text {control1,severe1 }}, p_{\text {control1,severe2, }} p_{\text {control1,severe3 }}, p_{\text {control1,severe4, }} p_{\text {control2,mild1 }}, p_{\text {control2,mild2 }}, p_{\text {control2,mild3 }}, p_{\text {control2,mild } 4,} p_{\text {control2,severel }}$, $\left.p_{\text {control2,severe2, }}, p_{\text {control2,severe } 3}, p_{\text {control2,severe }},\right\}$, were generated. For each group of $p$ values above, a combined $p$ value was calculated using Wilkinson's method (7). Cutoff for selection of significantly differentially expressed genes of each group was set to $p<\frac{0.05}{\text { Count of genes included for significant tests }}$, namely, $p<1.6 \times 10^{-6}$.

Tissue specificity was analyzed based on grouped meta $p$ values above. 23,570 transcripts that are expressed specifically from 28 tissues were selected based on GTEx database $(8,9)$.

\section{Microbiomes and mitochondrial cfDNA concentration estimation}


medRxiv preprint doi: https://doi.org/10.1101/2020.06.08.20124305; this version posted June 9, 2020. The copyright holder for this preprint

(which was not certified by peer review) is the author/funder, who has granted medRxiv a license to display the preprint in perpetuity.

It is made available under a CC-BY-NC-ND 4.0 International license .

The sequences remaining after removal of reads identified as human were aligned to microbial genome databases, contains 4153 viral and 2328 bacterial genomes, 208 fungi and 79 parasites genomes, coronavirus 2 (SARS-CoV-2) genome downloaded from NCBI, NC_045512.2. For identifying a positive microbe, we used the methodological criteria according to (10-12), focused on a). Coverage rate; b). Species level sequencing depth; c). Species level relative abundance and d). Unique mapped reads numbers.

Concentration of mitochondrial cfDNA was calculated as count of cfDNA fragments (sequencing reads pairs) that were uniquely mapped to mitochondrial DNA divided by total count of cfDNA fragments that were uniquely mapped to whole genome (Build hg38). 
medRxiv preprint doi: https://doi.org/10.1101/2020.06.08.20124305; this version posted June 9, 2020. The copyright holder for this preprint (which was not certified by peer review) is the author/funder, who has granted medRxiv a license to display the preprint in perpetuity.

It is made available under a CC-BY-NC-ND 4.0 International license .

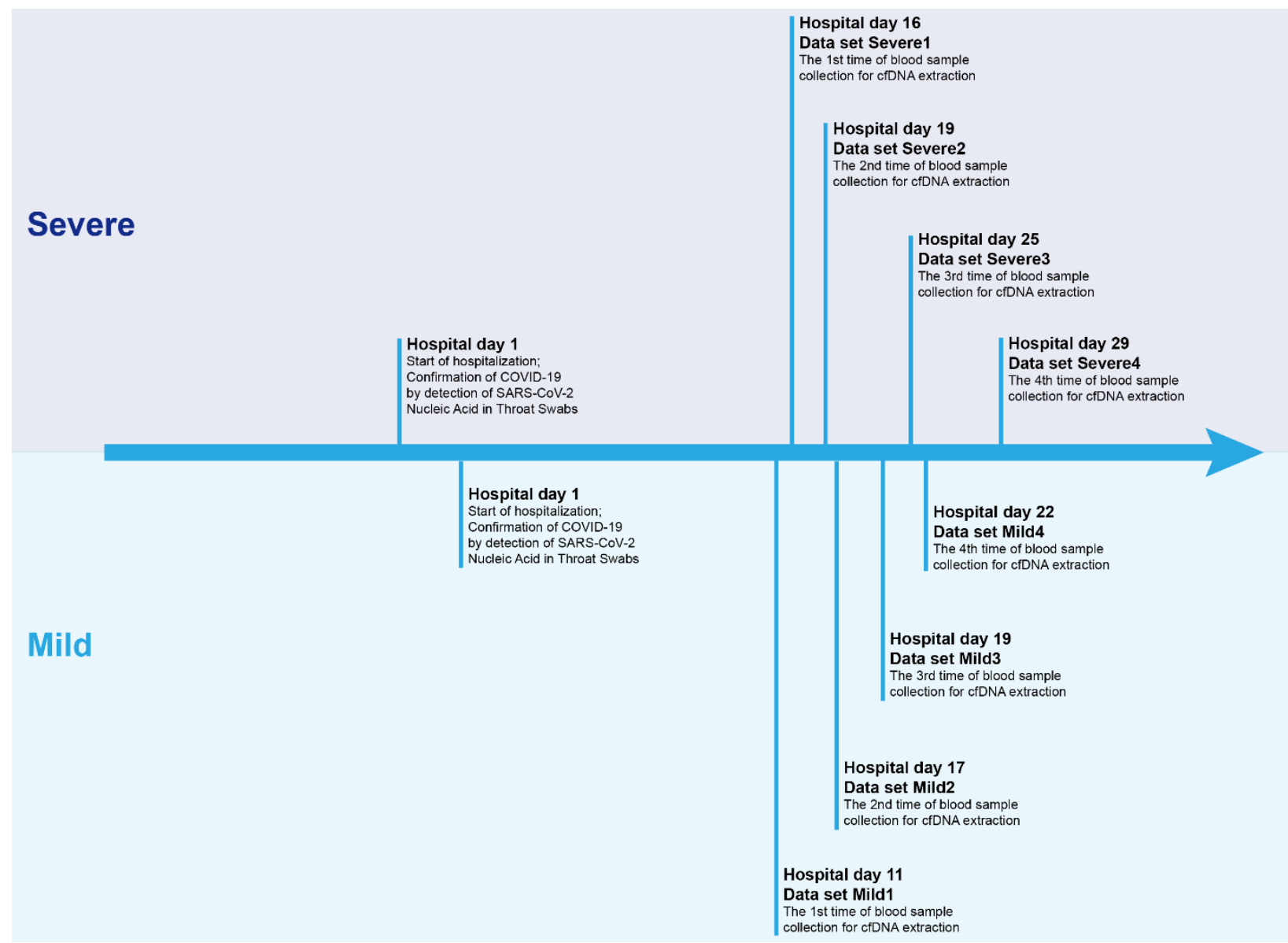

Fig. S1. Illustration of timelines for the mild and severe cases. 


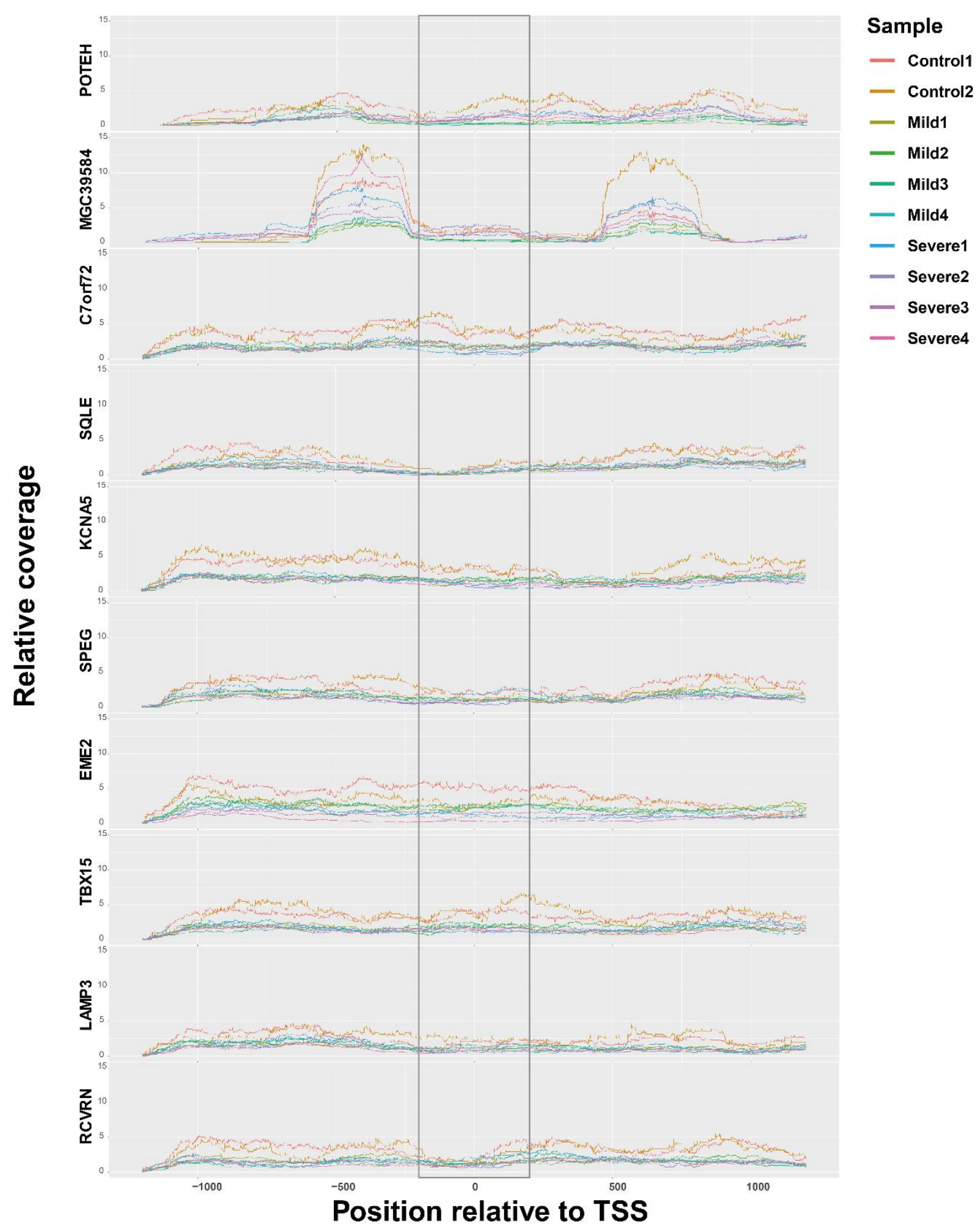

Fig. S2. Distribution of coverage around TSSs of genes significantly different between severe and mild cases. Relative coverage was calculated as coverage of cfDNA fragments weighted by average sequencing depth of each sample. Top 10 significant genes were ranked by $p$ values from top to bottom. Regions within the grey rectangle were used for significant test. 
medRxiv preprint doi: https://doi.org/10.1101/2020.06.08.20124305; this version posted June 9, 2020. The copyright holder for this preprint (which was not certified by peer review) is the author/funder, who has granted medRxiv a license to display the preprint in perpetuity.

It is made available under a CC-BY-NC-ND 4.0 International license .

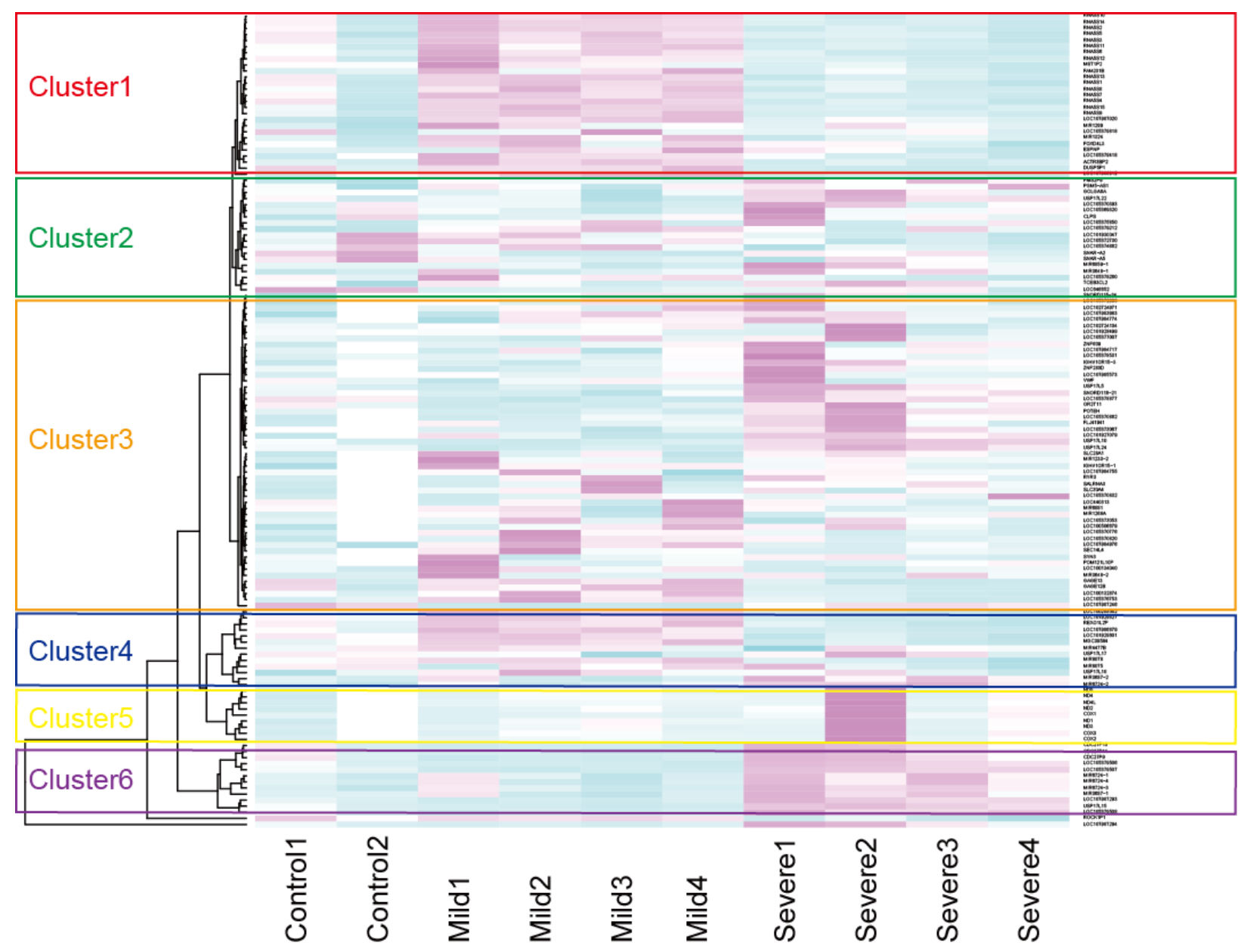

Fig. S3. Gene set enrichment analysis based on relative coverage around 200bp-TSSs. Same gene set enrichment analysis as Fig. 1 was performed on 200bp-TSSs regions alternatively, and 6 clusters of genes were used for pathway analysis (Table S8). 
Table S1. Summary on PCR testing of throat swab nucleic acids results.

\begin{tabular}{|c|c|c|}
\hline Sample & Testing date & ORF1ab/N Gene Detection ${ }^{1}$ \\
\hline \multirow{30}{*}{ Severe } & 2020/2/3 & Gray area \\
\hline & $2020 / 2 / 8$ & Negative \\
\hline & $2020 / 2 / 11$ & Positive \\
\hline & $2020 / 2 / 14$ & Positive \\
\hline & $2020 / 2 / 17$ & N Gene Positive \\
\hline & $2020 / 2 / 21$ & N Gene Positive \\
\hline & $2020 / 2 / 25$ & Positive \\
\hline & $2020 / 2 / 28$ & Positive \\
\hline & $2020 / 3 / 1$ & Positive \\
\hline & $2020 / 3 / 2$ & Gray area \\
\hline & $2020 / 3 / 3$ & Negative \\
\hline & $2020 / 3 / 4$ & Negative \\
\hline & $2020 / 3 / 5$ & Positive \\
\hline & $2020 / 3 / 6$ & Negative \\
\hline & $2020 / 3 / 7$ & Negative \\
\hline & $2020 / 3 / 8$ & Positive \\
\hline & $2020 / 3 / 9$ & Positive \\
\hline & $2020 / 3 / 10$ & Negative \\
\hline & $2020 / 3 / 11$ & Negative \\
\hline & 2020/3/18 & Gray area \\
\hline & $2020 / 2 / 17$ & Gray area \\
\hline & $2020 / 2 / 19$ & Positive \\
\hline & $2020 / 2 / 21$ & Negative \\
\hline & $2020 / 2 / 22$ & Positive \\
\hline & $2020 / 2 / 24$ & Positive \\
\hline & $2020 / 2 / 26$ & Positive \\
\hline & $2020 / 2 / 27$ & Negative \\
\hline & $2020 / 2 / 28$ & Negative \\
\hline & $2020 / 2 / 29$ & Negative \\
\hline & $2020 / 3 / 14$ & Negative \\
\hline Mild & $2020 / 3 / 31$ & Negative \\
\hline
\end{tabular}


medRxiv preprint doi: https://doi.org/10.1101/2020.06.08.20124305; this version posted June 9, 2020. The copyright holder for this preprint (which was not certified by peer review) is the author/funder, who has granted medRxiv a license to display the preprint in perpetuity.

It is made available under a CC-BY-NC-ND 4.0 International license .

Table S2. Summary on WGS data of the 2 cases and 2 controls.

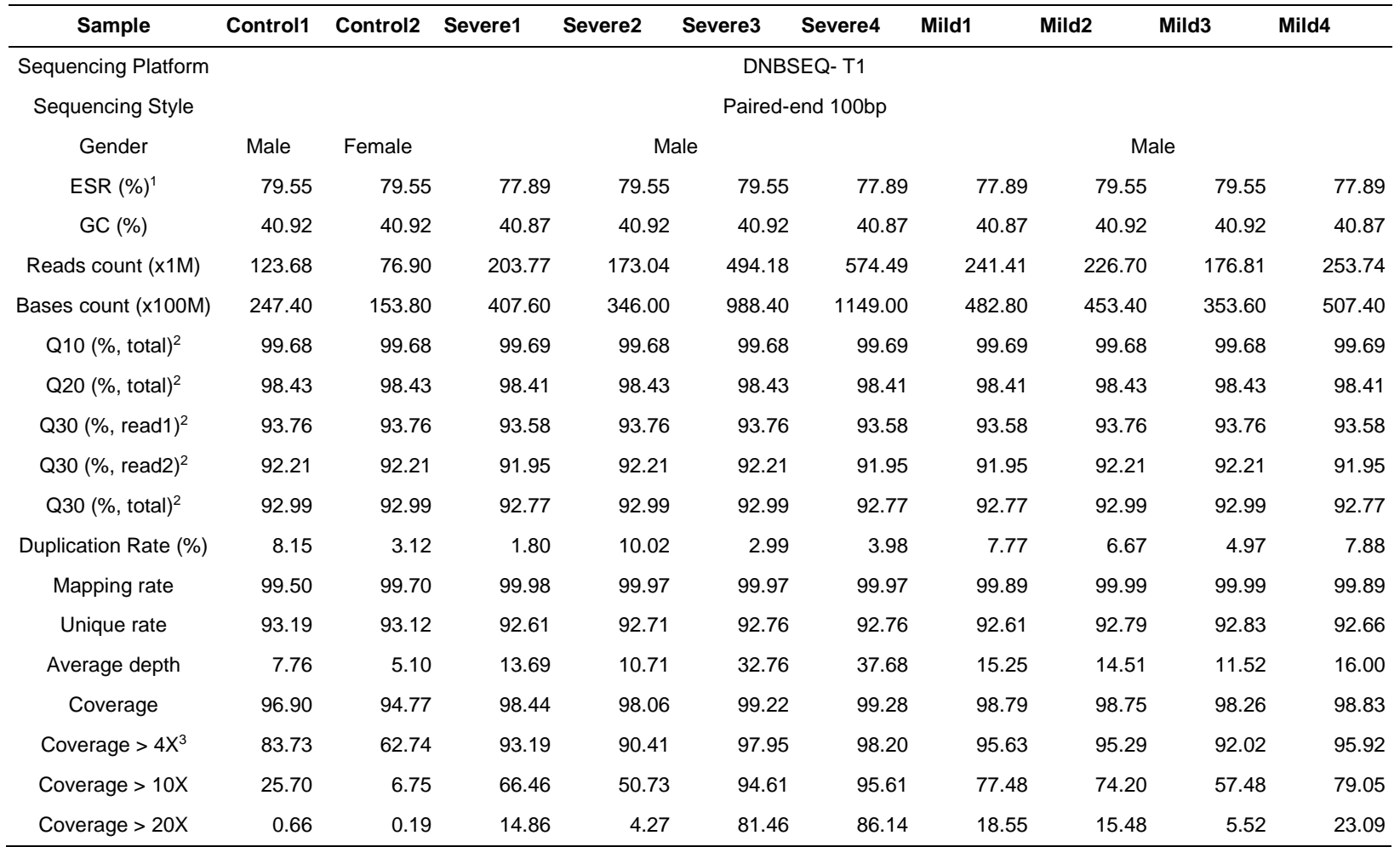

*1. Estimated sequencing error rate.

2. Q10: percent of bases with sequencing quality above 10; Q20: percent of bases with sequencing quality above 20; Q30: percent of bases with sequencing quality above 30 . 3. Coverage of bases with depth equal or above $1,4,10$, and 20 . 
medRxiv preprint doi: https://doi.org/10.1101/2020.06.08.20124305; this version posted June 9, 2020. The copyright holder for this preprint (which was not certified by peer review) is the author/funder, who has granted medRxiv a license to display the preprint in perpetuity.

It is made available under a CC-BY-NC-ND 4.0 International license .

Table S3. Results on pathway analysis of the 6 clusters from coverage around 2kb-TSSs from cfDNA of one mild case, one severe case, and two controls ${ }^{1}$.

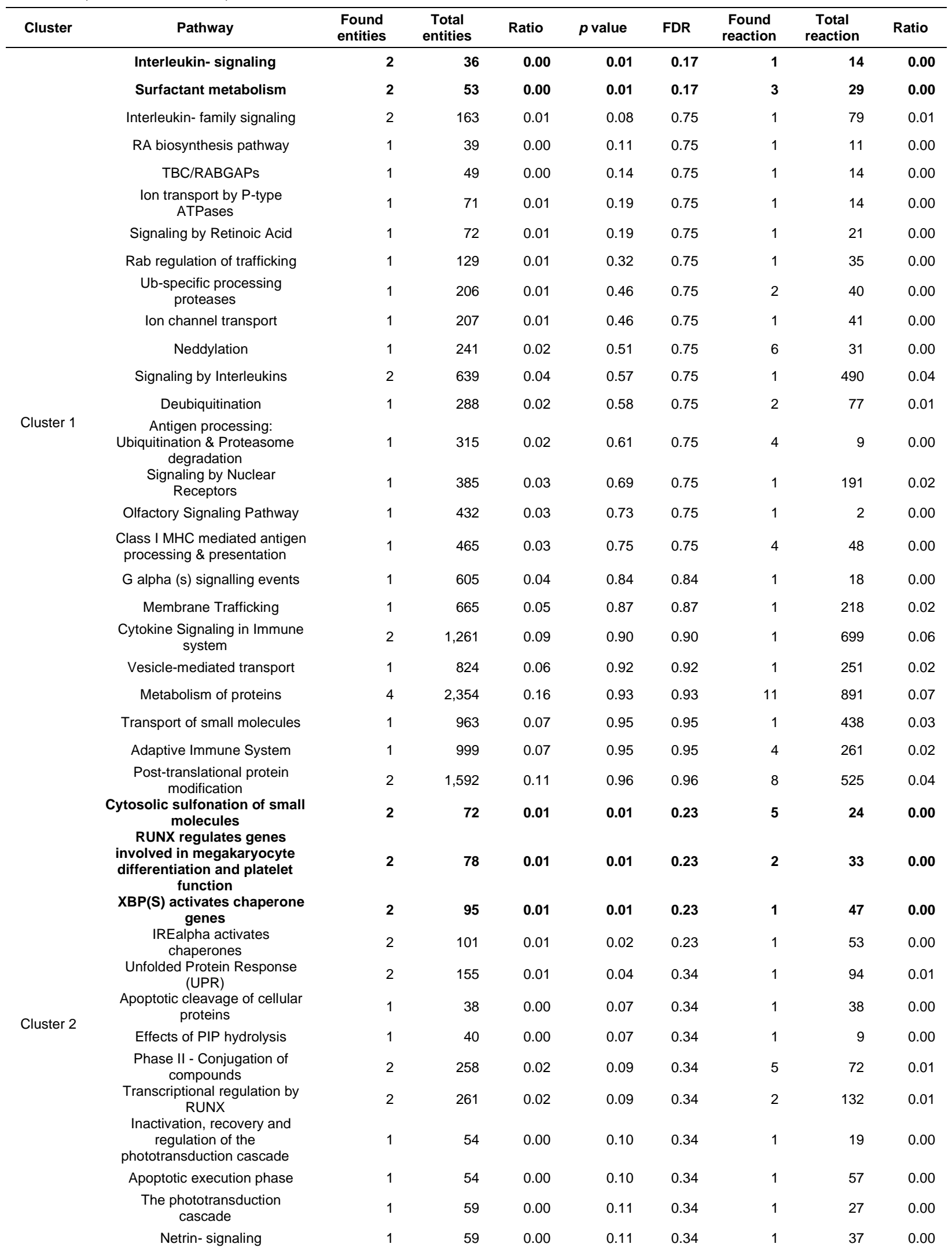


medRxiv preprint doi: https://doi.org/10.1101/2020.06.08.20124305; this version posted June 9, 2020. The copyright holder for this preprint (which was not certified by peer review) is the author/funder, who has granted medRxiv a license to display the preprint in perpetuity.

It is made available under a CC-BY-NC-ND 4.0 International license .

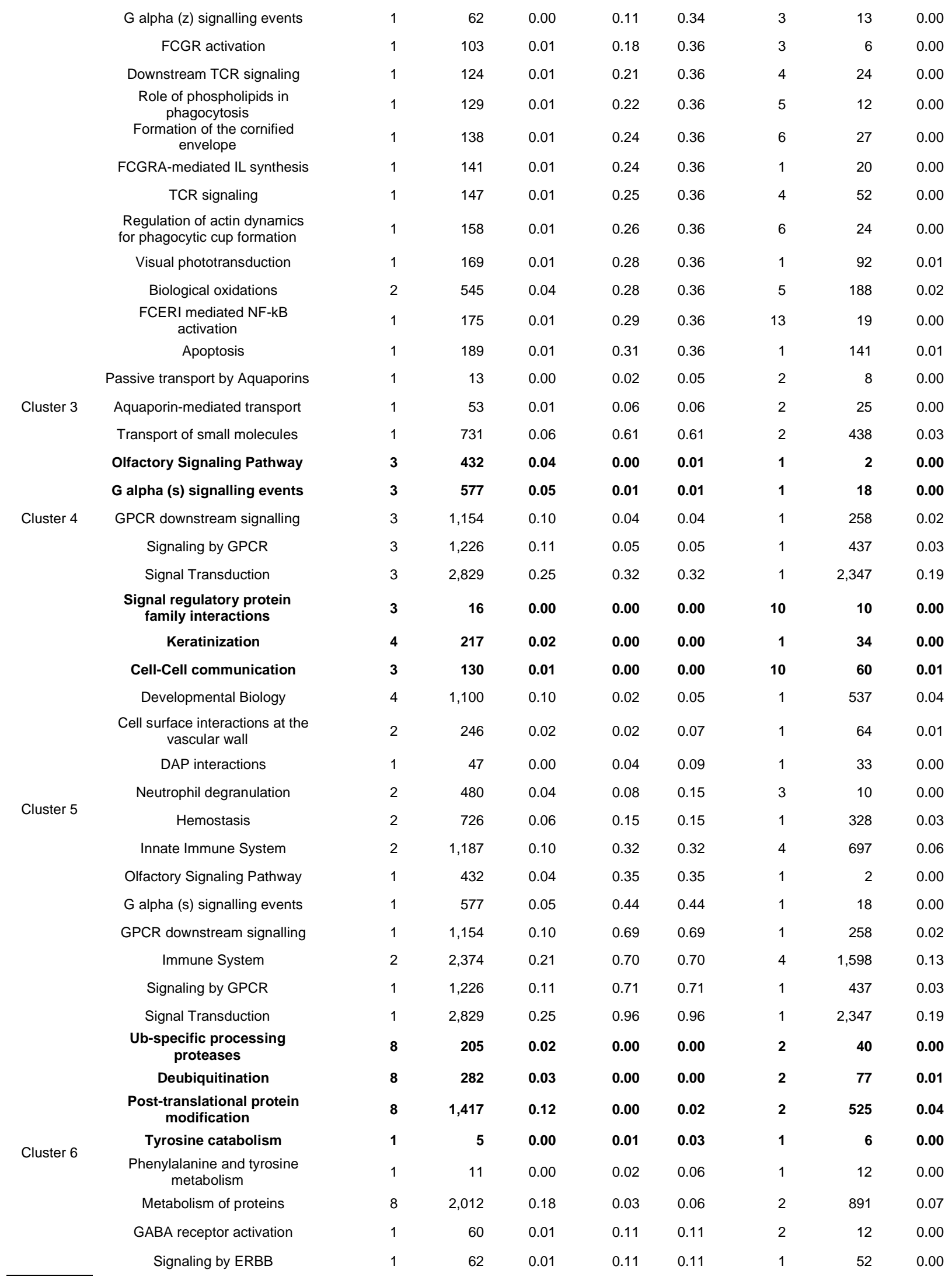


medRxiv preprint doi: https://doi.org/10.1101/2020.06.08.20124305; this version posted June 9, 2020. The copyright holder for this preprint (which was not certified by peer review) is the author/funder, who has granted medRxiv a license to display the preprint in perpetuity.

\section{It is made available under a CC-BY-NC-ND 4.0 International license .}

\begin{tabular}{|c|c|c|c|c|c|c|c|c|}
\hline $\begin{array}{l}\text { Neurotransmitter receptors } \\
\text { and postsynaptic signal } \\
\text { transmission }\end{array}$ & 1 & 208 & 0.02 & 0.33 & 0.33 & 2 & 109 & 0.01 \\
\hline $\begin{array}{l}\text { Transmission across Chemical } \\
\text { Synapses }\end{array}$ & 1 & 273 & 0.02 & 0.41 & 0.41 & 2 & 161 & 0.01 \\
\hline $\begin{array}{l}\text { Metabolism of amino acids and } \\
\text { derivatives }\end{array}$ & 1 & 376 & 0.03 & 0.52 & 0.52 & 1 & 285 & 0.02 \\
\hline Neuronal System & 1 & 419 & 0.04 & 0.56 & 0.56 & 2 & 214 & 0.02 \\
\hline $\begin{array}{l}\text { Signaling by Receptor } \\
\text { Tyrosine Kinases }\end{array}$ & 1 & 523 & 0.05 & 0.64 & 0.64 & 1 & 698 & 0.06 \\
\hline Metabolism & 1 & 2,142 & 0.19 & 0.99 & 0.99 & 1 & 2,241 & 0.18 \\
\hline Signal Transduction & 1 & 2,829 & 0.25 & 1.00 & 1.00 & 1 & 2,347 & 0.19 \\
\hline
\end{tabular}


medRxiv preprint doi: https://doi.org/10.1101/2020.06.08.20124305; this version posted June 9, 2020. The copyright holder for this preprint (which was not certified by peer review) is the author/funder, who has granted medRxiv a license to display the preprint in perpetuity.

It is made available under a CC-BY-NC-ND 4.0 International license.

Table S4. All significantly different genes between mild and severe cases ${ }^{1}$.

\begin{tabular}{|c|c|c|c|c|c|}
\hline Chromosome & Position & Gene & $\begin{array}{l}-\log _{10}(p \text { value of } \\
\text { control) }\end{array}$ & $\begin{array}{l}-\log _{10}(p \text { value of case } \\
\text { and control) }\end{array}$ & $\begin{array}{c}-\log _{10}(p \text { value of mild } \\
\text { and severe })\end{array}$ \\
\hline chr22 & 15690025 & POTEH & 0.76 & 0.62 & 27.59 \\
\hline chr21 & 9821060 & MGC39584 & 1.11 & 0.00 & 26.13 \\
\hline chr7 & 50096085 & C7orf72 & 0.95 & 2.56 & 24.66 \\
\hline chr8 & 124999756 & SQLE & 0.00 & 5.94 & 18.91 \\
\hline chr12 & 5043918 & KCNA5 & 0.76 & 0.00 & 18.06 \\
\hline chr2 & 219473003 & SPEG & 1.61 & 1.45 & 17.73 \\
\hline chr16 & 1773227 & EME2 & 2.33 & 0.49 & 17.14 \\
\hline chr1 & 118989555 & TBX15 & 0.73 & 2.10 & 17.12 \\
\hline chr3 & 183162878 & LAMP3 & 0.15 & 2.71 & 16.91 \\
\hline chr17 & 9905366 & RCVRN & 1.25 & 5.79 & 16.74 \\
\hline chr9 & 95086093 & MIR3074 & 0.14 & 0.00 & 16.61 \\
\hline chr19 & 40890825 & CYP2G1P & 1.80 & 0.00 & 16.26 \\
\hline chr16 & 1773150 & MRPS34 & 3.54 & 0.94 & 15.79 \\
\hline chr5 & 43067022 & LOC100506639 & 0.16 & 0.00 & 15.41 \\
\hline chr1 & 84997121 & MCOLN2 & 0.09 & 0.00 & 15.36 \\
\hline chr22 & 48274363 & MIR3201 & 0.22 & 0.79 & 15.31 \\
\hline chr6 & 138435293 & MIR3145 & 2.25 & 0.82 & 15.05 \\
\hline chr19 & 1026274 & CNN2 & 0.16 & 2.74 & 14.74 \\
\hline chr22 & 30289626 & GATSL3 & 0.75 & 0.00 & 14.74 \\
\hline chr9 & 21239978 & IFNA14 & 2.27 & 0.92 & 14.74 \\
\hline chr12 & 15911171 & DERA & 0.00 & 0.00 & 14.64 \\
\hline chr7 & 103347523 & PSMC2 & 0.42 & 1.17 & 14.63 \\
\hline chr12 & 7749472 & CLEC4C & 2.25 & 5.84 & 14.61 \\
\hline chr6 & 42746145 & TBCC & 0.00 & 1.79 & 14.21 \\
\hline chr13 & 24825651 & RNF17 & 0.49 & 0.00 & 14.20 \\
\hline chr11 & 57335876 & SSRP1 & 1.31 & 1.54 & 13.98 \\
\hline chr11 & 79422225 & MIR5579 & 2.47 & 0.00 & 13.86 \\
\hline chr16 & 28925210 & RABEP2 & 0.10 & 0.00 & 13.59 \\
\hline chr4 & 99511023 & C4orf17 & 0.23 & 0.09 & 13.55 \\
\hline chr3 & 10026135 & CIDECP & 2.67 & 2.74 & 13.47 \\
\hline chr21 & 34737181 & LINC00160 & 0.79 & 0.21 & 13.45 \\
\hline chr6 & 98834703 & POU3F2 & 0.24 & 4.43 & 13.42 \\
\hline chr6 & 35921179 & SRPK1 & 1.65 & 1.05 & 13.42 \\
\hline chr13 & 42781549 & FAM216B & 0.03 & 1.27 & 13.28 \\
\hline chr6 & 53262802 & GCM1 & 1.29 & 1.36 & 13.22 \\
\hline chr7 & 143959926 & OR2F1 & 1.09 & 0.83 & 13.09 \\
\hline chr20 & 63037027 & LINC00029 & 2.70 & 3.97 & 12.83 \\
\hline chr5 & 76290530 & SV2C & 0.52 & 1.01 & 12.73 \\
\hline chr3 & 100993507 & ABI3BP & 0.65 & 0.84 & 12.70 \\
\hline chr8 & 99536860 & MIR875 & 0.82 & 2.10 & 12.70 \\
\hline chr1 & 9093406 & SLC2A5 & 0.44 & 0.99 & 12.69 \\
\hline chr1 & 150765956 & CTSS & 1.58 & 0.00 & 12.65 \\
\hline chr16 & 67150998 & B3GNT9 & 0.87 & 0.99 & 12.55 \\
\hline chr12 & 10390053 & KLRK1 & 0.32 & 1.45 & 12.55 \\
\hline chr16 & 1782604 & SPSB3 & 4.29 & 2.96 & 12.51 \\
\hline chr17 & 49678162 & SPOP & 0.75 & 0.00 & 12.44 \\
\hline chr1 & 2352660 & LOC100129534 & 2.29 & 0.03 & 12.41 \\
\hline chr2 & 91775341 & GGT8P & 1.94 & 0.17 & 12.27 \\
\hline chr2 & 55983075 & MIR217 & 0.35 & 0.00 & 12.24 \\
\hline chr3 & 52226162 & TLR9 & 2.35 & 0.65 & 12.23 \\
\hline chr6 & 73354275 & DPPA5 & 1.02 & 1.02 & 12.19 \\
\hline chr16 & 66967474 & CES3 & 0.58 & 1.27 & 12.16 \\
\hline chr11 & 75717818 & MOGAT2 & 1.32 & 2.76 & 12.02 \\
\hline chr12 & 75390940 & CAPS2 & 0.74 & 0.00 & 12.00 \\
\hline chr10 & 31355206 & ZEB1 & 0.63 & 0.00 & 11.93 \\
\hline chr19 & 42528508 & CEACAM1 & 0.70 & 0.00 & 11.87 \\
\hline chr17 & 63773727 & CCDC47 & 0.00 & 0.00 & 11.85 \\
\hline chr3 & 48717277 & IP6K2 & 1.70 & 1.08 & 11.82 \\
\hline chr1 & 173866714 & SNORD76 & 0.52 & 0.79 & 11.70 \\
\hline chr9 & 102995310 & CYLC2 & 1.41 & 3.92 & 11.65 \\
\hline chr16 & 28931938 & CD19 & 1.92 & 2.51 & 11.60 \\
\hline
\end{tabular}


medRxiv preprint doi: https://doi.org/10.1101/2020.06.08.20124305; this version posted June 9, 2020. The copyright holder for this preprint (which was not certified by peer review) is the author/funder, who has granted medRxiv a license to display the preprint in perpetuity.

It is made available under a CC-BY-NC-ND 4.0 International license .

\begin{tabular}{|c|c|c|c|c|c|}
\hline chr1 & 161631962 & FCGR3B & 0.92 & 2.97 & 11.60 \\
\hline chr9 & 133377948 & SURF4 & 0.88 & 1.06 & 11.36 \\
\hline chr6 & 45197769 & MIR586 & 0.37 & 0.79 & 11.23 \\
\hline chr5 & 67196788 & CD180 & 0.12 & 0.00 & 11.21 \\
\hline chr3 & 112847003 & CD200R1L & 0.95 & 0.73 & 11.13 \\
\hline chr7 & 99784187 & CYP3A4 & 0.82 & 0.00 & 11.10 \\
\hline chr6 & 7402646 & RIOK1 & 0.00 & 0.00 & 11.08 \\
\hline chr10 & 96304327 & DNTT & 1.61 & 0.10 & 11.00 \\
\hline chr3 & 46736430 & PRSS46 & 0.36 & 3.08 & 10.98 \\
\hline chr13 & 48580900 & LINC00462 & 1.63 & 0.98 & 10.97 \\
\hline chr5 & 88439089 & LOC102546226 & 0.94 & 0.92 & 10.91 \\
\hline chr10 & 79560460 & SFTPA2 & 0.86 & 0.12 & 10.88 \\
\hline chr3 & 47011541 & NRADDP & 0.83 & 0.00 & 10.82 \\
\hline chr19 & 44671451 & CEACAM19 & 0.59 & 0.96 & 10.82 \\
\hline chr9 & 122800122 & OR1K1 & 3.25 & 0.97 & 10.81 \\
\hline chr1 & 196774815 & CFHR3 & 2.71 & 1.19 & 10.70 \\
\hline chr16 & 29863287 & CDIPT & 0.00 & 3.08 & 10.63 \\
\hline chr22 & 39432159 & LOC100506472 & 1.27 & 0.77 & 10.59 \\
\hline chr12 & 48203291 & OR10AD1 & 0.05 & 4.85 & 10.57 \\
\hline chr11 & 35420062 & SLC1A2 & 1.77 & 1.70 & 10.57 \\
\hline chr2 & 240868744 & AGXT & 0.42 & 0.82 & 10.57 \\
\hline chr14 & 95533628 & SCARNA13 & 0.45 & 2.09 & 10.56 \\
\hline chr10 & 92418660 & MARK2P9 & 0.36 & 1.67 & 10.54 \\
\hline chr6 & 149718255 & LATS1 & 1.96 & 0.14 & 10.44 \\
\hline chr8 & 7355353 & FAM66B & 2.82 & 0.00 & 10.40 \\
\hline chr3 & 179072278 & ZMAT3 & 2.74 & 0.91 & 10.38 \\
\hline chr16 & 75207173 & CTRB2 & 0.05 & 0.85 & 10.31 \\
\hline chr19 & 48637549 & DBP & 2.08 & 1.86 & 10.29 \\
\hline chr13 & 21145126 & SAP18 & 1.02 & 1.54 & 10.29 \\
\hline chr5 & 43066970 & LOC100132356 & 0.55 & 0.00 & 10.29 \\
\hline chr5 & 147081519 & PPP2R2B & 1.66 & 0.39 & 10.27 \\
\hline chr1 & 32362260 & TSSK3 & 0.74 & 0.00 & 10.27 \\
\hline chr5 & 122160175 & LOC100505841 & 1.55 & 0.59 & 10.27 \\
\hline chr5 & 100816564 & MIR548P & 0.36 & 0.23 & 10.25 \\
\hline chr12 & 19255048 & PLEKHA5 & 0.12 & 0.49 & 10.23 \\
\hline chr1 & 54998943 & BSND & 0.90 & 0.46 & 10.16 \\
\hline chr4 & 140154078 & MAML3 & 0.19 & 0.00 & 10.12 \\
\hline chr6 & 108751653 & LINC00222 & 0.63 & 0.33 & 10.10 \\
\hline chr9 & 41074624 & PGM5P2 & 3.31 & 0.30 & 10.06 \\
\hline chr1 & 24415532 & STPG1 & 2.26 & 0.98 & 10.05 \\
\hline chr11 & 5857701 & OR52E8 & 1.43 & 1.06 & 10.00 \\
\hline chr19 & 5690334 & RPL36 & 0.30 & 1.02 & 9.98 \\
\hline chr10 & 123154243 & BUB3 & 0.57 & 1.64 & 9.95 \\
\hline chr11 & 121102665 & TECTA & 0.77 & 2.55 & 9.91 \\
\hline chr19 & 49930203 & ATF5 & 0.19 & 0.00 & 9.89 \\
\hline chr21 & 42113146 & UMODL1 & 0.18 & 1.75 & 9.88 \\
\hline chr5 & 111512596 & STARD4 & 0.97 & 1.19 & 9.87 \\
\hline chr17 & 81125372 & MIR657 & 2.09 & 0.96 & 9.85 \\
\hline chr16 & 3578372 & NLRC3 & 1.28 & 0.00 & 9.85 \\
\hline chr19 & 9786173 & ZNF846 & 0.26 & 1.37 & 9.83 \\
\hline chr20 & 38033467 & TTI1 & 0.68 & 0.00 & 9.82 \\
\hline chr1 & 161118075 & PFDN2 & 1.20 & 0.00 & 9.77 \\
\hline chr5 & 42565863 & GHR & 1.54 & 0.94 & 9.69 \\
\hline chr1 & 173705429 & ANKRD45 & 0.31 & 0.00 & 9.68 \\
\hline chr17 & 44170705 & ASB16 & 0.84 & 3.33 & 9.66 \\
\hline chr1 & 54802378 & TTC22 & 0.07 & 2.53 & 9.66 \\
\hline chr11 & 56093307 & OR812 & 1.14 & 0.00 & 9.65 \\
\hline chr8 & 109540625 & EBAG9 & 0.38 & 0.00 & 9.59 \\
\hline chr19 & 15934865 & CYP4F11 & 0.29 & 0.79 & 9.50 \\
\hline chr6 & 41217946 & TREML3P & 2.58 & 0.87 & 9.43 \\
\hline chr19 & 43840523 & ZNF283 & 0.06 & 0.00 & 9.42 \\
\hline chr7 & 100969622 & MUC12 & 2.23 & 0.17 & 9.39 \\
\hline chr14 & 88839455 & TTC8 & 1.71 & 0.68 & 9.38 \\
\hline chr2 & 53767791 & $\mathrm{CHAC2}$ & 0.64 & 2.42 & 9.30 \\
\hline chr11 & 128909843 & KCNJ5 & 0.00 & 2.23 & 9.27 \\
\hline
\end{tabular}


medRxiv preprint doi: https://doi.org/10.1101/2020.06.08.20124305; this version posted June 9, 2020. The copyright holder for this preprint (which was not certified by peer review) is the author/funder, who has granted medRxiv a license to display the preprint in perpetuity.

It is made available under a CC-BY-NC-ND 4.0 International license.

\begin{tabular}{|c|c|c|c|c|c|}
\hline chr5 & 135803074 & MIR5692C1 & 0.13 & 0.97 & 9.27 \\
\hline chr2 & 33728216 & MYADML & 1.15 & 0.97 & 9.25 \\
\hline chr8 & 12134008 & USP17L7 & 2.91 & 1.70 & 9.24 \\
\hline chr14 & 81221230 & GTF2A1 & 0.10 & 0.00 & 9.18 \\
\hline chr9 & 116207520 & PAPPA & 0.33 & 0.00 & 9.18 \\
\hline chr11 & 60334881 & MS4A6E & 0.36 & 0.75 & 9.14 \\
\hline chr16 & 10183363 & GRIN2A & 1.46 & 1.32 & 9.10 \\
\hline chr8 & 30638599 & SMIM18 & 0.86 & 0.00 & 8.93 \\
\hline chr14 & 20891402 & RNASE3 & 3.24 & 2.23 & 8.91 \\
\hline chr8 & 94641135 & ESRP1 & 0.26 & 0.00 & 8.86 \\
\hline chr20 & 47166966 & MIR3616 & 1.33 & 0.00 & 8.86 \\
\hline chr3 & 114316568 & MIR568 & 1.10 & 0.07 & 8.84 \\
\hline chr4 & 77605794 & CXCL13 & 1.54 & 0.00 & 8.79 \\
\hline chr6 & 71420744 & LINC00472 & 1.01 & 0.00 & 8.74 \\
\hline chr11 & 59810871 & MRPL16 & 0.83 & 1.77 & 8.69 \\
\hline chr17 & 49848016 & TAC4 & 0.05 & 0.22 & 8.66 \\
\hline chr3 & 126655123 & TXNRD3 & 1.62 & 0.00 & 8.61 \\
\hline chr2 & 233718791 & UGT1A4 & 1.28 & 0.93 & 8.61 \\
\hline chr10 & 104122294 & SFR1 & 2.67 & 0.16 & 8.60 \\
\hline chr10 & 13234327 & UCMA & 1.76 & 1.45 & 8.59 \\
\hline chr1 & 205850147 & PM20D1 & 0.17 & 2.68 & 8.58 \\
\hline chr20 & 36541483 & MYL9 & 0.07 & 0.00 & 8.56 \\
\hline chr11 & 112074287 & PIH1D2 & 1.98 & 0.89 & 8.55 \\
\hline chr20 & 12936962 & LOC102606466 & 0.94 & 2.38 & 8.54 \\
\hline chr17 & 58540817 & 4-Sep & 1.15 & 0.94 & 8.53 \\
\hline chr17 & 56884912 & MTVR2 & 0.04 & 1.02 & 8.51 \\
\hline chr2 & 79120457 & REG1A & 2.21 & 0.82 & 8.50 \\
\hline chr12 & 121133014 & $\mathrm{P} 2 \mathrm{R} \times 7$ & 1.24 & 0.94 & 8.50 \\
\hline chr16 & 79600724 & MAF & 2.10 & 2.64 & 8.48 \\
\hline chr19 & 7763261 & CLEC4M & 2.00 & 1.94 & 8.47 \\
\hline chr9 & 92424553 & OMD & 0.00 & 0.97 & 8.43 \\
\hline chr19 & 23914881 & ZNF726 & 0.18 & 0.00 & 8.43 \\
\hline chr11 & 75351830 & ARRB1 & 0.41 & 0.00 & 8.40 \\
\hline chr1 & 92218015 & C1orf146 & 1.13 & 0.81 & 8.40 \\
\hline chr11 & 59514912 & OR4D9 & 0.33 & 0.74 & 8.37 \\
\hline chr1 & 78620943 & IFI44L & 1.07 & 0.00 & 8.35 \\
\hline chr2 & 219906564 & MIR4268 & 3.06 & 1.42 & 8.34 \\
\hline chr2 & 202961346 & CARF & 0.34 & 1.30 & 8.33 \\
\hline chr7 & 50319047 & IKZF1 & 0.05 & 0.00 & 8.33 \\
\hline chr2 & 110222939 & LINC00116 & 0.73 & 0.00 & 8.26 \\
\hline chr6 & 38723394 & DNAH8 & 2.10 & 0.86 & 8.26 \\
\hline chr11 & 65018504 & MIR6879 & 0.18 & 0.00 & 8.24 \\
\hline chr12 & 48106307 & SENP1 & 0.07 & 0.00 & 8.24 \\
\hline chr14 & 25050296 & STXBP6 & 0.78 & 1.10 & 8.24 \\
\hline chr8 & 18084997 & ASAH1 & 0.96 & 0.00 & 8.21 \\
\hline chr11 & 85665147 & CREBZF & 1.13 & 1.03 & 8.21 \\
\hline chr2 & 207625927 & METTL21A & 0.23 & 0.00 & 8.21 \\
\hline chr22 & 29319617 & RASL10A & 0.00 & 1.02 & 8.21 \\
\hline chr12 & 29499692 & $\mathrm{OVCH} 1$ & 1.46 & 0.00 & 8.18 \\
\hline chr3 & 146606215 & PLSCR5 & 1.79 & 2.97 & 8.18 \\
\hline chr16 & 70529498 & SNORD111B & 0.83 & 0.13 & 8.17 \\
\hline chr14 & 73851917 & PTGR2 & 0.53 & 2.03 & 8.12 \\
\hline chr7 & 128241277 & LEP & 2.94 & 0.00 & 8.11 \\
\hline chr19 & 3178737 & S1PR4 & 0.58 & 3.44 & 8.10 \\
\hline chr4 & 119304444 & C4orf3 & 0.33 & 0.82 & 8.04 \\
\hline chr6 & 142147204 & NMBR & 0.97 & 0.13 & 8.00 \\
\hline chr11 & 90002507 & TRIM53AP & 0.92 & 2.21 & 8.00 \\
\hline chr9 & 135521437 & LCN1 & 3.09 & 1.14 & 7.93 \\
\hline chr14 & 90455229 & LINC00642 & 3.20 & 0.78 & 7.91 \\
\hline chr7 & 101238819 & CLDN15 & 0.96 & 0.81 & 7.88 \\
\hline chr9 & 27297138 & EQTN & 0.43 & 0.72 & 7.88 \\
\hline chr10 & 68332957 & PBLD & 0.06 & 0.00 & 7.88 \\
\hline chr8 & 86069986 & PSKH2 & 0.34 & 0.06 & 7.88 \\
\hline chr2 & 28870308 & TRMT61B & 1.70 & 1.25 & 7.88 \\
\hline chr1 & 12716114 & AADACL3 & 1.29 & 0.96 & 7.87 \\
\hline
\end{tabular}


medRxiv preprint doi: https://doi.org/10.1101/2020.06.08.20124305; this version posted June 9, 2020. The copyright holder for this preprint (which was not certified by peer review) is the author/funder, who has granted medRxiv a license to display the preprint in perpetuity.

It is made available under a CC-BY-NC-ND 4.0 International license .

\begin{tabular}{|c|c|c|c|c|c|}
\hline chr5 & 160929410 & ATP10B & 0.59 & 3.30 & 7.87 \\
\hline chr19 & 15898119 & CYP4F2 & 0.38 & 0.00 & 7.87 \\
\hline chr17 & 73828536 & LINC00469 & 0.48 & 0.09 & 7.87 \\
\hline chr17 & 18644430 & TBC1D28 & 0.93 & 2.36 & 7.87 \\
\hline chr13 & 27969367 & CDX2 & 0.71 & 1.04 & 7.87 \\
\hline chr3 & 184138895 & EIF2B5 & 0.07 & 0.00 & 7.85 \\
\hline chr11 & 110429936 & FDX1 & 0.71 & 0.00 & 7.84 \\
\hline chr11 & 47395639 & SPI1 & 1.39 & 0.00 & 7.84 \\
\hline chr10 & 72893555 & ОІT3 & 1.40 & 0.75 & 7.83 \\
\hline chr3 & 156817061 & LINC00886 & 0.07 & 1.16 & 7.82 \\
\hline chr9 & 87148643 & C9orf170 & 1.36 & 0.00 & 7.81 \\
\hline chr2 & 232539726 & CHRNG & 0.25 & 0.84 & 7.81 \\
\hline chr8 & 12129296 & LOC392196 & 2.61 & 0.00 & 7.81 \\
\hline chr5 & 149732824 & MIR378A & 0.33 & 0.66 & 7.81 \\
\hline chr17 & 43125582 & NBR2 & 1.02 & 0.00 & 7.81 \\
\hline chr11 & 104164298 & PDGFD & 0.28 & 0.00 & 7.81 \\
\hline chr6 & 42879615 & RPL7L1 & 0.18 & 0.00 & 7.81 \\
\hline chr15 & 74614993 & CLK3 & 0.34 & 1.24 & 7.79 \\
\hline chr17 & 4796143 & PSMB6 & 0.18 & 0.64 & 7.79 \\
\hline chr8 & 104467074 & DPYS & 2.85 & 0.00 & 7.78 \\
\hline chr2 & 224401993 & FAM124B & 0.89 & 2.62 & 7.78 \\
\hline chr2 & 239943093 & MIR4786 & 1.73 & 2.56 & 7.78 \\
\hline chr3 & 13570321 & FBLN2 & 3.22 & 2.19 & 7.74 \\
\hline chr7 & 53035655 & POM121L12 & 0.47 & 0.61 & 7.71 \\
\hline chr22 & 20086057 & MIR1306 & 0.12 & 0.00 & 7.69 \\
\hline chr5 & 174751733 & MIR4634 & 1.57 & 1.10 & 7.68 \\
\hline chr17 & 4969770 & MIR6864 & 1.65 & 0.07 & 7.68 \\
\hline chr1 & 149886681 & HIST2H2BE & 0.07 & 0.00 & 7.67 \\
\hline chr17 & 18315279 & SMCR8 & 1.02 & 0.00 & 7.67 \\
\hline chr15 & 40039201 & SRP14 & 1.94 & 0.00 & 7.67 \\
\hline chr2 & 113072317 & IL1F10 & 1.55 & 0.21 & 7.61 \\
\hline chr3 & 69013960 & EOGT & 1.10 & 1.08 & 7.57 \\
\hline chr2 & 222656354 & FARSB & 0.37 & 0.00 & 7.57 \\
\hline chr1 & 113206252 & LOC643441 & 1.78 & 0.10 & 7.57 \\
\hline chr18 & 59899959 & PMAIP1 & 0.30 & 1.19 & 7.57 \\
\hline chr5 & 54075582 & MIR4459 & 1.20 & 0.00 & 7.56 \\
\hline chr1 & 158420865 & OR10K2 & 0.35 & 0.00 & 7.56 \\
\hline chr1 & 206772493 & IL10 & 1.33 & 0.06 & 7.55 \\
\hline chr20 & 38429803 & SNORA71C & 0.07 & 1.56 & 7.55 \\
\hline chr16 & 19456449 & TMC5 & 1.66 & 0.07 & 7.55 \\
\hline chr10 & 102837532 & CYP17A1 & 1.35 & 1.84 & 7.54 \\
\hline chr7 & 28979966 & LOC100506497 & 1.18 & 0.03 & 7.54 \\
\hline chr9 & 92292592 & SNORA84 & 1.00 & 0.00 & 7.51 \\
\hline chr5 & 39364552 & C9 & 1.91 & 0.34 & 7.47 \\
\hline chr15 & 76062996 & NRG4 & 0.39 & 2.09 & 7.46 \\
\hline chr10 & 88851974 & ANKRD22 & 3.49 & 3.13 & 7.44 \\
\hline chr1 & 15736313 & SLC25A34 & 0.51 & 0.89 & 7.44 \\
\hline chr4 & 139687664 & MGST2 & 1.31 & 2.94 & 7.42 \\
\hline chr21 & 42951013 & MIR5692B & 0.07 & 0.00 & 7.42 \\
\hline chr2 & 230327192 & SP140L & 0.70 & 0.00 & 7.42 \\
\hline chr17 & 15682878 & TRIM16 & 0.87 & 0.26 & 7.42 \\
\hline chr8 & 96235633 & UQCRB & 2.26 & 0.00 & 7.42 \\
\hline chr4 & 5019469 & CYTL1 & 2.22 & 0.07 & 7.41 \\
\hline chr4 & 138130684 & LINC00616 & 0.08 & 0.08 & 7.41 \\
\hline chr10 & 102359272 & GBF1 & 1.20 & 1.30 & 7.40 \\
\hline chr11 & 59443168 & OR5A1 & 1.45 & 0.24 & 7.39 \\
\hline chr5 & 149960736 & SLC26A2 & 0.28 & 0.00 & 7.38 \\
\hline chr8 & 10672636 & C8orf74 & 3.37 & 2.09 & 7.36 \\
\hline chr3 & 109409989 & LINC01205 & 0.19 & 1.02 & 7.35 \\
\hline chr11 & 59713844 & OR10V1 & 2.27 & 0.00 & 7.35 \\
\hline chr20 & 4721853 & PRND & 3.17 & 0.20 & 7.34 \\
\hline chr19 & 10817495 & MIR199A1 & 1.29 & 0.00 & 7.31 \\
\hline chr17 & 81309247 & LINC00482 & 0.76 & 0.00 & 7.29 \\
\hline chr1 & 3873296 & DFFB & 0.52 & 0.00 & 7.28 \\
\hline chr15 & 98900610 & IGF1R & 1.52 & 0.00 & 7.28 \\
\hline
\end{tabular}


medRxiv preprint doi: https://doi.org/10.1101/2020.06.08.20124305; this version posted June 9, 2020. The copyright holder for this preprint (which was not certified by peer review) is the author/funder, who has granted medRxiv a license to display the preprint in perpetuity.

It is made available under a CC-BY-NC-ND 4.0 International license.

\begin{tabular}{|c|c|c|c|c|c|}
\hline chr11 & 66052344 & SF3B2 & 0.25 & 0.00 & 7.28 \\
\hline chr8 & 17276395 & VPS37A & 1.87 & 0.00 & 7.28 \\
\hline chr7 & 5072059 & RBAKDN & 0.79 & 0.64 & 7.28 \\
\hline chr6 & 2987966 & LINC01011 & 0.52 & 0.00 & 7.23 \\
\hline chr14 & 101025563 & MIR1197 & 1.78 & 0.47 & 7.23 \\
\hline chr17 & 17779528 & SMCR5 & 0.07 & 4.25 & 7.22 \\
\hline chr6 & 6588700 & LY86 & 1.99 & 0.86 & 7.18 \\
\hline chr1 & 17372195 & PADI6 & 0.21 & 0.75 & 7.18 \\
\hline chr12 & 80217318 & OTOGL & 1.66 & 2.15 & 7.13 \\
\hline chr11 & 102317483 & BIRC3 & 0.46 & 0.00 & 7.13 \\
\hline chr1 & 234373700 & COA6 & 0.13 & 0.00 & 7.13 \\
\hline chr17 & 43171187 & NBR1 & 1.20 & 1.45 & 7.13 \\
\hline chr1 & 31704166 & COL16A1 & 0.37 & 0.00 & 7.12 \\
\hline chr10 & 114282512 & VWA2 & 0.75 & 0.80 & 7.12 \\
\hline chr8 & 85438826 & CA3 & 2.55 & 0.73 & 7.11 \\
\hline chr15 & 52709816 & FAM214A & 0.95 & 1.02 & 7.11 \\
\hline chr17 & 28861729 & MIR4732 & 0.75 & 0.13 & 7.11 \\
\hline chr7 & 64794387 & ZNF138 & 1.32 & 0.00 & 7.11 \\
\hline chr6 & 159805642 & PNLDC1 & 0.22 & 0.00 & 7.10 \\
\hline chr13 & 102880098 & METTL21EP & 0.89 & 0.96 & 7.09 \\
\hline chr20 & 45705179 & MIR3617 & 0.38 & 1.55 & 7.09 \\
\hline chr8 & 78724373 & LOC101241902 & 1.19 & 0.00 & 7.09 \\
\hline chr22 & 20114750 & MIR6816 & 0.21 & 0.00 & 7.09 \\
\hline chr12 & 102120138 & NUP37 & 0.22 & 0.00 & 7.09 \\
\hline chr3 & 39406688 & RPSA & 0.71 & 0.91 & 7.09 \\
\hline chr8 & 23854806 & STC1 & 1.51 & 0.00 & 7.08 \\
\hline chr3 & 105366712 & ALCAM & 0.11 & 0.00 & 7.06 \\
\hline chr1 & 114758049 & CSDE1 & 0.06 & 2.98 & 7.06 \\
\hline chr19 & 14529542 & MIR639 & 0.52 & 0.00 & 7.06 \\
\hline chr9 & 102519636 & LINC00587 & 0.10 & 1.56 & 7.03 \\
\hline chr9 & 122477925 & OR1J1 & 1.18 & 1.27 & 7.02 \\
\hline chr10 & 105086568 & SORCS3 & 0.09 & 1.10 & 7.00 \\
\hline chr3 & 169911571 & SAMD7 & 0.59 & 0.00 & 7.00 \\
\hline chr13 & 46797680 & ESD & 0.10 & 0.07 & 6.97 \\
\hline chr22 & 16592809 & CCT8L2 & 0.10 & 0.62 & 6.94 \\
\hline chr20 & 18379048 & LINC00851 & 0.88 & 0.62 & 6.94 \\
\hline chr1 & 103108579 & COL11A1 & 0.32 & 0.00 & 6.91 \\
\hline chr16 & 2033664 & SLC9A3R2 & 0.25 & 0.19 & 6.91 \\
\hline chr11 & 16476387 & SOX6 & 0.16 & 0.51 & 6.90 \\
\hline chr10 & 110871794 & PDCD4 & 2.52 & 0.00 & 6.89 \\
\hline chr13 & 70107212 & ATXN8OS & 1.13 & 1.49 & 6.88 \\
\hline chr7 & 111091005 & LRRN3 & 0.67 & 0.91 & 6.88 \\
\hline chr6 & 46687874 & TDRD6 & 1.12 & 0.00 & 6.86 \\
\hline chr1 & 145707506 & PDZK1 & 2.71 & 0.88 & 6.84 \\
\hline chr22 & 20917425 & CRKL & 0.09 & 0.00 & 6.83 \\
\hline chr14 & 104699406 & INF2 & 1.04 & 1.25 & 6.83 \\
\hline chr20 & 57321590 & MIR4325 & 1.48 & 0.73 & 6.82 \\
\hline chr17 & 2329209 & SNORD91B & 1.28 & 2.55 & 6.81 \\
\hline chr22 & 20249210 & MIR1286 & 1.87 & 0.40 & 6.80 \\
\hline chr16 & 67936876 & PSMB10 & 0.05 & 0.14 & 6.80 \\
\hline chr21 & 42219897 & ABCG1 & 0.01 & 0.00 & 6.80 \\
\hline chr3 & 8733799 & CAV3 & 0.60 & 0.66 & 6.80 \\
\hline chr16 & 86578508 & FOXL1 & 2.26 & 3.80 & 6.80 \\
\hline chr5 & 170199140 & LINC01187 & 0.66 & 0.00 & 6.80 \\
\hline chr6 & 89828020 & MDN1 & 0.15 & 1.08 & 6.80 \\
\hline chr1 & 157700984 & FCRL3 & 0.95 & 0.00 & 6.79 \\
\hline chr13 & 38349770 & UFM1 & 0.49 & 0.00 & 6.77 \\
\hline chr12 & 124915546 & MIR5188 & 0.55 & 1.97 & 6.75 \\
\hline chr5 & 140867512 & PCDHA11 & 0.96 & 0.00 & 6.73 \\
\hline chr14 & 94640724 & SERPINA13P & 0.73 & 2.72 & 6.73 \\
\hline chr1 & 145910188 & ITGA10 & 2.33 & 1.10 & 6.73 \\
\hline chr3 & 155745722 & PLCH1 & 3.06 & 1.34 & 6.73 \\
\hline chr16 & 81077266 & C16orf46 & 2.08 & 0.00 & 6.72 \\
\hline chr11 & 128587592 & ETS1 & 0.00 & 0.07 & 6.70 \\
\hline chr6 & 40378423 & TDRG1 & 0.74 & 0.50 & 6.70 \\
\hline
\end{tabular}


medRxiv preprint doi: https://doi.org/10.1101/2020.06.08.20124305; this version posted June 9, 2020. The copyright holder for this preprint (which was not certified by peer review) is the author/funder, who has granted medRxiv a license to display the preprint in perpetuity.

It is made available under a CC-BY-NC-ND 4.0 International license.

\begin{tabular}{|c|c|c|c|c|c|}
\hline chr7 & 29483815 & $\mathrm{CHN} 2$ & 2.64 & 0.64 & 6.69 \\
\hline chr7 & 100642779 & TFR2 & 1.45 & 2.51 & 6.68 \\
\hline chr16 & 5066144 & C16orf89 & 0.54 & 0.64 & 6.66 \\
\hline chr6 & 46746928 & ANKRD66 & 1.17 & 2.32 & 6.65 \\
\hline chr16 & 68236232 & ESRP2 & 2.37 & 0.77 & 6.65 \\
\hline chr10 & 5666594 & ASB13 & 1.13 & 0.00 & 6.63 \\
\hline chr3 & 138947139 & FOXL2 & 3.59 & 0.00 & 6.63 \\
\hline chr7 & 30594892 & GARS & 0.29 & 0.00 & 6.63 \\
\hline chr20 & 32052187 & HCK & 0.00 & 0.00 & 6.63 \\
\hline chr1 & 1013466 & ISG15 & 0.21 & 0.00 & 6.63 \\
\hline chr1 & 175023454 & MRPS14 & 0.98 & 1.37 & 6.63 \\
\hline chr13 & 31739552 & RXFP2 & 2.11 & 0.61 & 6.62 \\
\hline chr2 & 14400957 & LINC00276 & 2.32 & 1.87 & 6.61 \\
\hline chr12 & 7670598 & APOBEC1 & 1.13 & 0.90 & 6.61 \\
\hline chr17 & 48579946 & MIR10A & 1.81 & 0.82 & 6.61 \\
\hline chr15 & 74812852 & LMAN1L & 2.36 & 0.81 & 6.58 \\
\hline chr6 & 89595925 & ANKRD6 & 1.68 & 0.88 & 6.56 \\
\hline chr5 & 54744257 & LOC102467080 & 0.78 & 1.67 & 6.56 \\
\hline chr3 & 75630762 & MIR1324 & 0.00 & 3.62 & 6.56 \\
\hline chr14 & 64215953 & SYNE2 & 0.68 & 0.72 & 6.56 \\
\hline chr4 & 172697628 & GALNTL6 & 0.24 & 0.00 & 6.55 \\
\hline chr11 & 62299063 & SCGB1D4 & 1.61 & 0.00 & 6.55 \\
\hline chr15 & 76336723 & ISL2 & 1.35 & 0.91 & 6.51 \\
\hline chr1 & 3458701 & ARHGEF16 & 0.63 & 0.00 & 6.49 \\
\hline chr8 & 65634216 & ARMC1 & 0.16 & 0.99 & 6.49 \\
\hline chr2 & 180007358 & CWC22 & 1.08 & 0.00 & 6.49 \\
\hline chr3 & 25664938 & MIR4442 & 0.67 & 2.62 & 6.49 \\
\hline chr5 & 41510627 & PLCXD3 & 0.08 & 1.16 & 6.49 \\
\hline chr13 & 19561573 & TPTE2 & 2.10 & 1.36 & 6.48 \\
\hline chr5 & 40841307 & CARD6 & 1.54 & 1.97 & 6.45 \\
\hline chr6 & 49463327 & MUT & 2.67 & 5.01 & 6.42 \\
\hline chr15 & 52295797 & MYO5C & 0.82 & 0.00 & 6.41 \\
\hline chr9 & 89312224 & MIR3153 & 0.70 & 1.14 & 6.40 \\
\hline chr4 & 98997386 & MIR3684 & 0.16 & 0.76 & 6.39 \\
\hline chr17 & 32992850 & SPACA3 & 0.62 & 1.45 & 6.39 \\
\hline chr2 & 75646782 & MRPL19 & 0.62 & 0.00 & 6.38 \\
\hline chr3 & 157123001 & LINC00880 & 0.16 & 0.00 & 6.37 \\
\hline chr14 & 70564741 & ADAM20 & 0.26 & 0.04 & 6.36 \\
\hline chr20 & 18467184 & DZANK1 & 0.12 & 0.00 & 6.33 \\
\hline chr1 & 100178272 & LRRC39 & 2.18 & 0.04 & 6.32 \\
\hline chr7 & 102293102 & MIR4285 & 1.45 & 0.00 & 6.31 \\
\hline chr4 & 164977665 & TRIM61 & 3.22 & 1.02 & 6.31 \\
\hline chr6 & 100881371 & ASCC3 & 0.35 & 0.00 & 6.30 \\
\hline chr1 & 161707228 & FCRLA & 2.57 & 0.65 & 6.30 \\
\hline chr19 & 37507167 & ZNF793 & 1.36 & 0.00 & 6.30 \\
\hline chr11 & 61362298 & CYB561A3 & 0.55 & 0.00 & 6.30 \\
\hline chr12 & 57547330 & DCTN2 & 0.96 & 1.65 & 6.30 \\
\hline chr7 & 27165529 & HOXA9 & 0.47 & 2.53 & 6.30 \\
\hline chr19 & 55334042 & TMEM150B & 1.96 & 0.00 & 6.30 \\
\hline chr17 & 4264025 & ANKFY1 & 1.71 & 1.91 & 6.28 \\
\hline chr1 & 15976131 & ZBTB17 & 2.13 & 0.05 & 6.28 \\
\hline chr22 & 24181475 & SUSD2 & 1.66 & 0.34 & 6.28 \\
\hline chr13 & 19181851 & TUBA3C & 0.11 & 0.89 & 6.28 \\
\hline chr7 & 130543452 & COPG2IT1 & 0.28 & 1.10 & 6.26 \\
\hline chr16 & 66918983 & $\mathrm{CDH} 16$ & 1.33 & 0.99 & 6.26 \\
\hline chr16 & 86196180 & LINC01082 & 0.27 & 0.00 & 6.26 \\
\hline chr1 & 86156986 & COL24A1 & 0.93 & 3.07 & 6.26 \\
\hline chr17 & 31321748 & EVI2A & 0.30 & 0.73 & 6.26 \\
\hline chr2 & 186600204 & ITGAV & 1.23 & 0.19 & 6.26 \\
\hline chr4 & 146176008 & LSM6 & 0.15 & 0.97 & 6.26 \\
\hline chr22 & 30425622 & MTFP1 & 0.99 & 1.02 & 6.26 \\
\hline chr16 & 19522144 & GDE1 & 0.73 & 0.99 & 6.25 \\
\hline chr3 & 151329548 & P2RY13 & 0.99 & 1.51 & 6.24 \\
\hline chr5 & 34043265 & C1QTNF3 & 2.25 & 2.23 & 6.23 \\
\hline chr8 & 87874067 & DCAF4L2 & 0.60 & 0.00 & 6.21 \\
\hline
\end{tabular}


medRxiv preprint doi: https://doi.org/10.1101/2020.06.08.20124305; this version posted June 9, 2020. The copyright holder for this preprint (which was not certified by peer review) is the author/funder, who has granted medRxiv a license to display the preprint in perpetuity.

It is made available under a CC-BY-NC-ND 4.0 International license .

\begin{tabular}{|c|c|c|c|c|c|}
\hline chr19 & 39498916 & DLL3 & 0.43 & 0.00 & 6.20 \\
\hline chr6 & 3094001 & RIPK1 & 0.88 & 0.00 & 6.20 \\
\hline chr6 & 24495162 & GPLD1 & 0.06 & 0.00 & 6.20 \\
\hline chr8 & 98944328 & STK3 & 1.79 & 0.15 & 6.19 \\
\hline chr1 & 230714589 & AGT & 2.96 & 1.05 & 6.17 \\
\hline chr1 & 171338895 & TOP1P1 & 4.13 & 0.00 & 6.15 \\
\hline chr4 & 176002690 & GPM6A & 1.57 & 1.75 & 6.15 \\
\hline chr1 & 217137756 & ESRRG & 0.45 & 1.51 & 6.13 \\
\hline chr16 & 56904263 & MIR6863 & 1.65 & 0.92 & 6.12 \\
\hline chr19 & 42740515 & PSG3 & 1.70 & 1.96 & 6.10 \\
\hline chr1 & 47190098 & PDZK1IP1 & 0.46 & 0.85 & 6.10 \\
\hline chr14 & 71398336 & SNORD56B & 0.09 & 1.60 & 6.10 \\
\hline chr7 & 29990288 & SCRN1 & 0.59 & 0.55 & 6.08 \\
\hline chr2 & 219218989 & ABCB6 & 0.39 & 0.00 & 6.08 \\
\hline chr7 & 1056103 & GPR146 & 0.19 & 0.76 & 6.06 \\
\hline chr12 & 56362798 & APOF & 1.19 & 0.71 & 6.06 \\
\hline chr11 & 90555856 & MIR4490 & 1.05 & 2.23 & 6.05 \\
\hline chr1 & 158831377 & MNDA & 0.12 & 0.73 & 6.04 \\
\hline chr12 & 57430998 & R3HDM2 & 0.30 & 0.23 & 6.04 \\
\hline chr6 & 44342659 & SPATS1 & 0.79 & 0.76 & 6.04 \\
\hline chr7 & 149776041 & SSPO & 0.74 & 1.19 & 6.04 \\
\hline chr16 & 29790967 & KIF22 & 1.73 & 2.46 & 6.03 \\
\hline chr1 & 233624151 & MIR4427 & 1.03 & 2.16 & 6.03 \\
\hline chr5 & 27472291 & LINC01021 & 0.42 & 0.71 & 6.01 \\
\hline
\end{tabular}


medRxiv preprint doi: https://doi.org/10.1101/2020.06.08.20124305; this version posted June 9, 2020. The copyright holder for this preprint (which was not certified by peer review) is the author/funder, who has granted medRxiv a license to display the preprint in perpetuity.

It is made available under a CC-BY-NC-ND 4.0 International license .

Table S5. Clinical medication records of the severe case.

\begin{tabular}{|c|c|c|c|}
\hline Date & Clinical medication & Increase/Decrease Dosage & Auxiliary Survival \\
\hline Hospital Day 2 & $\begin{array}{l}\text { Use Doxycycline } \\
\text { Use Interferon atomization } \\
\text { Use Methylprednisolone } \\
\text { (80mg) } \\
\text { Use Thymopentin } \\
\quad+\text { Immunoglobulin }(10 \mathrm{~g}) \\
\text { Use Meropenem } \\
\quad+\text { Linezolid } \\
\text { Use Abidor + Kridge } \\
\text { Use Xuebijing + Ulinastatin } \\
\text { Use Norepinephrine } \\
\text { Use Mosapride } \\
\text { Use Human albumin (10g) }\end{array}$ & & $\begin{array}{l}\text { Invasive Ventilator ( } \\
\text { SIMV mode } \\
\text { VT } 450 \mathrm{~mL} \\
\text { PS } 15 \mathrm{cmH} 2 \mathrm{O} \\
\text { PEEP } 12 \mathrm{cmH} 2 \mathrm{O} \\
\text { FiO2 } 70 \% \\
\text { Respiration ratio } 1: 1.5 \\
\text { Frequency } 20 \mathrm{bpm} . \\
\text { R } \\
\text { Right subclavian vein puncture ca } \\
\text { theterization } \\
\text { Right femoral vein catheterization }\end{array}$ \\
\hline Hospital Day 3 & $\begin{array}{l}\text { Stop Linezolid } \\
\text { Stop Kridge } \\
\text { Use Midazolam } \\
\text { Use Morphine + Fentanyl } \\
\text { Use Amiodarone } \\
\text { (Intravenous injection) } \\
\text { Use Enteral nutrition } \\
(1000 \mathrm{~mL})\end{array}$ & $\begin{array}{l}\text { Maintain CRRT } 12 \mathrm{hr} \text {. } \\
\text { Maintain Meropenem } \\
\text { Maintain Thymopentin }\end{array}$ & $\begin{array}{l}\text { Invasive Ventilator ( } \\
\text { Decrease PS from } 15 \text { to } 12 \mathrm{~cm} \\
\mathrm{H} 2 \mathrm{O} \\
\text { Decrease FiO2 from } 70 \% \text { to } 50 \\
\% \\
\text { \% }\end{array}$ \\
\hline Hospital Day 4 & $\begin{array}{l}\text { Stop Amiodarone } \\
\text { Use Simendan }\end{array}$ & $\begin{array}{l}\text { Maintain CRRT } 12 \mathrm{hr} . \\
\text { Maintain Meropenem } \\
\text { Maintain Thymopentin } \\
\text { Maintain Midazolam } \\
\quad+\text { Fentanyl } \\
\begin{array}{l}\text { Maintain Enteral nutrition } \\
\text { Decrease Morphine to } 1 \\
\text { mg/h }\end{array} \text {. }\end{array}$ & $\begin{array}{l}\text { Invasive Ventilator ( } \\
\text { Increase VT from } 450 \text { to } 500 \mathrm{~mL} \\
\text { Increase PS from } 12 \text { to } 15 \mathrm{~cm} \\
\mathrm{H} 2 \mathrm{O} \\
\text { Increase PEEP from } 12 \mathrm{t} 16 \mathrm{~cm} \\
\mathrm{H} 2 \mathrm{O} \\
\text { Decrease Frequency from } 20 \text { to } \\
18 \mathrm{bpm} \text {. } \\
\text { ) }\end{array}$ \\
\hline Hospital Day 5 & Stop Morphine & $\begin{array}{l}\text { Maintain CRRT } 12 \mathrm{hr} \text {. } \\
\text { Maintain Meropenem } \\
\text { Maintain Thymopentin } \\
\text { Maintain Midazolam } \\
\quad+\text { Fentanyl } \\
\text { Increase Enteral nutrition } \\
\text { from } 1000 \text { to } 1500 \mathrm{~mL}\end{array}$ & $\begin{array}{l}\text { Intermittent non-invasive ventilato } \\
\text { r ( } \\
\text { ST mode } \\
\text { FiO2 } 60 \% \\
\text { IPAP } 15 \mathrm{cmH} 2 \mathrm{O} \\
\text { EPAP } 11 \mathrm{cmH} 2 \mathrm{O} \\
\text { Frequency } 20 \mathrm{bpm} . \\
\end{array}$ \\
\hline Hospital Day 6 & $\begin{array}{l}\text { Use Human albumin }(40 \mathrm{~g}, 10 \mathrm{mg} / \\
\mathrm{h})\end{array}$ & $\begin{array}{l}\text { Maintain CRRT } 12 \mathrm{hr} \text {. } \\
\text { Maintain Meropenem } \\
\text { Maintain Thymopentin } \\
\text { Maintain Midazolam } \\
\quad+\text { Fentanyl }\end{array}$ & $\begin{array}{l}\text { Invasive Ventilator ( } \\
\text { Increase VT from } 500 \text { to } 550 \mathrm{~mL} \\
\text { Increase PS from } 12 \text { to } 15 \mathrm{~cm} \\
\text { H2O } \\
\text { Decrease PEEP from } 16 \text { to } 11 \\
\text { cmH2O } \\
\text { Increase FiO2 from } 50 \% \text { to } 70 \\
\% \\
\text { Increase Frequency from18 to } \\
24 \text { bpm. } \\
\end{array}$ \\
\hline Hospital Day 7 & $\begin{array}{l}\text { Stop Meropenem } \\
\text { Use Caspofungin } \\
\quad+\text { Tezhixing } \\
\quad+\text { Daltotropin } \\
\text { Use Amiodarone (oral) }\end{array}$ & $\begin{array}{l}\text { Maintain CRRT } 8 \mathrm{hr} \text {. } \\
\text { Maintain Thymopentin } \\
\text { Maintain Midazolam } \\
\quad \text { + Fentanyl }\end{array}$ & \\
\hline Hospital Day 8 & $\begin{array}{l}\text { Stop Xuebijing } \\
\text { Stop Mucosolvan }\end{array}$ & $\begin{array}{l}\text { Maintain Amiodarone (oral) } \\
\text { Maintain CRRT } 8 \mathrm{hr} \text {. } \\
\text { Maintain Caspofungin } \\
\quad \text { + piperacillin } \\
\quad+\text { tazobactam } \\
\quad+\text { Daltotropin } \\
\text { Maintain Abidor } \\
\text { Maintain Thymopentin } \\
\text { Maintain Midazolam } \\
\text { + Fentanyl } \\
\text { Maintain Human albumin (at least } \\
\quad 30 \mathrm{~g}, 10 \mathrm{mg} / \mathrm{h} \text { ) } \\
\text { Decrease Enteral nutrition } \\
\text { from } 1500 \text { to } 1000 \mathrm{~mL}\end{array}$ & $\begin{array}{l}\text { Invasive Ventilator ( } \\
\text { Increase VT from } 550 \text { to } 650 \mathrm{~mL} \\
\text { Decrease PEEP from } 11 \text { to } 10 \\
\text { cmH2O } \\
\text { Increase FiO2 from } 70 \% \text { to } 100 \\
\% \\
\text { ) }\end{array}$ \\
\hline Hospital Day 9 & $\begin{array}{l}\text { Use } \\
\text { (0.04 ug/Kg-min) } \\
\text { Stop CRRT } \\
\text { Stop Caspofungin ( } 1 \text { day) }\end{array}$ & $\begin{array}{l}\text { Maintain } \\
\text { Midazolam } \\
\text { (3 ug/Kg-min) } \\
\text { Maintain piperacillin } \\
+ \text { tazobactam }\end{array}$ & $\begin{array}{l}\text { Invasive Ventilator ( } \\
\text { Decrease } \mathrm{FiO} 2 \text { from } 100 \% \text { to } 9 \\
0 \% \\
\end{array}$ \\
\hline
\end{tabular}


medRxiv preprint doi: https://doi.org/10.1101/2020.06.08.20124305; this version posted June 9, 2020. The copyright holder for this preprint (which was not certified by peer review) is the author/funder, who has granted medRxiv a license to display the preprint in perpetuity.

It is made available under a CC-BY-NC-ND 4.0 International license .

\begin{tabular}{|c|c|c|c|}
\hline & $\begin{array}{l}\text { Use Saline }(100 \quad \mathrm{~mL}, \\
\text { total <= } 2500 \mathrm{~mL})\end{array}$ & $\begin{array}{l}\quad \text { + Daltotropin } \\
\text { Maintain Amiodarone (oral) } \\
\text { Maintain Abidor } \\
\text { Maintain Thymopentin } \\
\text { Maintain Fentanyl }\end{array}$ & \\
\hline Hospital Day 10 & $\begin{array}{l}\text { Use Ceylon } \\
\text { Use Amiodarone } \\
\text { (Intravenous injection, } 0.15 \mathrm{~g} \text { ) } \\
\text { Remove subclavian and } \\
\text { femoral vein catheters } \\
\text { Use Rivaroxaban }\end{array}$ & 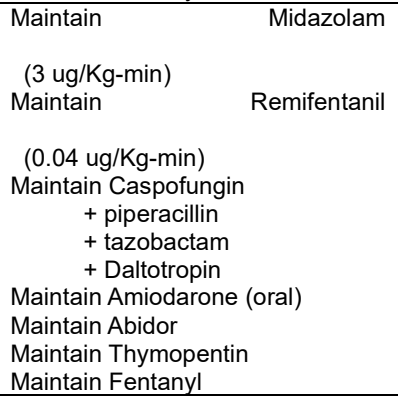 & $\begin{array}{l}\text { Invasive Ventilator ( } \\
\text { Decrease VT from } 650 \\
\text { to } 600 \mathrm{~mL} \\
\text { Increase PEEP from } 11 \text { to } 12 \mathrm{c} \\
\mathrm{mH} 2 \mathrm{O} \\
\text { Decrease FiO2 from } 90 \% \text { to } 65 \\
\% \\
\text { ) } \\
\text { Left subclavian vein puncture cath } \\
\text { eterization }\end{array}$ \\
\hline Hospital Day 11 & $\begin{array}{l}\text { Use } \\
\text { Norepinephrine } \\
\text { (0.4 ug/Kg-min) } \\
\text { Stop Tezhixing } \\
\text { Stop Daltotropin } \\
\text { Use Supran + Tigecycline } \\
\text { Stop Rivaroxaban (10mg) }\end{array}$ & $\begin{array}{l}\text { Maintain } \\
(3 \text { ug/Kg-min) } \\
\text { Maintain } \\
\\
(0.04 \text { ug/Kg-min) } \\
\text { Maintain Caspofungin } \\
\text { Maintain Amiodarone (oral) } \\
\text { Maintain Abidor } \\
\text { Maintain Thymopentin } \\
\text { Maintain Fentanyl }\end{array}$ & $\begin{array}{l}\text { Invasive Ventilator ( } \\
\text { Increase FiO2 from } 65 \% \text { to } 70 \\
\% \\
\text { ) }\end{array}$ \\
\hline Hospital Day 12 & $\begin{array}{l} \\
\text { Use Furosemide diuretic } \\
\text { + calcium gluconate } \\
\text { Use Trimetazidine tablets } \\
\text { + glycyrrhizin tablets }\end{array}$ & 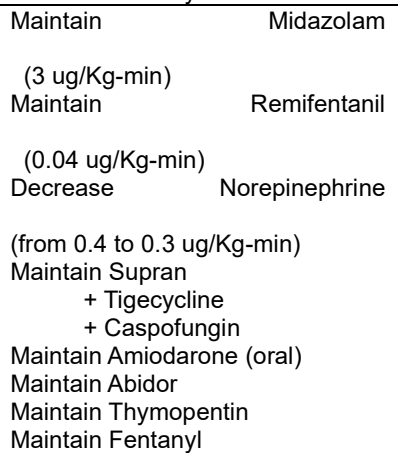 & $\begin{array}{l}\text { Invasive Ventilator ( } \\
\text { Decrease FiO2 from } 70 \% \text { to } 45 \\
\% \\
\text { C } \\
\text { CRRT } 6 \mathrm{hr} \text {. } \\
\text { Left femoral vein catheterization }\end{array}$ \\
\hline Hospital Day 13 & Use Bisorol 2.5mg qd. & $\begin{array}{l}\text { Decrease Amiodarone } \\
\text { to } 0.2 \mathrm{~g} \text { qd. } \\
\text { Maintain CRRT 8hr. } \\
\text { Increase Albumin } \\
\text { Decrease } \\
\text { (from } 0.04 \text { to } 0.01 \mathrm{ug} / \mathrm{Kg} \text {-min) }\end{array}$ & $\begin{array}{l}\text { Invasive Ventilator ( } \\
\text { Increase FiO2 from } 45 \% \text { to } 55 \\
\% \\
\text { ) }\end{array}$ \\
\hline Hospital Day 14 & & 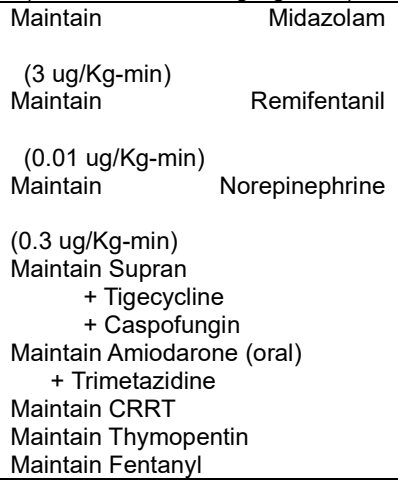 & $\begin{array}{l}\text { Invasive Ventilator ( } \\
\text { Increase } \mathrm{FiO} 2 \text { from } 55 \% \text { to } 60 \\
\% \\
\end{array}$ \\
\hline Hospital Day 15 & $\begin{array}{l}\text { Stop Supran } \\
\text { Use Tezhixing } \\
\text { Stop CRRT }\end{array}$ & 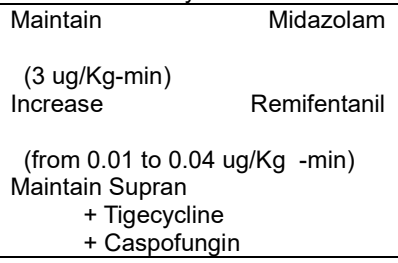 & $\begin{array}{l}\text { Blood transfusion ( } \\
\text { 02/16 01:45-03:00 } \\
\mathrm{A}+400 \mathrm{~mL} \\
02 / 1620: 45-23: 00 \\
\mathrm{~A}+200 \mathrm{~mL} \\
02 / 1623: 25 \text { to } \\
\text { 02/17 04:00 } \\
\text { Suspended red blood cells } 4 \mathrm{U} \\
\text { ) }\end{array}$ \\
\hline
\end{tabular}


medRxiv preprint doi: https://doi.org/10.1101/2020.06.08.20124305; this version posted June 9, 2020. The copyright holder for this preprint (which was not certified by peer review) is the author/funder, who has granted medRxiv a license to display the preprint in perpetuity.

It is made available under a CC-BY-NC-ND 4.0 International license .

\begin{tabular}{|c|c|c|c|}
\hline & & $\begin{array}{l}\text { Maintain Thymopentin } \\
\text { Maintain Fentanyl }\end{array}$ & $\begin{array}{l}\text { Invasive Ventilator ( } \\
\text { Decrease PEEP from } 12 \text { to } 10 \\
\mathrm{cmH} 2 \mathrm{O} \\
\text { ) }\end{array}$ \\
\hline Hospital Day 16 & $\begin{array}{l}\text { Stop Anticoagulant related } \\
\quad \text { medicine } \\
\text { Stop CRRT } \\
\text { Use Albumin }(20 \mathrm{~g}) \\
\text { Use Somatostatin } \\
\text { Use Omeprazole } \\
\text { Use Cavin + Vitamins }\end{array}$ & $\begin{array}{ll}\text { Maintain } & \text { Midazolam } \\
& \\
\text { (3 ug/Kg-min) } & \text { Remifentanil } \\
\text { Maintain } & \\
& \\
\text { (0.04 ug/Kg-min }) & \\
\text { Maintain Tezhixing } & \\
\quad+\text { Tigecycline } & \\
\quad+\text { Caspofungin } & \end{array}$ & $\begin{array}{l}\text { Invasive Ventilator ( } \\
\text { Decrease FiO2 from } 60 \% \text { to } 50 \\
\% \\
\%\end{array}$ \\
\hline Hospital Day 17 & $\begin{array}{l}\text { Remove femoral vein } \\
\text { catheters } \\
\text { Stop CRRT }\end{array}$ & $\begin{array}{l}\text { Maintain Cavin }(800 \mathrm{~mL}) \\
\text { + Enteral nutrition }(500 \mathrm{~mL}) \\
\text { Maintain Tezhixing } \\
\quad+\text { Tigecycline } \\
\quad \text { + Caspofungin }\end{array}$ & $\begin{array}{l}\text { Invasive Ventilator ( } \\
\text { Decrease PEEP from } 10 \text { to } 8 \mathrm{c} \\
\mathrm{mH} 2 \mathrm{O} \\
\end{array}$ \\
\hline Hospital Day 18 & $\begin{array}{l}\text { Use Propofol (15ug/Kg-min) } \\
\text { Stop Somatostatin } \\
\text { Stop Omeprazole } \\
\text { Use Pantoprazole (oral) } \\
\text { Stop Amiodarone } \\
\text { Use Bisorol } 2.5 \mathrm{mg} \text { qd. } \\
\text { Stop Cavin } \\
\text { Stop Tezhixing } \\
\text { Use Ceftazidime avitastat } \\
\text { Use Albumin (30g) } \\
\text { Use Chloroquine (oral) }\end{array}$ & $\begin{array}{l}\text { Decrease Remifentanil } \\
\text { (from } 0.04 \text { to } 0.02 \mathrm{ug} / \mathrm{Kg} \text {-min) } \\
\text { Maintain Tezhixing } \\
\quad+\text { Tigecycline } \\
\quad+\text { Caspofungin } \\
\text { Increase Enteral nutrition } \\
\text { from } 500 \text { to } 1000 \mathrm{~mL}\end{array}$ & $\begin{array}{l}\text { Invasive Ventilator ( } \\
\text { Increase PEEP from } 8 \text { to } 9 \mathrm{cmH} \\
2 \mathrm{O} \\
\end{array}$ \\
\hline Hospital Day 19 & $\begin{array}{l}\text { Use Rivaroxaban } \\
\text { Stop Caspofungin } \\
\text { Use Voricone } \\
\text { Stop } \\
\text { phosphate } \\
\text { Use Albumin }(20 \mathrm{~g}, 10 \mathrm{~mL} / \mathrm{h})\end{array}$ & $\begin{array}{c}\text { Maintain Tigecycline } \\
+ \\
\text { avitastat }\end{array}$ & $\begin{array}{l}\text { Invasive Ventilator ( } \\
\text { Decrease FiO2 from } 60 \% \text { to } 45 \\
\% \\
\text { Decrease VT from } 600 \text { to } 500 \\
\mathrm{~mL} \\
\text { Decrease PEEP from } 9 \text { to } 8 \mathrm{c} \\
\mathrm{mH} 2 \mathrm{O} \\
\text { Decrease Frequency from } 24 \text { to } \\
19 \text { bpm } \\
\text { ) }\end{array}$ \\
\hline Hospital Day 20 & $\begin{array}{l}\text { Use Linezamide } \\
\text { + Caspofungin } \\
\text { + Daltotropin } \\
\text { Use Somatostatin } \\
\text { Use Omeprazole } \\
\text { Stop Enteral nutrition } \\
\text { Use CRRT } 6 \mathrm{hr} \text {. } \\
\text { Stop Traditional Chinese } \\
\text { medicine Acetylcysteine } \\
\text { Use nebulization }\end{array}$ & 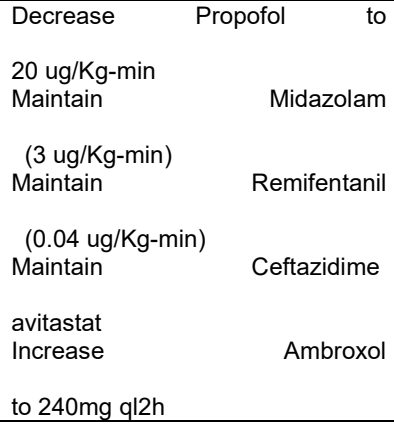 & $\begin{array}{l}\text { Invasive Ventilator ( } \\
\text { Decrease FiO2 from } 45 \% \text { to } 40 \\
\% \\
\text { Decrease VT from } 500 \text { to } 450 \\
\text { mL } \\
\text { Decrease PS from } 15 \text { to } 12 \mathrm{~cm} \\
\text { H2O } \\
\text { Decrease PEEP from } 8 \text { to } 4 \mathrm{c} \\
\text { mH2O } \\
\text { Increase Frequency from } 19 \text { to } \\
20 \mathrm{bpm} \\
\text { ) }\end{array}$ \\
\hline Hospital Day 21 & $\begin{array}{l}\text { Use Chloroquine }(0.4 \mathrm{~g}) \\
\text { Stop Daltotropin } \\
\text { Use } \\
(0.5 \mathrm{~g} \text { q8h) Vancomycin } \\
\text { Use Recovery patient's } \\
\text { plasma } \\
\text { Use Albumin }(20 \mathrm{~g}, 10 \mathrm{~mL} / \mathrm{h}) \\
\text { Use CRRT }\end{array}$ & $\begin{array}{l}\text { Maintain Linezamide } \\
\quad+\text { Caspofungin } \\
\quad+\end{array}$ & $\begin{array}{l}\text { Invasive Ventilator ( } \\
\text { Increase FiO2 from } 40 \% \text { to } 70 \\
\% \\
\text { Decrease VT from } 450 \text { to } 440 \\
\mathrm{~mL} \\
\text { Increase Frequency from } 20 \text { to } \\
35 \mathrm{bpm} \\
\text { ) }\end{array}$ \\
\hline
\end{tabular}


medRxiv preprint doi: https://doi.org/10.1101/2020.06.08.20124305; this version posted June 9, 2020. The copyright holder for this preprint (which was not certified by peer review) is the author/funder, who has granted medRxiv a license to display the preprint in perpetuity.

It is made available under a CC-BY-NC-ND 4.0 International license .

Table S6. Clinical medication records of the mild case.

\begin{tabular}{|l|l|l|l|}
\hline Date & \multicolumn{1}{|c|}{ Clinical medication } & Increase/Decrease Dosage & Auxiliary Survival \\
\hline Hospital Day 1 & $\begin{array}{l}\text { Use Interferon atomization } \\
\text { Use Lopinavilitonavi } \\
\text { Use Moxifloxacin } \\
\text { Use Abidor + Kreiz }\end{array}$ & \\
\hline Hospital Day 1 & & $\begin{array}{l}\text { Maintain } \\
\text { atomization } \\
\text { + Lopinavilitonavi } \\
\text { Maintain Moxifloxacin } \\
\text { Maintain Abidor + Kreiz }\end{array}$ & \\
\hline Hospital Day 11 & Scheme as before & \\
\hline Hospital Day 17 & Scheme as before & \\
\hline Hospital Day 22 & Stop Kreiz Chloroquine & & \\
\hline
\end{tabular}


Table S7. Microbiomes infected in plasma of cases and controls ${ }^{1}$.

\begin{tabular}{|c|c|c|c|c|c|}
\hline Sample & Species & $\begin{array}{l}\text { Coverate } \\
\text { rate }\end{array}$ & Depth & $\begin{array}{l}\text { No. of uniquely } \\
\text { mapped reads }\end{array}$ & $\begin{array}{c}\text { Type of } \\
\text { microbimes }\end{array}$ \\
\hline \multirow{9}{*}{ Control1 } & Stenotrophomonas maltophilia & 82.06 & 6.51 & 89132 & Bacteria \\
\hline & Pseudomonas sp. TKP & 8.31 & 1.08 & 4129 & Bacteria \\
\hline & Pseudomonas fluorescens & 9.17 & 1.11 & 1088 & Bacteria \\
\hline & Cuti Bacteriaterium acnes & 28.39 & 1.21 & 7045 & Bacteria \\
\hline & Elizabethkingia miricola & 8.32 & 1.10 & 1113 & Bacteria \\
\hline & Elizabethkingia anophelis & 5.38 & 1.09 & 425 & Bacteria \\
\hline & Staphylococcus capitis & 4.30 & 1.04 & 876 & Bacteria \\
\hline & Staphylococcus haemolyticus & 3.45 & 1.03 & 851 & Bacteria \\
\hline & Variovorax paradoxus & 6.10 & 1.17 & 639 & Bacteria \\
\hline \multirow{6}{*}{ Control2 } & Stenotrophomonas maltophilia & 78.30 & 4.27 & 56407 & Bacteria \\
\hline & Pseudomonas sp. TKP & 9.79 & 1.08 & 4937 & Bacteria \\
\hline & Pseudomonas fluorescens & 12.09 & 1.14 & 1430 & Bacteria \\
\hline & Cuti Bacteriaterium acnes & 9.07 & 1.06 & 2014 & Bacteria \\
\hline & Elizabethkingia miricola & 4.45 & 1.06 & 608 & Bacteria \\
\hline & Variovorax paradoxus & 6.02 & 1.15 & 628 & Bacteria \\
\hline \multirow{3}{*}{ Mild1 } & Chryseo Bacteriaterium indologenes & 46.02 & 1.49 & 32259 & Bacteria \\
\hline & Cuti Bacteriaterium acnes & 7.48 & 1.05 & 1661 & Bacteria \\
\hline & Methylophilus methylotrophus & 6.43 & 1.05 & 1437 & Bacteria \\
\hline \multirow{2}{*}{ Mild2 } & Chryseo Bacteriaterium indologenes & 42.17 & 1.42 & 28162 & Bacteria \\
\hline & Methylophilus methylotrophus & 5.19 & 1.03 & 1148 & Bacteria \\
\hline \multirow{2}{*}{ Mild3 } & Chryseo Bacteriaterium indologenes & 35.68 & 1.33 & 22399 & Bacteria \\
\hline & Methylophilus methylotrophus & 4.27 & 1.03 & 940 & Bacteria \\
\hline \multirow{2}{*}{ Mild4 } & Chryseo Bacteriaterium indologenes & 47.46 & 1.54 & 34338 & Bacteria \\
\hline & Methylophilus methylotrophus & 7.29 & 1.05 & 1641 & Bacteria \\
\hline Severe3 & Chryseo Bacteriaterium indologenes & 4.99 & 1.03 & 2326 & Bacteria \\
\hline Severe4 & Chryseo Bacteriaterium indologenes & 5.50 & 1.04 & 2658 & Bacteria \\
\hline Severe3 & Human betaherpesvirus 5 & 10.60 & 1.10 & 249 & Virus \\
\hline \multirow{2}{*}{ Severe4 } & Human betaherpesvirus 5 & 74.81 & 2.18 & 3593 & Virus \\
\hline & Human alphaherpesvirus 1 & 3.54 & 1.03 & 52 & Virus \\
\hline
\end{tabular}

1. Microbiomes with no. of uniquely mapped reads above 10 and coverage rate (coverage of viruses divided by coverage of autosomes) above 3 were included. 
Table S8. Results on pathway analysis of the 6 clusters from coverage around 200bp-TSSs from cfDNA of one mild case, one severe case, and two controls ${ }^{1}$.

\begin{tabular}{|c|c|c|c|c|c|c|c|c|c|}
\hline Cluster & Pathway & $\begin{array}{l}\text { Found } \\
\text { entities }\end{array}$ & $\begin{array}{c}\text { Total } \\
\text { entities }\end{array}$ & Ratio & $p$ value & FDR & $\begin{array}{l}\text { Found } \\
\text { reaction }\end{array}$ & $\begin{array}{l}\text { Total } \\
\text { reaction }\end{array}$ & Ratio \\
\hline & Digestion of dietary lipid & 1 & 7 & $6.14 \mathrm{E}-04$ & 1.16E-02 & $1.54 \mathrm{E}-01$ & 3 & 8 & 6.47E-04 \\
\hline & Digestion & 1 & 22 & $1.93 \mathrm{E}-03$ & 3.61E-02 & $1.54 \mathrm{E}-01$ & 3 & 24 & $1.94 \mathrm{E}-03$ \\
\hline & Digestion and absorption & 1 & 27 & 2.37E-03 & $4.41 \mathrm{E}-02$ & $1.54 \mathrm{E}-01$ & 3 & 30 & 2.42E-03 \\
\hline & $\begin{array}{l}\text { Tat-mediated HIV elongation arrest } \\
\text { and recovery }\end{array}$ & 1 & 35 & 3.07E-03 & $5.68 \mathrm{E}-02$ & $1.54 \mathrm{E}-01$ & 3 & 3 & $2.42 \mathrm{E}-04$ \\
\hline & $\begin{array}{l}\text { Pausing and recovery of Tat-mediated } \\
\text { HIV elongation }\end{array}$ & 1 & 35 & 3.07E-03 & $5.68 \mathrm{E}-02$ & $1.54 \mathrm{E}-01$ & 2 & 2 & $1.62 \mathrm{E}-04$ \\
\hline & HIV elongation arrest and recovery & 1 & 36 & $3.16 \mathrm{E}-03$ & 5.84E-02 & $1.54 \mathrm{E}-01$ & 3 & 3 & $2.42 \mathrm{E}-04$ \\
\hline & $\begin{array}{l}\text { Pausing and recovery of HIV } \\
\text { elongation }\end{array}$ & 1 & 36 & $3.16 \mathrm{E}-03$ & $5.84 \mathrm{E}-02$ & $1.54 \mathrm{E}-01$ & 2 & 2 & $1.62 \mathrm{E}-04$ \\
\hline & Retinoid metabolism and transport & 1 & 44 & 3.86E-03 & 7.09E-02 & $1.54 \mathrm{E}-01$ & 1 & 26 & $2.10 \mathrm{E}-03$ \\
\hline & $\begin{array}{l}\text { Tat-mediated elongation of the HIV-1 } \\
\text { transcript }\end{array}$ & 1 & 47 & 4.12E-03 & 7.55E-02 & $1.54 \mathrm{E}-01$ & 4 & 8 & 6.47E-04 \\
\hline & HIV Transcription Elongation & 1 & 47 & $4.12 \mathrm{E}-03$ & $7.55 \mathrm{E}-02$ & $1.54 \mathrm{E}-01$ & 4 & 15 & $1.21 \mathrm{E}-03$ \\
\hline & $\begin{array}{l}\text { Formation of HIV-1 elongation complex } \\
\text { containing HIV-1 Tat }\end{array}$ & 1 & 47 & 4.12E-03 & 7.55E-02 & $1.54 \mathrm{E}-01$ & 1 & 5 & 4.04E-04 \\
\hline & $\begin{array}{l}\text { Formation of HIV elongation complex } \\
\text { in the absence of HIV Tat }\end{array}$ & 1 & 48 & 4.21E-03 & 7.71E-02 & $1.54 \mathrm{E}-01$ & 1 & 2 & $1.62 \mathrm{E}-04$ \\
\hline & Metabolism of fat-soluble vitamins & 1 & 48 & 4.21E-03 & 7.71E-02 & $1.54 \mathrm{E}-01$ & 1 & 32 & $2.59 \mathrm{E}-03$ \\
\hline & $\begin{array}{l}\text { RNA Polymerase II Transcription } \\
\text { Elongation }\end{array}$ & 1 & 61 & $5.35 \mathrm{E}-03$ & $9.70 \mathrm{E}-02$ & $1.54 \mathrm{E}-01$ & 4 & 8 & 6.47E-04 \\
\hline & $\begin{array}{l}\text { Formation of RNA Pol II elongation } \\
\text { complex }\end{array}$ & 1 & 61 & $5.35 \mathrm{E}-03$ & $9.70 \mathrm{E}-02$ & $1.54 \mathrm{E}-01$ & 1 & 2 & $1.62 \mathrm{E}-04$ \\
\hline & $\begin{array}{l}\text { TP53 Regulates Transcription of DNA } \\
\text { Repair Genes }\end{array}$ & 1 & 65 & $5.70 \mathrm{E}-03$ & 1.03E-01 & $1.54 \mathrm{E}-01$ & 3 & 17 & 1.37E-03 \\
\hline & Transcription of the HIV genome & 1 & 74 & $6.49 \mathrm{E}-03$ & $1.16 \mathrm{E}-01$ & $1.54 \mathrm{E}-01$ & 15 & 47 & $3.80 \mathrm{E}-03$ \\
\hline & $\begin{array}{l}\text { RNA Polymerase II Pre-transcription } \\
\text { Events }\end{array}$ & 1 & 84 & 7.37E-03 & $1.31 \mathrm{E}-01$ & $1.54 \mathrm{E}-01$ & 7 & 17 & 1.37E-03 \\
\hline & Visual phototransduction & 1 & 100 & $8.78 \mathrm{E}-03$ & $1.54 \mathrm{E}-01$ & $1.54 \mathrm{E}-01$ & 1 & 82 & $6.63 \mathrm{E}-03$ \\
\hline & Late Phase of HIV Life Cycle & 1 & 152 & 1.33E-02 & $2.25 \mathrm{E}-01$ & $2.25 \mathrm{E}-01$ & 15 & 76 & $6.14 \mathrm{E}-03$ \\
\hline & HIV Life Cycle & 1 & 165 & $1.45 \mathrm{E}-02$ & $2.42 \mathrm{E}-01$ & $2.42 \mathrm{E}-01$ & 15 & 114 & $9.21 \mathrm{E}-03$ \\
\hline & Metabolism of vitamins and cofactors & 1 & 192 & 1.69E-02 & $2.76 \mathrm{E}-01$ & $2.76 \mathrm{E}-01$ & 1 & 185 & $1.50 \mathrm{E}-02$ \\
\hline & Ub-specific processing proteases & 1 & 205 & $1.80 \mathrm{E}-02$ & 2.92E-01 & 2.92E-01 & 2 & 40 & $3.23 \mathrm{E}-03$ \\
\hline & HIV Infection & 1 & 248 & $2.18 \mathrm{E}-02$ & $3.42 \mathrm{E}-01$ & $3.42 \mathrm{E}-01$ & 15 & 157 & 1.27E-02 \\
\hline & Deubiquitination & 1 & 282 & 2.47E-02 & 3.79E-01 & $3.79 \mathrm{E}-01$ & 2 & 77 & $6.22 \mathrm{E}-03$ \\
\hline & Transcriptional Regulation by TP53 & 1 & 367 & $3.22 \mathrm{E}-02$ & 4.63E-01 & 4.63E-01 & 3 & 258 & $2.09 \mathrm{E}-02$ \\
\hline & $\mathrm{G}$ alpha (i) signalling events & 1 & 408 & $3.58 \mathrm{E}-02$ & $5.00 \mathrm{E}-01$ & $5.00 \mathrm{E}-01$ & 1 & 155 & $1.25 \mathrm{E}-02$ \\
\hline & Infectious disease & 1 & 1040 & $9.13 \mathrm{E}-02$ & 8.38E-01 & 8.38E-01 & 15 & 485 & $3.92 \mathrm{E}-02$ \\
\hline & GPCR downstream signalling & 1 & 1154 & $1.01 \mathrm{E}-01$ & 8.69E-01 & 8.69E-01 & 1 & 248 & $2.00 \mathrm{E}-02$ \\
\hline & Signaling by GPCR & 1 & 1226 & $1.08 \mathrm{E}-01$ & $8.85 \mathrm{E}-01$ & $8.85 \mathrm{E}-01$ & 1 & 427 & $3.45 \mathrm{E}-02$ \\
\hline & Generic Transcription Pathway & 1 & 1257 & $1.10 \mathrm{E}-01$ & 8.91E-01 & $8.91 \mathrm{E}-01$ & 3 & 823 & $6.65 \mathrm{E}-02$ \\
\hline & RNA Polymerase II Transcription & 1 & 1379 & $1.21 \mathrm{E}-01$ & $9.14 \mathrm{E}-01$ & $9.14 \mathrm{E}-01$ & 14 & 884 & 7.15E-02 \\
\hline & Post-translational protein modification & 1 & 1417 & $1.24 \mathrm{E}-01$ & $9.20 \mathrm{E}-01$ & $9.20 \mathrm{E}-01$ & 2 & 513 & 4.15E-02 \\
\hline & Gene expression (Transcription) & 1 & 1521 & 1.33E-01 & $9.34 \mathrm{E}-01$ & $9.34 \mathrm{E}-01$ & 14 & 994 & 8.03E-02 \\
\hline & Disease & 1 & 1735 & $1.52 \mathrm{E}-01$ & 9.57E-01 & $9.57 \mathrm{E}-01$ & 15 & 1201 & $9.71 \mathrm{E}-02$ \\
\hline & Metabolism of proteins & 1 & 2012 & 1.77E-01 & $9.75 \mathrm{E}-01$ & $9.75 \mathrm{E}-01$ & 2 & 874 & 7.06E-02 \\
\hline & Metabolism & 1 & 2142 & $1.88 \mathrm{E}-01$ & $9.81 \mathrm{E}-01$ & $9.81 \mathrm{E}-01$ & 1 & 2001 & $1.62 \mathrm{E}-01$ \\
\hline \multirow[t]{3}{*}{ Cluster2 } & Signal Transduction & 1 & 2829 & 2.48E-01 & $9.96 \mathrm{E}-01$ & $9.96 \mathrm{E}-01$ & 1 & 2333 & $1.89 \mathrm{E}-01$ \\
\hline & $\begin{array}{l}\text { Transport of nucleosides and free } \\
\text { purine and pyrimidine bases across the } \\
\text { plasma membrane }\end{array}$ & 2 & 12 & $1.05 \mathrm{E}-03$ & $1.53 \mathrm{E}-03$ & $2.00 \mathrm{E}-01$ & 2 & 16 & $1.29 \mathrm{E}-03$ \\
\hline & $\begin{array}{l}\text { Transport of vitamins, nucleosides, and } \\
\text { related molecules }\end{array}$ & 2 & 44 & $3.86 \mathrm{E}-03$ & 1.87E-02 & $3.16 \mathrm{E}-01$ & 2 & 39 & $3.15 \mathrm{E}-03$ \\
\hline
\end{tabular}


PKA-mediated phosphorylation of key metabolic factors

HDL assembly

ROBO receptors bind AKAP5

GP1b-IX-V activation signalling

CREB1 phosphorylation through the activation of Adenylate Cyclase

Regulation of glycolysis by fructose

2,6-bisphosphate metabolism

p130Cas linkage to MAPK signaling for integrins

GRB2:SOS provides linkage to MAPK signaling for Integrins

Platelet Adhesion to exposed collagen

Rap1 signalling

Ub-specific processing proteases

Serotonin Neurotransmitter Release

Cycle

PKA activation

PKA activation in glucagon signalling

Plasma lipoprotein assembly

PKA-mediated phosphorylation of

CREB

CD209 (DC-SIGN) signaling

Dopamine Neurotransmitter Release

Cycle

Intrinsic Pathway of Fibrin Clot

Formation

DARPP-32 events

Triglyceride catabolism

Integrin signaling

Glucagon signaling in metabolic regulation

Deubiquitination

Calmodulin induced events

CaM pathway

Signaling by high-kinase activity BRAF mutants

Ca-dependent events

Triglyceride metabolism

Formation of Fibrin Clot (Clotting

Cascade)

Platelet Aggregation (Plug Formation)

MAP2K and MAPK activation

DAG and IP3 signaling

RET signaling

Glucagon-like Peptide-1 (GLP1)

regulates insulin secretion

Vasopressin regulates renal water

homeostasis via Aquaporins

Signaling downstream of RAS mutants

Signaling by moderate kinase activity

BRAF mutants

Paradoxical activation of RAF signaling

by kinase inactive BRAF

Signaling by RAS mutants

Neurotransmitter release cycle

PLC beta mediated events

Aquaporin-mediated transport

G-protein mediated events

\begin{tabular}{|c|c|c|c|c|c|c|c|}
\hline 1 & 5 & 4.39E-04 & 2.34E-02 & $3.16 \mathrm{E}-01$ & 3 & 5 & 4.04E-04 \\
\hline 1 & 8 & 7.02E-04 & 3.72E-02 & $3.16 \mathrm{E}-01$ & 1 & 9 & 7.27E-04 \\
\hline 1 & 9 & 7.90E-04 & 4.18E-02 & 3.16E-01 & 1 & 7 & 5.66E-04 \\
\hline 1 & 12 & $1.05 \mathrm{E}-03$ & $5.53 \mathrm{E}-02$ & $3.16 \mathrm{E}-01$ & 5 & 7 & 5.66E-04 \\
\hline 1 & 12 & $1.05 \mathrm{E}-03$ & 5.53E-02 & $3.16 \mathrm{E}-01$ & 4 & 6 & 4.85E-04 \\
\hline 1 & 12 & $1.05 \mathrm{E}-03$ & 5.53E-02 & $3.16 \mathrm{E}-01$ & 1 & 4 & $3.23 E-04$ \\
\hline 1 & 15 & $1.32 \mathrm{E}-03$ & 6.87E-02 & $3.16 \mathrm{E}-01$ & 3 & 3 & 2.42E-04 \\
\hline 1 & 15 & $1.32 \mathrm{E}-03$ & 6.87E-02 & $3.16 \mathrm{E}-01$ & 2 & 2 & $1.62 \mathrm{E}-04$ \\
\hline 1 & 15 & $1.32 \mathrm{E}-03$ & 6.87E-02 & 3.16E-01 & 2 & 6 & 4.85E-04 \\
\hline 1 & 16 & $1.40 \mathrm{E}-03$ & 7.31E-02 & $3.16 \mathrm{E}-01$ & 1 & 7 & 5.66E-04 \\
\hline 3 & 205 & $1.80 \mathrm{E}-02$ & 7.35E-02 & $3.16 \mathrm{E}-01$ & 2 & 40 & $3.23 E-03$ \\
\hline 1 & 18 & $1.58 \mathrm{E}-03$ & 8.18E-02 & $3.16 \mathrm{E}-01$ & 2 & 3 & 2.42E-04 \\
\hline 1 & 18 & $1.58 \mathrm{E}-03$ & 8.18E-02 & 3.16E-01 & 2 & 4 & 3.23E-04 \\
\hline 1 & 18 & $1.58 \mathrm{E}-03$ & $8.18 \mathrm{E}-02$ & $3.16 \mathrm{E}-01$ & 1 & 2 & $1.62 \mathrm{E}-04$ \\
\hline 1 & 19 & 1.67E-03 & 8.62E-02 & $3.16 \mathrm{E}-01$ & 1 & 19 & $1.54 \mathrm{E}-03$ \\
\hline 1 & 20 & $1.76 \mathrm{E}-03$ & 9.05E-02 & $3.16 \mathrm{E}-01$ & 4 & 7 & 5.66E-04 \\
\hline 1 & 22 & $1.93 \mathrm{E}-03$ & $9.91 \mathrm{E}-02$ & $3.16 \mathrm{E}-01$ & 1 & 11 & 8.89E-04 \\
\hline 1 & 23 & 2.02E-03 & $1.03 \mathrm{E}-01$ & $3.16 \mathrm{E}-01$ & 2 & 4 & 3.23E-04 \\
\hline 1 & 23 & $2.02 E-03$ & $1.03 \mathrm{E}-01$ & $3.16 \mathrm{E}-01$ & 2 & 20 & $1.62 \mathrm{E}-03$ \\
\hline 1 & 24 & $2.11 \mathrm{E}-03$ & $1.08 \mathrm{E}-01$ & $3.16 \mathrm{E}-01$ & 4 & 12 & $9.70 \mathrm{E}-04$ \\
\hline 1 & 24 & $2.11 \mathrm{E}-03$ & $1.08 \mathrm{E}-01$ & $3.16 \mathrm{E}-01$ & 2 & 17 & 1.37E-03 \\
\hline 1 & 28 & $2.46 \mathrm{E}-03$ & $1.24 \mathrm{E}-01$ & $3.16 \mathrm{E}-01$ & 15 & 24 & 1.94E-03 \\
\hline 1 & 34 & $2.98 \mathrm{E}-03$ & $1.49 \mathrm{E}-01$ & $3.16 \mathrm{E}-01$ & 1 & 6 & 4.85E-04 \\
\hline 3 & 282 & $2.47 \mathrm{E}-02$ & $1.49 \mathrm{E}-01$ & $3.16 \mathrm{E}-01$ & 2 & 77 & $6.22 \mathrm{E}-03$ \\
\hline 1 & 35 & 3.07E-03 & $1.53 \mathrm{E}-01$ & $3.16 \mathrm{E}-01$ & 4 & 23 & $1.86 \mathrm{E}-03$ \\
\hline 1 & 35 & 3.07E-03 & $1.53 \mathrm{E}-01$ & $3.16 \mathrm{E}-01$ & 4 & 24 & 1.94E-03 \\
\hline 1 & 37 & 3.25E-03 & $1.61 \mathrm{E}-01$ & 3.16E-01 & 4 & 6 & 4.85E-04 \\
\hline 1 & 37 & $3.25 \mathrm{E}-03$ & $1.61 \mathrm{E}-01$ & $3.16 \mathrm{E}-01$ & 4 & 27 & $2.18 \mathrm{E}-03$ \\
\hline 1 & 38 & 3.34E-03 & $1.65 \mathrm{E}-01$ & $3.16 \mathrm{E}-01$ & 2 & 24 & $1.94 \mathrm{E}-03$ \\
\hline 1 & 39 & $3.42 E-03$ & $1.69 \mathrm{E}-01$ & $3.16 \mathrm{E}-01$ & 2 & 57 & 4.61E-03 \\
\hline 1 & 40 & $3.51 \mathrm{E}-03$ & $1.73 \mathrm{E}-01$ & $3.16 \mathrm{E}-01$ & 16 & 27 & $2.18 \mathrm{E}-03$ \\
\hline 1 & 41 & $3.60 \mathrm{E}-03$ & 1.77E-01 & $3.16 \mathrm{E}-01$ & 4 & 8 & 6.47E-04 \\
\hline 1 & 41 & $3.60 \mathrm{E}-03$ & $1.77 \mathrm{E}-01$ & $3.16 \mathrm{E}-01$ & 4 & 28 & $2.26 \mathrm{E}-03$ \\
\hline 1 & 41 & $3.60 \mathrm{E}-03$ & $1.77 \mathrm{E}-01$ & $3.16 \mathrm{E}-01$ & 1 & 24 & $1.94 \mathrm{E}-03$ \\
\hline 1 & 43 & 3.77E-03 & $1.85 \mathrm{E}-01$ & $3.16 \mathrm{E}-01$ & 3 & 11 & 8.89E-04 \\
\hline 1 & 44 & $3.86 \mathrm{E}-03$ & $1.89 \mathrm{E}-01$ & $3.16 \mathrm{E}-01$ & 3 & 15 & $1.21 \mathrm{E}-03$ \\
\hline 1 & 47 & $4.12 \mathrm{E}-03$ & $2.00 \mathrm{E}-01$ & $3.16 \mathrm{E}-01$ & 4 & 7 & 5.66E-04 \\
\hline 1 & 47 & 4.12E-03 & $2.00 \mathrm{E}-01$ & $3.16 \mathrm{E}-01$ & 4 & 7 & 5.66E-04 \\
\hline 1 & 47 & $4.12 \mathrm{E}-03$ & $2.00 \mathrm{E}-01$ & $3.16 \mathrm{E}-01$ & 4 & 7 & 5.66E-04 \\
\hline 1 & 47 & $4.12 \mathrm{E}-03$ & $2.00 \mathrm{E}-01$ & $3.16 \mathrm{E}-01$ & 4 & 8 & 6.47E-04 \\
\hline 1 & 51 & $4.48 \mathrm{E}-03$ & $2.15 \mathrm{E}-01$ & $3.16 \mathrm{E}-01$ & 4 & 32 & $2.59 E-03$ \\
\hline 1 & 53 & $4.65 \mathrm{E}-03$ & $2.23 \mathrm{E}-01$ & $3.16 \mathrm{E}-01$ & 4 & 32 & 2.59E-03 \\
\hline 1 & 53 & $4.65 \mathrm{E}-03$ & 2.23E-01 & $3.16 \mathrm{E}-01$ & 3 & 25 & $2.02 E-03$ \\
\hline 1 & 54 & 4.74E-03 & $2.26 \mathrm{E}-01$ & $3.16 \mathrm{E}-01$ & 4 & 41 & 3.31E-03 \\
\hline
\end{tabular}


Ion homeostasis

NRAGE signals death through JNK GLI3 is processed to GLI3R by the proteasome

Degradation of GLI2 by the

proteasome

Degradation of GLI1 by the

proteasome

Signaling by BRAF and RAF fusions

Plasma lipoprotein assembly, remodeling, and clearance

Oncogenic MAPK signaling

Cell death signalling via NRAGE, NRIF and NADE

Glycolysis

Regulation of insulin secretion

$G$ alpha (12/13) signalling events

Post NMDA receptor activation events

Integrin cell surface interactions

SLC-mediated transmembrane

transport

MAPK6/MAPK4 signaling

Opioid Signalling

Activation of NMDA receptors and

postsynaptic events

Transmission across Chemical

Synapses

Glucose metabolism

VEGFA-VEGFR2 Pathway

p75 NTR receptor-mediated signalling

Stimuli-sensing channels

Signaling by VEGF

Integration of energy metabolism

Hedgehog 'off' state

MAPK family signaling cascades

FCGR3A-mediated IL10 synthesis

Platelet degranulation

Transport of small molecules

Response to elevated platelet cytosolic

$\mathrm{Ca} 2+$

ADORA2B mediated anti-inflammatory cytokines production

Cardiac conduction

Rho GTPase cycle

Death Receptor Signalling

Signaling by Hedgehog

Factors involved in megakaryocyte development and platelet production

C-type lectin receptors (CLRs)

Ion channel transport

Neuronal System

Muscle contraction

Neurotransmitter receptors and postsynaptic signal transmission Signaling by ROBO receptors Leishmania parasite growth and survival

\begin{tabular}{|c|c|c|c|c|c|c|c|}
\hline 1 & 54 & $4.74 \mathrm{E}-03$ & $2.26 \mathrm{E}-01$ & $3.16 \mathrm{E}-01$ & 1 & 15 & $1.21 \mathrm{E}-03$ \\
\hline 1 & 59 & $5.18 \mathrm{E}-03$ & 2.44E-01 & $3.16 \mathrm{E}-01$ & 1 & 7 & $5.66 \mathrm{E}-04$ \\
\hline 1 & 60 & 5.27E-03 & $2.48 \mathrm{E}-01$ & $3.16 \mathrm{E}-01$ & 1 & 5 & 4.04E-04 \\
\hline 1 & 60 & 5.27E-03 & 2.48E-01 & $3.16 \mathrm{E}-01$ & 1 & 5 & 4.04E-04 \\
\hline 1 & 60 & 5.27E-03 & 2.48E-01 & $3.16 \mathrm{E}-01$ & 1 & 6 & 4.85E-04 \\
\hline 1 & 66 & $5.79 \mathrm{E}-03$ & 2.69E-01 & $3.16 \mathrm{E}-01$ & 4 & 5 & 4.04E-04 \\
\hline 1 & 72 & $6.32 \mathrm{E}-03$ & $2.90 \mathrm{E}-01$ & 3.16E-01 & 1 & 83 & $6.71 \mathrm{E}-03$ \\
\hline 1 & 74 & $6.49 \mathrm{E}-03$ & 2.97E-01 & $3.16 \mathrm{E}-01$ & 20 & 34 & $2.75 \mathrm{E}-03$ \\
\hline 1 & 76 & $6.67 \mathrm{E}-03$ & 3.03E-01 & $3.16 \mathrm{E}-01$ & 1 & 17 & 1.37E-03 \\
\hline 1 & 78 & $6.85 \mathrm{E}-03$ & $3.10 \mathrm{E}-01$ & 3.16E-01 & 1 & 24 & $1.94 \mathrm{E}-03$ \\
\hline 1 & 79 & $6.93 \mathrm{E}-03$ & 3.13E-01 & $3.16 \mathrm{E}-01$ & 4 & 34 & 2.75E-03 \\
\hline 1 & 80 & 7.02E-03 & 3.16E-01 & $3.16 \mathrm{E}-01$ & 1 & 14 & 1.13E-03 \\
\hline 1 & 84 & 7.37E-03 & $3.29 \mathrm{E}-01$ & $3.29 \mathrm{E}-01$ & 4 & 39 & 3.15E-03 \\
\hline 1 & 85 & 7.46E-03 & 3.33E-01 & 3.33E-01 & 2 & 54 & 4.36E-03 \\
\hline 2 & 251 & $2.20 \mathrm{E}-02$ & 3.34E-01 & 3.34E-01 & 2 & 190 & $1.54 \mathrm{E}-02$ \\
\hline 1 & 89 & 7.81E-03 & $3.45 \mathrm{E}-01$ & $3.45 \mathrm{E}-01$ & 1 & 40 & $3.23 E-03$ \\
\hline 1 & 90 & $7.90 \mathrm{E}-03$ & $3.48 \mathrm{E}-01$ & $3.48 \mathrm{E}-01$ & 6 & 59 & 4.77E-03 \\
\hline 1 & 97 & 8.51E-03 & $3.70 \mathrm{E}-01$ & $3.70 \mathrm{E}-01$ & 4 & 71 & $5.74 \mathrm{E}-03$ \\
\hline 2 & 273 & $2.40 \mathrm{E}-02$ & 3.72E-01 & $3.72 \mathrm{E}-01$ & 8 & 156 & 1.26E-02 \\
\hline 1 & 98 & $8.60 \mathrm{E}-03$ & 3.73E-01 & 3.73E-01 & 1 & 49 & 3.96E-03 \\
\hline 1 & 98 & $8.60 \mathrm{E}-03$ & 3.73E-01 & 3.73E-01 & 1 & 77 & $6.22 \mathrm{E}-03$ \\
\hline 1 & 99 & 8.69E-03 & 3.76E-01 & $3.76 \mathrm{E}-01$ & 1 & 50 & 4.04E-03 \\
\hline 1 & 107 & $9.39 \mathrm{E}-03$ & 3.99E-01 & 3.99E-01 & 1 & 26 & $2.10 \mathrm{E}-03$ \\
\hline 1 & 108 & $9.48 \mathrm{E}-03$ & 4.02E-01 & $4.02 \mathrm{E}-01$ & 1 & 84 & $6.79 \mathrm{E}-03$ \\
\hline 1 & 109 & 9.57E-03 & 4.05E-01 & $4.05 \mathrm{E}-01$ & 8 & 62 & $5.01 \mathrm{E}-03$ \\
\hline 1 & 114 & $1.00 \mathrm{E}-02$ & 4.19E-01 & 4.19E-01 & 4 & 32 & $2.59 \mathrm{E}-03$ \\
\hline 2 & 306 & 2.69E-02 & 4.27E-01 & 4.27E-01 & 5 & 86 & 6.95E-03 \\
\hline 1 & 128 & 1.12E-02 & 4.57E-01 & 4.57E-01 & 4 & 20 & 1.62E-03 \\
\hline 1 & 128 & $1.12 \mathrm{E}-02$ & 4.57E-01 & 4.57E-01 & 1 & 11 & 8.89E-04 \\
\hline 4 & 731 & 6.42E-02 & 4.59E-01 & $4.59 \mathrm{E}-01$ & 7 & 436 & $3.52 \mathrm{E}-02$ \\
\hline 1 & 133 & 1.17E-02 & 4.70E-01 & 4.70E-01 & 1 & 14 & $1.13 \mathrm{E}-03$ \\
\hline 1 & 136 & 1.19E-02 & 4.77E-01 & 4.77E-01 & 4 & 12 & $9.70 \mathrm{E}-04$ \\
\hline 1 & 138 & $1.21 \mathrm{E}-02$ & 4.82E-01 & 4.82E-01 & 1 & 26 & 2.10E-03 \\
\hline 1 & 141 & $1.24 \mathrm{E}-02$ & $4.90 \mathrm{E}-01$ & $4.90 \mathrm{E}-01$ & 1 & 5 & 4.04E-04 \\
\hline 1 & 147 & 1.29E-02 & 5.04E-01 & $5.04 \mathrm{E}-01$ & 1 & 90 & 7.27E-03 \\
\hline 1 & 150 & 1.32E-02 & 5.11E-01 & $5.11 \mathrm{E}-01$ & 4 & 82 & $6.63 \mathrm{E}-03$ \\
\hline 1 & 160 & $1.40 \mathrm{E}-02$ & 5.34E-01 & 5.34E-01 & 1 & 43 & $3.48 \mathrm{E}-03$ \\
\hline 1 & 174 & $1.53 \mathrm{E}-02$ & $5.64 \mathrm{E}-01$ & $5.64 \mathrm{E}-01$ & 1 & 68 & $5.50 \mathrm{E}-03$ \\
\hline 1 & 184 & $1.61 \mathrm{E}-02$ & $5.85 \mathrm{E}-01$ & $5.85 \mathrm{E}-01$ & 1 & 41 & $3.31 \mathrm{E}-03$ \\
\hline 2 & 419 & $3.68 \mathrm{E}-02$ & 5.95E-01 & $5.95 \mathrm{E}-01$ & 8 & 209 & $1.69 \mathrm{E}-02$ \\
\hline 1 & 207 & 1.82E-02 & $6.28 \mathrm{E}-01$ & $6.28 \mathrm{E}-01$ & 1 & 41 & $3.31 \mathrm{E}-03$ \\
\hline 1 & 208 & 1.83E-02 & 6.30E-01 & $6.30 \mathrm{E}-01$ & 4 & 109 & 8.81E-03 \\
\hline 1 & 218 & 1.91E-02 & $6.48 \mathrm{E}-01$ & $6.48 \mathrm{E}-01$ & 1 & 59 & 4.77E-03 \\
\hline 1 & 259 & 2.27E-02 & 7.11E-01 & 7.11E-01 & 4 & 40 & $3.23 \mathrm{E}-03$ \\
\hline
\end{tabular}


Anti-inflammatory response favouring Leishmania parasite infection

RAF/MAP kinase cascade

Platelet activation, signaling and aggregation

MAPK1/MAPK3 signaling

FLT3 Signaling

Metabolism of carbohydrates

Extracellular matrix organization

Intracellular signaling by second

messengers

Leishmania infection

Diseases of signal transduction by growth factor receptors and second messengers

$\mathrm{G}$ alpha (i) signalling events

Hemostasis

Signaling by Rho GTPases

Olfactory Signaling Pathway

GPCR downstream signalling

Signaling by Receptor Tyrosine

Kinases

Axon guidance

Signaling by GPCR

G alpha (s) signalling events

Nervous system development

Post-translational protein modification

Metabolism of lipids

Adaptive Immune System

Cytokine Signaling in Immune system

Infectious disease

Developmental Biology

Innate Immune System

Metabolism of proteins

Disease

Signal Transduction

Immune System

Metabolism

Ub-specific processing proteases

Deubiquitination

Post-translational protein modification

Cluster4

Metabolism of proteins

Respiratory electron transport

Respiratory electron transport, ATP

synthesis by chemiosmotic coupling,

and heat production by uncoupling

proteins.

The citric acid (TCA) cycle and

respiratory electron transport

Complex I biogenesis

TP53 Regulates Metabolic Genes

Metabolism

Synthesis of Prostaglandins (PG) and

Cluster5

\begin{tabular}{|c|c|c|c|c|c|c|c|}
\hline 1 & 259 & 2.27E-02 & 7.11E-01 & 7.11E-01 & 4 & 40 & $3.23 \mathrm{E}-03$ \\
\hline 1 & 260 & 2.28E-02 & 7.12E-01 & 7.12E-01 & 4 & 39 & $3.15 \mathrm{E}-03$ \\
\hline 1 & 265 & 2.33E-02 & 7.19E-01 & 7.19E-01 & 22 & 115 & $9.30 \mathrm{E}-03$ \\
\hline 1 & 267 & 2.34E-02 & 7.22E-01 & 7.22E-01 & 4 & 46 & $3.72 \mathrm{E}-03$ \\
\hline 1 & 278 & 2.44E-02 & 7.37E-01 & 7.37E-01 & 4 & 61 & 4.93E-03 \\
\hline 1 & 300 & 2.63E-02 & 7.63E-01 & 7.63E-01 & 1 & 236 & 1.91E-02 \\
\hline 1 & 301 & 2.64E-02 & 7.64E-01 & 7.64E-01 & 2 & 318 & 2.57E-02 \\
\hline 1 & 316 & 2.77E-02 & 7.81E-01 & 7.81E-01 & 4 & 114 & $9.21 \mathrm{E}-03$ \\
\hline 1 & 343 & 3.01E-02 & 8.08E-01 & 8.08E-01 & 4 & 95 & 7.68E-03 \\
\hline 1 & 393 & 3.45E-02 & 8.50E-01 & $8.50 \mathrm{E}-01$ & 20 & 356 & 2.88E-02 \\
\hline 1 & 408 & 3.58E-02 & $8.60 \mathrm{E}-01$ & $8.60 \mathrm{E}-01$ & 6 & 155 & $1.25 \mathrm{E}-02$ \\
\hline 2 & 726 & 6.37E-02 & 8.66E-01 & 8.66E-01 & 27 & 328 & $2.65 \mathrm{E}-02$ \\
\hline 1 & 426 & 3.74E-02 & 8.72E-01 & $8.72 \mathrm{E}-01$ & 1 & 117 & $9.46 \mathrm{E}-03$ \\
\hline 1 & 432 & 3.79E-02 & 8.76E-01 & 8.76E-01 & 1 & 2 & 1.62E-04 \\
\hline 3 & 1154 & $1.01 \mathrm{E}-01$ & $9.21 \mathrm{E}-01$ & $9.21 \mathrm{E}-01$ & 8 & 248 & $2.00 \mathrm{E}-02$ \\
\hline 1 & 523 & 4.59E-02 & $9.21 \mathrm{E}-01$ & $9.21 \mathrm{E}-01$ & 1 & 698 & 5.64E-02 \\
\hline 1 & 558 & 4.90E-02 & 9.34E-01 & 9.34E-01 & 2 & 296 & 2.39E-02 \\
\hline 3 & 1226 & $1.08 \mathrm{E}-01$ & $9.39 E-01$ & 9.39E-01 & 8 & 427 & $3.45 \mathrm{E}-02$ \\
\hline 1 & 577 & 5.06E-02 & $9.40 \mathrm{E}-01$ & $9.40 \mathrm{E}-01$ & 1 & 18 & $1.45 \mathrm{E}-03$ \\
\hline 1 & 584 & 5.13E-02 & $9.42 \mathrm{E}-01$ & 9.42E-01 & 2 & 322 & $2.60 \mathrm{E}-02$ \\
\hline 3 & 1417 & $1.24 \mathrm{E}-01$ & $9.71 \mathrm{E}-01$ & $9.71 \mathrm{E}-01$ & 2 & 513 & 4.15E-02 \\
\hline 1 & 748 & 6.56E-02 & $9.74 \mathrm{E}-01$ & $9.74 \mathrm{E}-01$ & 2 & 814 & $6.58 \mathrm{E}-02$ \\
\hline 1 & 944 & 8.29E-02 & $9.91 \mathrm{E}-01$ & 9.91E-01 & 1 & 260 & $2.10 \mathrm{E}-02$ \\
\hline 1 & 954 & 8.37E-02 & $9.91 \mathrm{E}-01$ & $9.91 \mathrm{E}-01$ & 4 & 699 & 5.65E-02 \\
\hline 1 & 1040 & $9.13 \mathrm{E}-02$ & $9.94 \mathrm{E}-01$ & $9.94 \mathrm{E}-01$ & 4 & 485 & 3.92E-02 \\
\hline 1 & 1100 & $9.65 \mathrm{E}-02$ & $9.96 \mathrm{E}-01$ & $9.96 \mathrm{E}-01$ & 2 & 536 & 4.33E-02 \\
\hline 1 & 1187 & $1.04 \mathrm{E}-01$ & 9.97E-01 & 9.97E-01 & 1 & 662 & 5.35E-02 \\
\hline 3 & 2012 & 1.77E-01 & $9.98 \mathrm{E}-01$ & $9.98 \mathrm{E}-01$ & 2 & 874 & 7.06E-02 \\
\hline 2 & 1735 & $1.52 \mathrm{E}-01$ & 9.99E-01 & 9.99E-01 & 24 & 1201 & 9.71E-02 \\
\hline 4 & 2829 & $2.48 \mathrm{E}-01$ & $1.00 \mathrm{E}+00$ & $1.00 \mathrm{E}+00$ & 35 & 2333 & $1.89 \mathrm{E}-01$ \\
\hline 2 & 2374 & 2.08E-01 & $1.00 \mathrm{E}+00$ & $1.00 \mathrm{E}+00$ & 6 & 1562 & 1.26E-01 \\
\hline 1 & 2142 & $1.88 \mathrm{E}-01$ & $1.00 \mathrm{E}+00$ & $1.00 \mathrm{E}+00$ & 10 & 2001 & 1.62E-01 \\
\hline 2 & 205 & $1.80 \mathrm{E}-02$ & $2.21 \mathrm{E}-02$ & 7.97E-02 & 2 & 40 & $3.23 \mathrm{E}-03$ \\
\hline 2 & 282 & 2.47E-02 & 3.99E-02 & 7.97E-02 & 2 & 77 & 6.22E-03 \\
\hline 2 & 1417 & $1.24 \mathrm{E}-01$ & 4.94E-01 & 4.94E-01 & 2 & 513 & 4.15E-02 \\
\hline 2 & 2012 & 1.77E-01 & 6.97E-01 & 6.97E-01 & 2 & 874 & 7.06E-02 \\
\hline 8 & 115 & 7.92E-03 & $9.51 \mathrm{E}-14$ & 4.66E-12 & 8 & 19 & $1.50 \mathrm{E}-03$ \\
\hline 8 & 150 & 1.03E-02 & $7.85 \mathrm{E}-13$ & $1.88 \mathrm{E}-11$ & 8 & 31 & $2.44 \mathrm{E}-03$ \\
\hline 8 & 233 & $1.61 \mathrm{E}-02$ & $2.57 \mathrm{E}-11$ & 4.11E-10 & 8 & 67 & $5.28 \mathrm{E}-03$ \\
\hline 5 & 57 & 3.93E-03 & 2.71E-09 & $3.26 \mathrm{E}-08$ & 6 & 13 & $1.02 \mathrm{E}-03$ \\
\hline 3 & 125 & 8.61E-03 & 2.69E-04 & 2.42E-03 & 1 & 34 & $2.68 \mathrm{E}-03$ \\
\hline 10 & 3650 & $2.51 \mathrm{E}-01$ & 8.36E-04 & 6.69E-03 & 23 & 2241 & $1.76 \mathrm{E}-01$ \\
\hline 2 & 58 & $4.00 \mathrm{E}-03$ & 1.62E-03 & 1.13E-02 & 7 & 32 & $2.52 \mathrm{E}-03$ \\
\hline
\end{tabular}




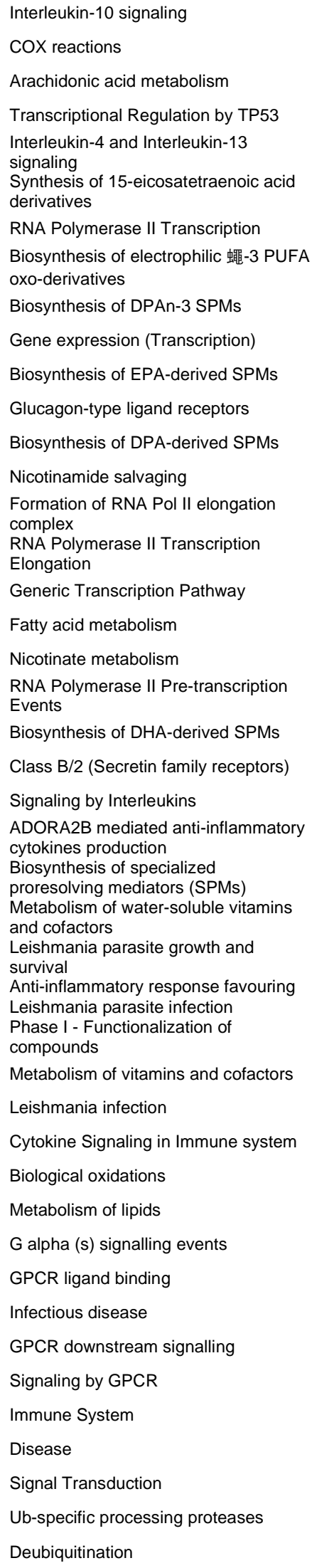

\begin{tabular}{|c|c|c|c|c|c|c|c|}
\hline 2 & 86 & $5.93 \mathrm{E}-03$ & $3.50 \mathrm{E}-03$ & 2.10E-02 & 1 & 15 & $1.18 \mathrm{E}-03$ \\
\hline 1 & 9 & $6.20 \mathrm{E}-04$ & $9.26 \mathrm{E}-03$ & 4.63E-02 & 2 & 2 & 1.57E-04 \\
\hline 2 & 166 & 1.14E-02 & $1.24 \mathrm{E}-02$ & 4.98E-02 & 8 & 77 & 6.06E-03 \\
\hline 3 & 486 & 3.35E-02 & $1.26 \mathrm{E}-02$ & 5.05E-02 & 1 & 259 & 2.04E-02 \\
\hline 2 & 211 & $1.45 \mathrm{E}-02$ & 1.96E-02 & $6.70 \mathrm{E}-02$ & 1 & 46 & $3.62 \mathrm{E}-03$ \\
\hline 1 & 22 & $1.52 \mathrm{E}-03$ & 2.25E-02 & 6.70E-02 & 1 & 4 & $3.15 E-04$ \\
\hline 5 & 1692 & 1.17E-01 & 2.36E-02 & $6.70 \mathrm{E}-02$ & 13 & 885 & 6.97E-02 \\
\hline 1 & 29 & $2.00 \mathrm{E}-03$ & $2.96 \mathrm{E}-02$ & $6.70 \mathrm{E}-02$ & 4 & 20 & $1.57 \mathrm{E}-03$ \\
\hline 1 & 31 & 2.14E-03 & $3.16 \mathrm{E}-02$ & $6.70 \mathrm{E}-02$ & 1 & 18 & 1.42E-03 \\
\hline 5 & 1850 & 1.27E-01 & 3.35E-02 & $6.70 \mathrm{E}-02$ & 13 & 996 & 7.84E-02 \\
\hline 1 & 33 & 2.27E-03 & 3.36E-02 & 6.71E-02 & 1 & 17 & $1.34 \mathrm{E}-03$ \\
\hline 1 & 35 & $2.41 \mathrm{E}-03$ & $3.56 \mathrm{E}-02$ & 7.11E-02 & 1 & 8 & $6.30 \mathrm{E}-04$ \\
\hline 1 & 35 & $2.41 \mathrm{E}-03$ & $3.56 \mathrm{E}-02$ & 7.11E-02 & 1 & 21 & 1.65E-03 \\
\hline 1 & 59 & 4.07E-03 & 5.93E-02 & 7.11E-02 & 1 & 12 & $9.45 \mathrm{E}-04$ \\
\hline 1 & 63 & 4.34E-03 & 6.32E-02 & 7.11E-02 & 2 & 2 & $1.57 \mathrm{E}-04$ \\
\hline 1 & 66 & $4.55 \mathrm{E}-03$ & 6.61E-02 & 7.11E-02 & 5 & 8 & $6.30 \mathrm{E}-04$ \\
\hline 4 & 1553 & 1.07E-01 & 6.83E-02 & 7.11E-02 & 2 & 824 & $6.49 \mathrm{E}-02$ \\
\hline 2 & 429 & 2.96E-02 & 7.11E-02 & 7.11E-02 & 8 & 217 & $1.71 \mathrm{E}-02$ \\
\hline 1 & 84 & 5.79E-03 & 8.34E-02 & 8.34E-02 & 1 & 29 & $2.28 \mathrm{E}-03$ \\
\hline 1 & 88 & 6.06E-03 & 8.72E-02 & 8.72E-02 & 6 & 17 & $1.34 \mathrm{E}-03$ \\
\hline 1 & 89 & $6.13 \mathrm{E}-03$ & 8.81E-02 & 8.81E-02 & 1 & 58 & 4.57E-03 \\
\hline 1 & 99 & $6.82 \mathrm{E}-03$ & $9.76 \mathrm{E}-02$ & $9.76 \mathrm{E}-02$ & 1 & 20 & 1.57E-03 \\
\hline 2 & 639 & 4.40E-02 & $1.39 \mathrm{E}-01$ & 1.39E-01 & 1 & 490 & 3.86E-02 \\
\hline 1 & 159 & 1.10E-02 & $1.52 \mathrm{E}-01$ & $1.52 \mathrm{E}-01$ & 1 & 12 & $9.45 \mathrm{E}-04$ \\
\hline 1 & 159 & 1.10E-02 & $1.52 \mathrm{E}-01$ & $1.52 \mathrm{E}-01$ & 7 & 124 & $9.76 \mathrm{E}-03$ \\
\hline 1 & 254 & 1.75E-02 & 2.33E-01 & $2.33 \mathrm{E}-01$ & 1 & 144 & 1.13E-02 \\
\hline 1 & 297 & 2.05E-02 & 2.67E-01 & 2.67E-01 & 1 & 40 & $3.15 \mathrm{E}-03$ \\
\hline 1 & 297 & 2.05E-02 & 2.67E-01 & 2.67E-01 & 1 & 40 & $3.15 \mathrm{E}-03$ \\
\hline 1 & 298 & 2.05E-02 & 2.67E-01 & 2.67E-01 & 2 & 98 & 7.72E-03 \\
\hline 1 & 382 & 2.63E-02 & 3.30E-01 & 3.30E-01 & 1 & 205 & $1.61 \mathrm{E}-02$ \\
\hline 1 & 403 & $2.78 \mathrm{E}-02$ & 3.45E-01 & 3.45E-01 & 1 & 95 & $7.48 \mathrm{E}-03$ \\
\hline 2 & 1261 & 8.69E-02 & $3.79 \mathrm{E}-01$ & 3.79E-01 & 1 & 699 & $5.50 \mathrm{E}-02$ \\
\hline 1 & 545 & 3.75E-02 & 4.37E-01 & 4.37E-01 & 2 & 188 & $1.48 \mathrm{E}-02$ \\
\hline 2 & 1445 & 9.96E-02 & 4.49E-01 & 4.49E-01 & 15 & 943 & 7.43E-02 \\
\hline 1 & 605 & 4.17E-02 & 4.72E-01 & 4.72E-01 & 3 & 18 & 1.42E-03 \\
\hline 1 & 652 & 4.49E-02 & 4.98E-01 & $4.98 \mathrm{E}-01$ & 1 & 179 & $1.41 \mathrm{E}-02$ \\
\hline 1 & 1174 & 8.09E-02 & 7.18E-01 & 7.18E-01 & 1 & 494 & 3.89E-02 \\
\hline 1 & 1359 & 9.36E-02 & 7.71E-01 & 7.71E-01 & 3 & 258 & 2.03E-02 \\
\hline 1 & 1485 & 1.02E-01 & 8.02E-01 & 8.02E-01 & 4 & 437 & $3.44 \mathrm{E}-02$ \\
\hline 2 & 2823 & $1.95 \mathrm{E}-01$ & 8.20E-01 & $8.20 \mathrm{E}-01$ & 1 & 1598 & 1.26E-01 \\
\hline 1 & 2171 & $1.50 \mathrm{E}-01$ & $9.12 \mathrm{E}-01$ & $9.12 \mathrm{E}-01$ & 1 & 1216 & 9.57E-02 \\
\hline 1 & 3364 & 2.32E-01 & $9.81 \mathrm{E}-01$ & 9.81E-01 & 4 & 2347 & 1.85E-01 \\
\hline 1 & 205 & $1.80 \mathrm{E}-02$ & $1.96 \mathrm{E}-01$ & 5.19E-01 & 2 & 40 & 3.23E-03 \\
\hline 1 & 282 & 2.47E-02 & $2.60 \mathrm{E}-01$ & 5.19E-01 & 2 & 77 & $6.22 \mathrm{E}-03$ \\
\hline
\end{tabular}


medRxiv preprint doi: https://doi.org/10.1101/2020.06.08.20124305; this version posted June 9, 2020. The copyright holder for this preprint (which was not certified by peer review) is the author/funder, who has granted medRxiv a license to display the preprint in perpetuity.

\begin{abstract}
It is made available under a CC-BY-NC-ND 4.0 International license.
\end{abstract}

\begin{tabular}{llllllllll} 
Post-translational protein modification & 1 & 1417 & $1.24 \mathrm{E}-01$ & $7.97 \mathrm{E}-01$ & $7.97 \mathrm{E}-01$ & 2 & 513 & $4.15 \mathrm{E}-02$ \\
Metabolism of proteins & 1 & 2012 & $1.77 \mathrm{E}-01$ & $9.03 \mathrm{E}-01$ & $9.03 \mathrm{E}-01$ & 2 & 874 & $7.06 \mathrm{E}-02$ \\
\hline
\end{tabular}

*1. cluster 1 did not have any entities output 


\section{References}

1. World Health Organization (WHO), Laboratory biosafety guidance related to coronavirus disease 2019 (COVID-19): interim guidance, 12 February 2020 (https://apps.who.int/iris/bitstream/handle/10665/331138/WHO-WPE-GIH-2020.1-eng.pdf).

2. Y. Chen, Y. Chen, C. Shi, Z. Huang, Y. Zhang, S. Li, Y. Li, J. Ye, C. Yu, Z. Li, X. Zhang, J. Wang, H. Yang, L. Fang, Q. Chen, SOAPnuke: a MapReduce acceleration-supported software for integrated quality control and preprocessing of high-throughput sequencing data. Gigascience. 7(1), 1-6 (2018).

3. H. Li, R. Durbin, Fast and accurate short read alignment with Burrows-Wheeler transform. Bioinformatics. 25(14), 1754-60 (2009).

4. A. McKenna, M. Hanna, E. Banks, A. Sivachenko, K. Cibulskis, A. Kernytsky, K. Garimella, D. Altshuler, S. Gabriel, M. Daly, M.A. DePristo, The Genome Analysis Toolkit: a MapReduce framework for analyzing nextgeneration DNA sequencing data. Genome. Res. 20(9),1297-303 (2010).

5. K.I. Kendig, S. Baheti, M.A. Bockol, T.M. Drucker, S.N. Hart, J.R. Heldenbrand, M. Hernaez, M.E. Hudson, M.T. Kalmbach, E.W. Klee, N.R. Mattson, C.A. Ross, M. Taschuk, E.D. Wieben, M. Wiepert, D.E. Wildman, L.S. Mainzer, Sentieon DNASeq variant calling workflow demonstrates strong computational performance and accuracy. Front. Genet. 10,736 (2019).

6. A. Fabregat, S. Jupe, L. Matthews, K. Sidiropoulos, M. Gillespie, P. Garapati, R. Haw, B. Jassal, F. Korninger, B. May, M. Milacic, C.D. Roca, K. Rothfels, C. Sevilla, V. Shamovsky, S. Shorser, T. Varusai, G. Viteri, J. Weiser, G. Wu, L. Stein, H. Hermjakob, P. D'Eustachio,The Reactome Pathway Knowledgebase. Nucleic Acids Res. 46(D1), D649-D655 (2018).

7. B. Wilkinson, A statistical consideration in psychological research. Psychol. Bull. 48(3), 156-8 (1951).

8. R. Y. Yang et al., https://www.biorxiv.org/content/10.1101/311563v1.article-info (2020).

9. GTEx Consortium, The Genotype-Tissue Expression (GTEx) project. Nat. Genet. 45, 580-585 (2013).

10. Q. Miao, Y. Ma, Q. Wang, J. Pan, Y. Zhang, W. Jin, Y. Yao, Y. Su, Y. Huang, M. Wang, et al. Microbiological diagnostic performance of metagenomic next-generation sequencing when applied to clinical practice. Clin. Infect. Dis. 67, S231-S240 (2018).

11. R. Schlaberg, C.Y. Chiu, S. Miller, G.W. Procop, G. Weinstock, Validation of metagenomic Next-Generation sequencing tests for universal pathogen detection. Arch. Pathol. Lab. Med. 141, 776-786 (2017).

12. C. Langelier, M.S. Zinter, K. Kalantar, G.A. Yanik, S. Christenson, B. O'Donovan, C. White, M. Wilson, A. Sapru, C. C. Dvorak, S. Miller, C. Y. Chiu, J. L. DeRisi, Metagenomic sequencing detects respiratory pathogens in hematopoietic cellular transplant patients. Am. J. Respir. Crit. Care. Med. 197, 524-528 (2018). 